\title{
LA-SUB- $95-31-\mathrm{VO} 1.1$
}

\section{Commercialization of Los Alamos National \\ Laboratory Technologies via Small Businesses}

\author{
The Final Report of Los Alamos \\ Contract No. 4790L0013-9Z, Volume 1: \\ "Study of Concept for Model System for \\ Commercializing Technology from \\ Los Alamos National Laboratory"
}

Revision History:

First Draft released to Los Alamos for Review on April 11, 1994

Final Report delivered to Los Alamos on May 12, 1994

by

MCC Ventures, Inc.

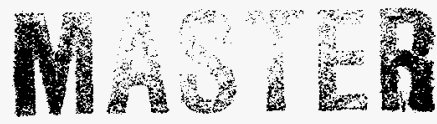

A Subsidiary of the

\section{Microelectronics and Computer Technology Corporation (MCC)}

\author{
3500 W. Balcones Center Drive \\ Austin, TX $\mathbf{7 8 7 5 9}$
}

\author{
Authored by: \\ Richard Brice, Dominique Cartron, Tom Rhyne, Merlin Schulze, and Lyle Welty
}

This report was prepared as an account of the work sponsored by an agency of the United States Government. Neither the Regents of the University of California, the United States Government, nor any other agency thereof, nor any of their employees, makes any warranty, express or implied, or assumes any legal liability or responsibility for the accuracy, completeness, or usefulness of any information, apparatus, product, or process disclosed, or represents that its use would not infringe privately owned rights. Reference herein to any specific commercial product, process, or service by trade name, trademark, manufacturer, or otherwise, does not necessarily constitute or imply its endorsement, recommendation, or favoring by the Regents of the University of California, the United States Government, or any agency thereof. The views and opinions expressed herein do not necessarily reflect those of the Regents of the University of California, the United States Government, or any agency thereof. 


\section{DISCLAIMER}

This report was prepared as an account of work sponsored by an agency of the United States Government. Neither the United States Government nor any agency thereof, nor any of their employees, make any warranty, express or implied, or assumes any legal liability or responsibility for the accuracy, completeness, or usefulness of any information, apparatus, product, or process disclosed, or represents that its use would not infringe privately owned rights. Reference herein to any specific commercial product, process, or service by trade name, trademark, manufacturer, or otherwise does not necessarily constitute or imply its endorsement, recommendation, or favoring by the United States Government or any agency thereof. The views and opinions of authors expressed herein do not necessarily state or reflect those of the United States Government or any agency thereof. 


\section{DISCLAMMER}

Portions of this document may be illegible in electronic image products. Images are produced from the best available original document. 


\section{Executive Summary}

\section{Introduction}

Over the past decade, numerous companies have been formed to commercialize research results from leading U.S. academic and research institutions. Emerging small businesses in areas such as Silicon Valley, Boston's Route 128 corridor, and North Carolina's Research Triangle have been especially effective in moving promising technologies from the laboratory bench to the commercial marketplace-creating new jobs and economic expansion in the process. Unfortunately, many of the U.S. national laboratories have not been major participants in this technology/commercialization activity, a result of a wide variety of factors which, until recently, acted against successful commercialization.

This "commercialization gap" exists partly due to a lack, within Los Alamos in particular and the DOE in general, of in-depth expertise and experience in such business areas as new business development, securities regulation, market research and the determination of commercial potential, the identification of entrepreneurial management, marketing and distribution, and venture capital sources. The immediate consequence of these factors is the disappointingly small number of startup companies based on technologies from Los Alamos National Laboratory that have been attempted, the modest financial return Los Alamos has received from these start-ups, and the lack of significant national recognition that Los Alamos has received for creating and commercializing these technologies.

Recognizing the need for improvement in its processes for technology commercialization, Los Alamos contracted with MCC Ventures, Inc. (MVI), a subsidiary of the Microelectronics and Computer Technology Corporation (MCC) of Austin, Texas, in late 1993 to perform a detailed review of the current expertise, resources, impediments, and services at Los Alamos for linking its highly successful programs for the generation of new technologies with the successful commercialization of those technologies by small businesses. This report details the findings of that review.

The principal objectives defined for the MVI review project have been to:

a) Assess and report on the current climate for and past history of technology commercialization emphasizing small businesses at Los Alamos;

b) Assess and report on the practices at other government laboratories and in the commercial sector as they relate to technology commercialization by small businesses; and,

c) Assess and report on the options available to the DOE and to the University of California, in its capacity as operator of the Los Alamos National Laboratory under contract to the DOE, for commercialization of technologies by small businesses that are developed at Los Alamos and which may have useful applications in the U.S. electronics and/or computer industries.

\section{Commercialization Practices in the Non-Government Arena}

The practice of commercializing new technology in the non-government business environment is characterized by a high degree of flexibility and individuality. A significant fraction of technology commercialization by large businesses occurs in-house. However, even large, established corporations find it useful to commercialize selected technologies through the creation of small start-ups. The process of creating and funding a start-up is a complex, high-risk endeavor which demands patience, persistence, and a high degree of business management ability. Each start-up is uniqueno two are alike-and while an individual start-up may develop along lines which might be de- 
scribed as a "process," each will demand special attention and time, and will go through a series of problems and opportunities specific to that particular business.

The key ingredients that are absolutely essential in creating a successful technology-based start-up business consist of:

- An outstanding, experienced management team familiar with the technology and the marketplace for products based on the technology. Venture capital managers and other risk capital investors generally invest in situations which have management with a proven demonstrated record in successfully managing similar early-stage businesses.

- A large and growing market that will provide an opportunity for small businesses that can react quickly to obtain a potentially sizable portion of the market.

- Technology which represents a substantial and sustainable competitive advantage, presenting an attractive platform for launching or expanding small businesses. Ownership of the technology (i.e., exclusive licenses to the intellectual property) is essential to the attraction of funding.

- The financial resources required to grow the business to a self-sustaining state. This may require multiple rounds of financing, but the potential to attract the financing must be present from the outset.

- Technology and the people who created it are not easily separable. Movement of the people with the technology must be anticipated and managed.

\section{Commercialization Potential and Practices at Los Alamos}

Technology commercialization can take place through a multitude of circumstances and formal mechanisms. From inside Los Alamos, for example, principal investigators may wish to move their inventions outside and create a new business based on a technology they helped to create. A slightly different scenario would involve an outside entrepreneur who wishes to export a technology from Los Alamos to begin a business based on that technology. Finally, an existing business, small or large, might wish to gain access to a Los Alamos technology as a means of = business expansion or to create a new product. A host of other mechanisms allows Los Alamos' expertise and technology to be transferred to both small and large businesses.

At Los Alamos, as is the case for all of the national laboratories, commercialization activities such as these take place within an existing framework of regulations, policies, and procedures. In most cases, the basis for those regulations and other mandates is in one or more documents that relate to Los Alamos as an institution, to the University of California in its role as the operator of Los Alamos, to the U.S. Department of Energy, or to the U.S. Government in general. MVI has reviewed all of the documents relating to current policies, procedures, and regulations affecting technology transfer that have been provided by Los Alamos.

Los Alamos faces some fairly unique problems in seeking to apply any generic commercialization model typically found in industry. This is due to a number of existing restrictions, principal of which are the following:

- As a government-owned contractor-operated (GOCO) facility, Los Alamos is subject to the restrictions shared by all GOCO laboratories. For example, concerns for conflict of interest (both actual and apparent) and faimess of opportunity issues are paramount at all such laboratories. In addition, Los Alamos is 


\section{The Final Report of Los Alamos Contract No. 4790L0013-9Z, Volume 1}

affected by policies and statutes that are specific to the University of California system.

- The DOE and other U.S. governmental policies, statutes, and regulations exert restrictive forces on any process for converting technology developed with U.S. tax dollars into private gain by those individuals who developed the technology.

- The prevailing organizational attention, historical mission, management style, and general culture at Los Alamos serve to work against the commercialization of technology through the formation of start-ups.

- Los Alamos' location and the available infrastructure impose formidable obstacles to finding risk capital, forming experienced management teams, acquiring office space and manufacturing facilities, connecting with the marketplace, etc.

A comparison of commercialization practices at Los Alamos with those commonly observed in the commercial arena illuminates several key differences which will need to be addressed by Los Alamos in order to create a more vigorous and successful commercialization program there.

Section 5 of this report lists and discusses twenty-three separate issues that insert impediments into the commercialization process at Los Alamos. No single one of them represents an insurmountable obstacle, but collectively they exert a stifling influence that has tended to reduce the flow of technology from Los Alamos National Laboratory into the private sector to a trickle rather than the torrent that both DOE and Los Alamos desire, and which should be sustainable given the depth and breadth of the technical expertise and rich technology inventory that exists at Los Alamos.

As expected, many of the issues relate to statutes of the State of California or the U.S. Government, to policies of the University of California and the DOE, and to interpretations or implementations of those regulations by Los Alamos' management. Other issues which are equally important relate to the management style and lack of an entrepreneurial culture at Los Alamos. Finally, ingredients which are essential to the commercialization process are missing from the northern New Mexico infrastructure.

\section{A Model Commercialization Process Tailored to Los Alamos}

Two case-based scenarios are provided in this report which identify the contractual and policy mechanisms that either support or impede the commercialization of technologies from Los Alamos. These scenarios demonstrate that their contractual arrangements are sufficient to allow commercialization of such technologies to proceed. However, many of the issues that are identified and discussed in Section 5 of this report arise from these scenarios, and each issue that has been identified increases the threshold of risk as perceived by potential investors in businesses based on technologies from Los Alamos.

Most of the issues which are raised in Sections 5 and 6 result from policy interpretation and do not require new legislation or changes to the prime contract which governs the operation of Los Alamos by the University of California in order to reduce their impact on the commercialization process. In many cases, minor DOE policy changes or more liberal interpretation of the intent of existing policy can provide a substantial impetus to the commercialization process. Examples of fundamental changes to management practice by both Los Alamos and the DOE which could have a dramatic positive influence on the commercialization potential at Los Alamos include the following:

- Design and deploy better techniques to identify and document emerging intellectual property as it is developed and provide a system to maintain this infor- 
mation in a readily-accessible database. These procedures must also include provisions for protecting intellectual property, e.g., more rigorous laboratorywide maintenance of laboratory notebooks.

- Develop and apply a market-oriented screening process to select those technologies which represent the best opportunities for successful commercialization.

- Consider the circumstances and administrative procedures that are necessary to enable principal investigators (PIs), on their own time, to selectively use laboratory resources to explore the prospects for starting spin-off businesses based on Los Alamos technologies.

- Reinstitute some form of entrepreneurial leave (EL) or other sabbatical program to encourage qualified PIs to participate in the technology commercialization process.

- Speed up and simplify the licensing procedures used when small companies are attempting to obtain exclusive rights to Los Alamos' technologies. This can bring Los Alamos' time-scale more in line with what exists in the commercial environment, especially with respect to small businesses.

- Establish Los Alamos' ability to accept and administer minority equity interests in small companies in lieu of cash for licenses.

- Institute an expanded internal communications program to educate laboratory management and PIs as to the requirements, risks, and opportunities represented by new business ventures based on laboratory technologies.

\section{Commercialization Practices at Other DOE Facilities}

As part of the MVI review, visits were made to Argonne National Laboratory, The Ames Laboratory Center for Advanced Technology Development, Sandia National Laboratory, and The Oak Ridge National Laboratory. Each of these facilities has established relationships with organizations whose missions are to support technology commercialization. These include the Argonne Industrial Technology Development Center, the Argonne/Chicago Development Corporation, The Ames Center for Advanced Technology Development, the Technology Development Corporation, The Tennessee Center for Research and Development, and the Tennessee Resource Valley.

Each of these organizations has enjoyed limited success in commercializing technologies developed at their collaborating DOE facility. However, none of the organizations that were visited appears to have developed a solution to the commercialization problem that is well-suited to the needs of Los Alamos. In particular:

- None of the organizations have solved the conflict of interest (COI) problems which can arise when a Los Alamos employee attempts to obtain an exclusive license to his/her own technology,

- No solution was found for Los Alamos' lack of support for entrepreneurial initiatives or for technology maturation funds,

- The missing components of the northern New Mexico infrastructure can only be corrected by actions taken in New Mexico, and 
- The intellectual property issues which characterize Los Alamos and which are discussed above remain unresolved.

The other laboratories are faced with similar problems and in some cases have found ways to deal with them. As a specific example, CATD (The Ames Center for Advanced Technology Development) is closest to having an answer. Their facility has a well-established process for protecting intellectual property rights and for the maturation of selected technologies. As each specific technology is selected for commercialization, the PI signs a contract with the company to produce a deliverable product. This process includes mandatory due diligence based on standards that must be met.

However, it must be remembered that each laboratory within the DOE complex is unique due to factors such as the makeup of their field offices, the identity of the management and operating (M\&O) contractor and the contractor's institution type, the amount of oversight from DOE/HQ, local interpretation of policies and directives, contents of their prime contracts, management support and enthusiasm for technology commercialization, culture and historical patterns, laboratory mission and the resulting technology content, and regional infrastructure components, among others. Any local solutions to the commercialization problems are inherently biased by these local factors to the extent that they are usually rendered useless (without modifications) outside the environment in which they were created.

\section{Conclusions}

This review clearly identifies procedures and practices at Los Alamos which have been used successfully to transfer Los Alamos' technologies into the private sector. The key findings of this review, if they can be reduced to a single sentence, are that these procedures and practices will not be adequate if the desired goal is a substantial ramp-up in the rate of commercialization of Los Alamos' technology by small businesses, but many of the remedies to the most important problems lie in the hands of Los Alamos and DOE management. This review specifically avoids any attempt to provide a detailed roadmap for how to achieve the goal of accelerating the commercialization of Los Alamos technologies through small businesses. Establishing increased commercialization through small business as a technology transfer goal is solely a Los Alamos decision. However, the report does identify a number of landmarks and guidepost issues which can be used by Los Alamos if the laboratory chooses to move decidedly in the direction of fostering technology commercialization through small business creations. Since many of the issues are related to social, cultural, and political practices, in addition to those operational procedures governed by law or policy, it is important to recognize that modifications and improvements made to commercialization processes as a result of this report should be tested. Furthermore, until the implications of certain actions are understood, practice and procedural testing should be conducted in a carefully controlled environment. The purpose of such experimentation would be to discover (and quantify) which of the alternate remedies described in the report provide the most effective route to the desired goal.

As a result of the large number of variables, their character, and the unique aspects that combine to form the commercialization environment at Los Alamos, this report can only speculate on the degree of success any such experiments may produce. It now becomes Los Alamos' responsibility to review the contents of the report, determine which of the alternatives should be emphasized, establish the details of the experiment(s), specify the metrics that will be used to evaluate the success of the experiment(s) and finally, make the commitment and assemble the resources required to conduct the experiment(s) and demonstrate the results. This approach is typical of that followed by industry with the key exception that metrics to evaluate the success of industrial experiments are usually already well-established. 
The Final Report of Los Alamos Contract No. 4790L0013-9Z, Volume 1 


\section{Table of Contents}

\section{Volume 1}

Executive Summary

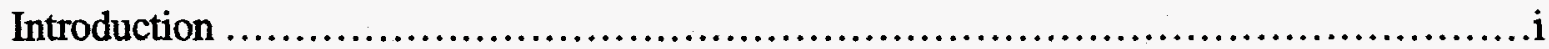

Commercialization Practices in the Non-Government Arena ................................ i

Commercialization Potential and Practices at Los Alamos.............................. ii

A Model Commercialization Process Tailored to Los Alamos ............................. iii

Commercialization Practices at Other DOE Facilities ...................................... iv

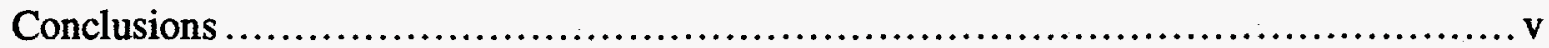

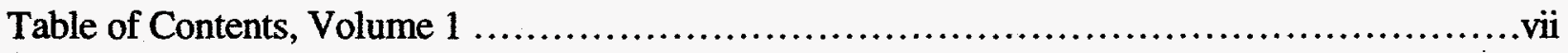

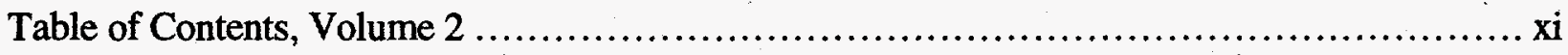

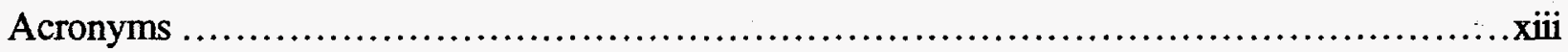

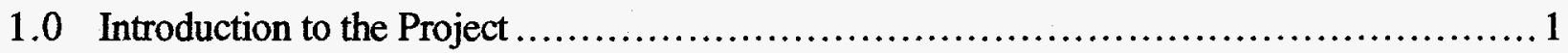

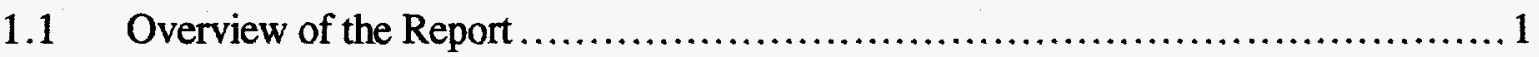

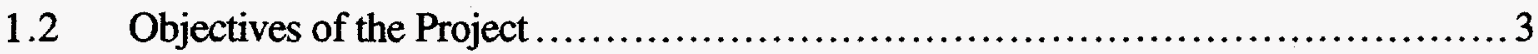

$1.3 \quad$ Statement of Work for the Project ................................................ 3

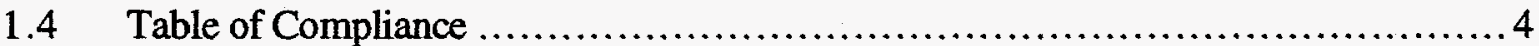

2.0 Summary of Commercialization Practices in the Non-Government Business Environment... 5

2.1 Major Considerations in the Formation and Capitalization of Start-ups................ 5

2.1.1 The Generic Enterprise Creation Process ...............................6

2.2 Major Considerations in Creating a Technology-based New Enterprise ............. 7

2.3 Common Business Policies and Practices for Investing in and Developing Commercial Start-ups ........................................................ 9

2.4 Adapting the Generic Commercialization Model to Los Alamos.....................11

2.4.1 The Los Alamos Enterprise Creation Model .............................12

2.4.2 Typical Start-up and Early-stage Business Arrangements ..................14

3.0 Summary of Technology Commercialization Practices at other DOE Laboratories...........17

3.1 Practices at the Argonne National Laboratory (ANL) .......................... 17

3.1.1 The Argonne Industrial Technology Development Center (ITDC) .........17

3.1.2 The Argonne/Chicago Development Corporation (ARCH),...................17

3.1.3 ITDC's Priorities for Commercialization ................................18

3.1.4 Equity Handling at ANL ............................................18

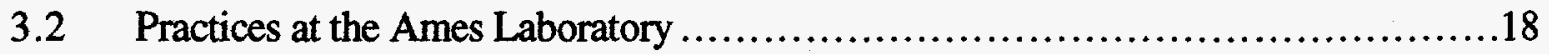

3.2.1 Center for Advanced Technology Development ..........................18

3.2.2 Office of Contract Research ..............................................19

3.2.3 Ames Laboratory ................................................. 19 
3.2.4 Research Foundation.................................................

3.2.5 Exploratory Research Program .......................................19

3.2.6 Commercialization Plans ............................................ 20

3.2.7 Licensing ..................................................... 20

3.2.8 CATD's Entrepreneur's Forum..................................20

3.2.9 Prospective Spin-Offs ..............................................20

3.3 Practices at the Oak Ridge National Laboratory (ORNL) ..........................21

3.3.1 Licensing ........................................................22

3.3.2 Tennessee Center for Research and Development (TCRD).................23

3.3.3 Tennessee Resource Valley (TRV) ..................................23

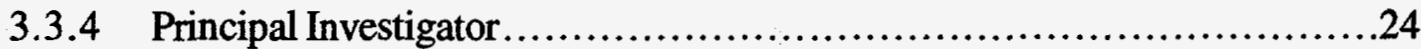

3.3.5 Tennessee Innovation Center (TIC) ................................24

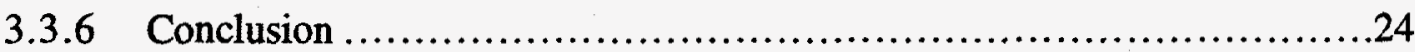

3.4 Sandia National Laboratory ...............................................24

3.5 Summary of Technology Commercialization Practices at Other Laboratories........26

4.0 Current and Historical Commercialization Practices at Los Alamos.......................27

4.1 The New DOE Technology Transfer Initiative.................................27

4.2 The Los Alamos Industrial Partnership Office (IPO) .............................27

4.3 Examples of Small-Business Commercialization of Los Alamos Technologies ......27

4.3.1 Cell Robotics, Inc. (CRI) ......................................... 28

4.3.2 Essential Communications................................................

4.3.3 Paradigm Concepts..................................................... 30

4.3.4 Amtech..............................................................

4.3.5 Prediction Company................................................ 31

4.3.6 Mesa Diagnostics/Los Alamos Diagnostics ............................32

4.3.7 Other Selected Commercialization Interviews............................. 34

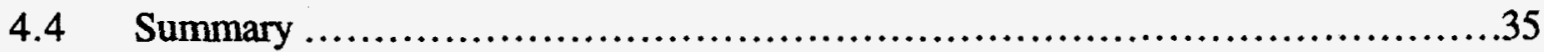

5.0 Issues Associated with Los Alamos Affecting Commercialization ..........................37

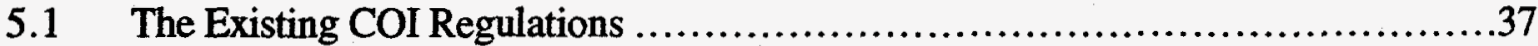

5.2 Uniformity and Discipline in Intellectual Property Procedures, Including Los Alamos IPO Licensing Guidelines ......................................39

5.3 Fairness of Opportunity Requirements ......................................41

5.4 Ability to Accept Equity and Use of Equity as Compensation .....................43

5.5 Sharing Licensing Compensation with Managers .............................45

5.6 Time Required to Obtain a License ........................................45

5.7 Restrictions on Licensing and Inability to Assign a Patent ........................46 
The Final Report of Los Alamos Contract No. 4790L0013-9Z, Volume 1

5.8 Knowledge and Identification of Existing Technologies. .47

5.9 Current State of Los Alamos' Commercial Knowledge and Market Orientation ......48

5.10 Lack of Knowledge about Small Business Commercialization Practices at Los Alamos. .48

5.11 Lack of Availability of Recent Successful Small Business Spin-off Role Models....49

5.12 Availability of Funding for Maturation of Commercially Viable Technologies ......49

5.13 Ability of Los Alamos Employees, Former Employees, Consultants, or Companies who Employ them, to Obtain Licenses .............................5

5.14 Availability and Conditions for Entrepreneurial Leave........................51

5.15 Effects of Los Alamos Organization on Would-be Entrepreneurs ..................51

5.16 Rights of Others to Use Technology Licensed from Los Alamos/UC ..............52

5.17 Dual-benefit Requirements .............................................53

5.18 Substantial U.S. Manufacture Réquirement................................53

5.19 Indemnification Language in Licenses and Contracts ...........................54

5.20 Assignment of IP Rights Originating from Work for Others ....................54

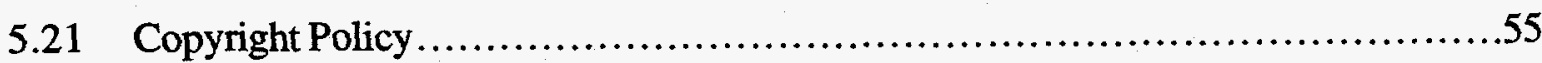

5.22 Internal Los Alamos Infrastructure Issues................................55

5.23 Litigation in Case of Alleged Infringement .................................55

6.0 Alternative Procedures for Commercialization of Los Alamos Technologies ...............57

6.1 Models for Enterprise Creation .........................................5

6.1.1 Technology Source Responsibilities ..............................57

6.1.1.1 Technology Maturation ....................................57

6.1.1.2 Protection and Identification of Intellectual Property...............58

6.1.1.3 Envision Products and Services ............................58

6.1.1.4 Determine Role of Inventors.............................58

6.1.1.5 Determine a Commercialization Strategy .....................58

6.1.2 Public Sector Responsibilities ....................................59

6.1.2.1 Creating a Venture Package .................................59

6.1.2.2 Establish the New Enterprise ................................59

6.1.2.3 Establish Initial Market Presence .............................59

6.1.2.4 Steady-State Operation ...................................60

6.1 .3 Interface Issues .................................................60

6.2 Introduction of the Scenario Concept .....................................60

6.2.1 Scenario A: Los Alamos Employee Spins-out with Technology ...........61

6.2.1.1 A Three Stage Scenario....................................61

6.2.1.2 Technology Identification, Screening, and Selection ............62

6.2.1.3 Maturation and Commercialization Planning ...................64 
The Final Report of Los Alamos Contract No. 4790L0013-9Z, Volume 1

6.2.1.4 Business Creation and Spin-Off.

6.2.2 Scenario B: Entrepreneur from Outside Los Alamos Laboratory Spins-out a Los Alamos Technology. .68

6.2.2.1 Scenario Assumptions ......................................69

6.2.2.2 Commercialization Stages .....................................70

6.2.2.3 Technology Identification, Screening, and Selection and Initial Commercialization Planning .............................. 71

6.2.2.4 Develop Technology Evaluation and Transfer Strategy...........73

6.2.2.5 Technology Transfer and Licensing Strategy ...................75

6.2.3 Summary of Contractual and Policy Support for Commercialization at Los Alamos National Laboratory ...................................76

6.3 A Model Commercialization Process ............................................77

6.3.1 Technology Screening and Selection.................................77

6.3.1.1 Producing the First Output .................................77

6.3.1.2 Application of Methodology ..................................78

6.3.1.3 Producing Commercialization Strategies .........................78

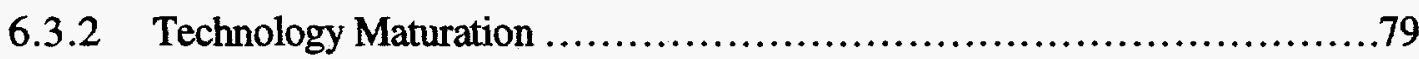

6.3.2.1 Technology Evolution .................................... 79

6.3.2.2 Business Development Strategy ............................79

6.3.2.3 Results of Phase Two ......................................... 79

6.3.3 Business Creation and Spin-Off ..................................... 79

6.3.3.1 Form Key Venture Teams......................................80

6.3.3.2 Complete and Refine the Business Plan .......................80

6.3.3.3 Form the Company ....................................... 80

6.3.3.4 Obtain Additional Investment .................................80

6.3.4 Uncertainties in the Maturation Process...................................81 
The Final Report of Los Alamos Contract No. 4790L0013-9Z, Volume 1

\section{Table of Contents}

\section{Volume 2}

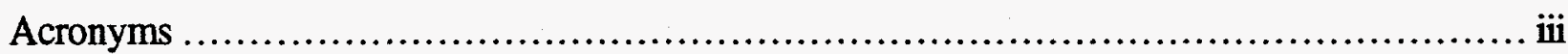

Appendix A. Summary Information on the Joint MCC/Los Alamos Technology Conference ...... 1

Appendix B. Comparison of New Mexico Infrastructure to Other Areas..........................5

B.1 Factors of Importance to New High-Technology Businesses ......................5

B.2 Assessment of the Los Alamos Infrastructure .................................. 8

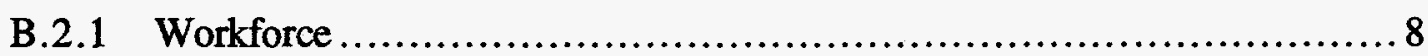

B.2.2 Proximity to Markets ..................................................... 8

B.2.3 Public Education System ........................................ 9

B.2.4 Interaction Between Government, Business, and Academia ................9

B.2.5 Costs of Doing Business ............................................10

B.2.6 Access to Capital ..................................................... 10

B.2.7 Access to Emerging Technologies..................................11

B.2.8 Technical Support Services and Equipment ...........................11

B.2.9 Communication Facilities..........................................12

B.2.10 Quality of Life .....................................................

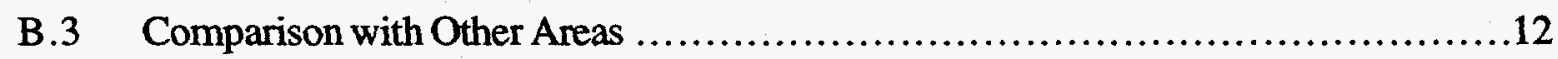

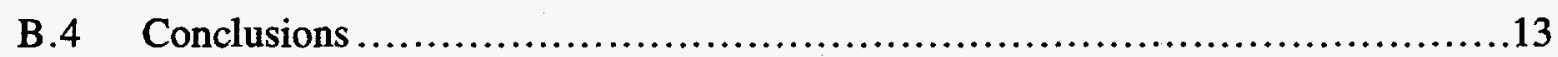

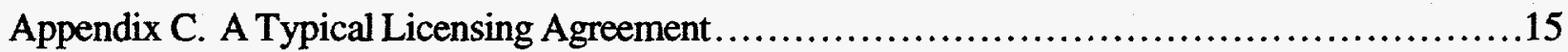

Appendix D. Technology Screening Guidelines ...........................................

D.1 Technology Screening Information Requirements .............................19

D.2 Screening Technologies: Initial Market and Business Evaluation..................20

D.3 Other Comments On Screening: Locating and Classifying Los Alamos

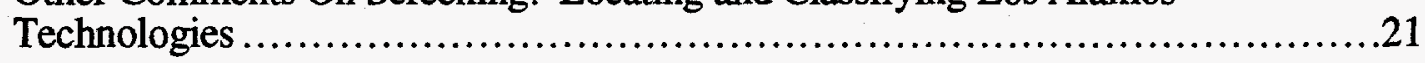

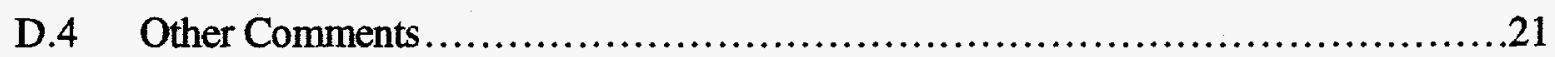

Appendix E. Summaries of Specific DOE/UC/Los Alamos Documents .........................23

E.1 List of Documents Provided by Los Alamos for Review .........................23

E.2 The Prime Contract (No. W-7405-Eng-36, Mod No. M 359) ....................27

E.3 Documents Relating to Patent Policies and Procedures ........................... 31

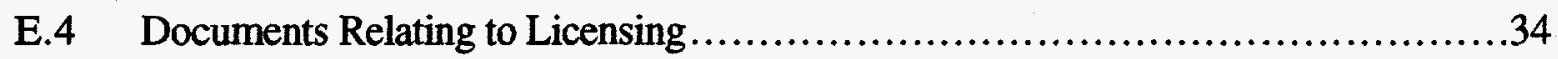

E.4.1 The Exclusive Patent License Agreement ...................................34

E.4.2 Differences between the UC Exclusive License and a Typical Industry Exclusive License ...........................................36

E.4.3 Exclusive Computer Software License Agreement .........................37

E.4.4 The Non-Exclusive Patent License Agreement...................................38 
E.4.5 Draft Development License Agreement (1/27/93)..............................39

E.4.6 Instructions for Completing a Proprietary Information Agreement..........41

E.5 Documents Relating to Research and Development/Technology Transfer...........42

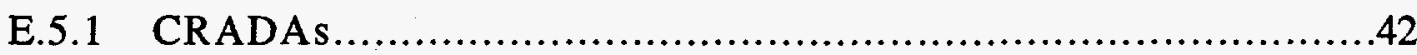

E.5.2 DOE Work for Non-Federal Partners ..................................46

E.5.3 The Funds-In Agreement ...............................................48

E.5.4 Los Alamos' Technical Consulting Services Agreement....................49

E.5.5 User Facility and Proprietary User Facility Agreements ....................50

E.5.6 Industrial Staff Member Agreement (ISMA) .........................51

E.5.7 Outside Employment Policy, Entrepreneurial Leave Policy, Leave Without Pay Policy .........................................52

E.6 Documents Relating to DOE Policy and Guidance ..............................53

E.6.1 Partnerships for Global Competitiveness: A Draft Strategic Plan...........53

E.7 Documents Describing Relevant Los Alamos Programs..........................55

E.7.1 New Program Opportunities for Small Businesses.......................55

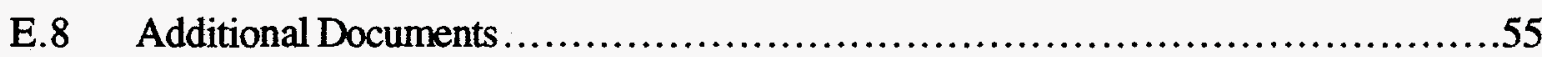

E.8.1 Draft Copy Equity Bulletin, dated 10/8/93 ..........................55

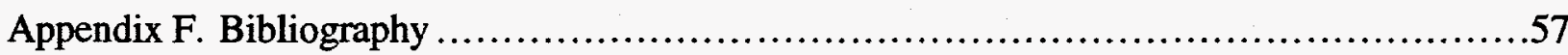

Appendix G. Detailed Information on the Joint MCC/Los Alamos Technology Conference .......61

Appendix H. ARCH: The Argonne National Laboratory/The University of Chicago Development Corporation ...................................................................

Appendix I. The Oak Ridge National Laboratory TCRD............................................131

Appendix J. The Ames Center for Advanced Technology Development.......................159

Appendix K. Los Alamos National Laboratory Licensing Procedures .......................... 183

Appendix L. Presentation Slides from Monthly MCC/Los Alamos Review Meetings ...........223

Appendix M. Generalized Entrepreneurship Model................................................ 327

Appendix N. Receiving Equity for Technology: Opportunities, Issues, and Structures........... 345 


\section{Acronyms}

\begin{tabular}{|l|l|}
\hline ALO & Albuquerque Liaison Office \\
\hline AM & Administrative Manual \\
\hline ANL & Argonne National Laboratory \\
\hline ARCH & Argonne/Chicago Development Corporation \\
\hline ATP & DOC's Advanced Technology Program \\
\hline CAD & Computer Aided Design \\
\hline CADET & Center for Applied Development of Environmental Technology \\
\hline CAE & Computer Aided Engineering \\
\hline CATD & Ames Laboratory's Center for Advanced Technology Development \\
\hline CATV & Cable Access Television \\
\hline CBD & Commerce Business Daily \\
\hline CEDRA & Center for Economic Development Research and Assistance \\
\hline CEO & Chief Executive Officer \\
\hline CFR & Code of Federal Regulations \\
\hline COI & Conflict of Interest \\
\hline CRADA & Cooperative Research and Development Agreement \\
\hline CRI & Cell Robotics, Inc. \\
\hline DEC & Digital Equipment Corporation \\
\hline DOC & Department of Commerce \\
\hline DOD & Department of Defense \\
\hline DOE & Department of Energy \\
\hline EL & Entrepreneurial Leave \\
\hline EPRI & Electrical Power Research Institute \\
\hline ES\&H & Environmental Safety and Health \\
\hline ESTSC & DOE's Energy Science and Technology Software Center \\
\hline FED & Field Emission Transmitter \\
\hline FOO & Fairness of Opportunity \\
\hline G\&A & General and Administrative \\
\hline GAO & Government Accounting Office \\
\hline GOCO & Government-owned Contractor-operated \\
\hline HIPPI & High-speed Interactive Parallel Processing Interconnection \\
\hline IAO & Industrial Applications Office \\
\hline IG & Inspector General \\
\hline IP & Intellectual Property \\
\hline IPI & International Presence Index \\
\hline IPO & Los Alamos' Industrial Partnership Office \\
\hline
\end{tabular}


The Final Report of Los Alamos Contract No. 4790L0013-9Z, Volume 1

\begin{tabular}{|c|c|}
\hline IPRT & Institute for Physical Research and Technology \\
\hline ISMA & Industrial Staff Member Agreement \\
\hline ITDC & ANL's Industrial Development Center \\
\hline LANL & Los Alamos National Laboratory \\
\hline$\overline{\mathrm{LS}}$ & Life Sciences \\
\hline LWOP & Leave Without Pay \\
\hline $\mathrm{M} \& \mathrm{O}$ & Management and Operating \\
\hline MCC & Microelectronics and Computer Technology Corporation \\
\hline MCI & Manufacturing Competitiveness Index \\
\hline MIT & Massachusetts Institute of Technology \\
\hline MMES & Martin Marietta Energy Systems \\
\hline MVI & MCC Ventures, Inc. \\
\hline NAFTA & North American Free Trade Agreement \\
\hline NASA & National Aeronautics and Space Agency \\
\hline NIH & National Institute of Health \\
\hline NMRDI & New Mexico Research and Development Institute \\
\hline $\mathrm{OCI}$ & Organizational Conflict of Interest \\
\hline OEM & Original Equipment Manufacturer \\
\hline ORNL & Oak Ridge National Laboratory \\
\hline OTT & MMES's Office of Technology Transfer \\
\hline PI & Principal Investigator \\
\hline PIA & Proprietary Information Agreement \\
\hline R\&D & Research and Development \\
\hline RREDC & Rio Rancho Economic Development Corporation \\
\hline SAR & Stock Appreciation Rights \\
\hline SBIR & Small Business Innovation Research Program \\
\hline SOW & Statement of Work \\
\hline TCRD & Tennessee Center for Research and Development \\
\hline TIC & Tennessee Innovation Center \\
\hline TRADE & Tri-Area Association for Economic Development \\
\hline TRV & Tennessee Resource Valley \\
\hline TVA & Tennessee Valley Authority \\
\hline TVC & Technology Ventures Corporation \\
\hline $\mathrm{UC}$ & University of California \\
\hline UNM & University of New Mexico \\
\hline UPI & University Patents, Inc. \\
\hline VAR & Value Added Reseller \\
\hline
\end{tabular}




\subsection{Introduction to the Project}

\subsection{Overview of the Report}

Over the past decade, numerous companies have been formed to commercialize research results from leading U.S. academic and research institutions. Emerging small businesses in areas such as Silicon Valley, Boston's Route 128 corridor, and North Carolina's Research Triangle have been especially effective in moving promising technologies from the laboratory bench to the commercial marketplace-creating new jobs and economic expansion in the process. Unfortunately, many of the U.S. Department of Energy (DOE) National Laboratories have not been major participants in this technology-transfer activity, a result of a wide variety of factors which, until recently, acted against such transfers. However, some positive results have appeared from these laboratories that have been directed to include technology transfer in their primary missions.

The University of California (UC), in its capacity as operator of the Los Alamos National Laboratory (Los Alamos) for the U.S. Department of Energy, has sought for some time to commercialize its technological findings through a variety of contractual vehicles, including Cooperative Research and Development Agreements (CRADAs), Licensing Agreements for patented inventions and software, Work for Others Agreements, User Facility Agreements, and Technical Assistance Agreements, among others. However, no one agreement provides for the assessment of technologies at the national laboratories, the identification of promising technologies for commercialization by small businesses, the development and maturation of those identified technologies, and the spinning-off of these technologies as new products produced by new businesses. As a result, both Los Alamos and DOE have perceived that there is a need for new methods for bridging the gap between the generation of new technologies at Los Alamos and the successful creation of small U.S. businesses based on those technologies.

The "commercialization gap" cited above exists in part due to a lack, within Los Alamos in particular and the DOE in general, of in-depth expertise and experience in such business areas as securities regulation, marketing and distribution, venture capital financing, and the formation of small high technology corporations funded with venture capital. Faced with this gap, private businesses, investors, entrepreneurs, and venture capital professionals which could potentially benefit from the commercialization of Los Alamos technologies, have too often been impeded or frustrated by the unique administrative requirements arising from the dual status of Los Alamos as both a government contractor and a facility operated by a public educational institution.

Recognizing the need for improvement in its processes for technology commercialization, Los Alamos contracted with MCC Ventures, Inc. (MVI), a subsidiary of the Microelectronics and Computer Technology Corporation (MCC) of Austin, TX, in late 1993 to perform a detailed review of the current expertise, resources, and services of Los Alamos for linking its highly successful programs for the generation of new technologies with the successful commercialization of those technologies by small businesses.

Los Alamos' expertise is in the research and development (R\&D) of technologies for government programs and not in the formation and enhancement of commercially oriented, small businesses. Accordingly, an industrial participant with experience in developing small businesses with immature technologies is needed to successfully review the contractual obligations, policies, and statutes which govern Los Alamos' practices and procedures for commercializing technologies that are developed at Los Alamos National Laboratory.

MCC Ventures, Inc. (MVI) is a leader among companies in the American electronics and computer R\&D industry that specializes in the formation of new, small businesses to commercialize technologies developed at the Microelectronics and Computer Technology Corporation (MCC). MVI serves as the commercialization arm of MCC, which is the only U.S. consortium in the information and electronics systems industries. Founded in 1982 to perform R\&D in computer hard- 
ware and software technology, MCC leverages investments from multiple companies to sustain competitiveness in meeting broad industry needs through application-driven research, development, and timely deployment of innovative technology. The member companies of MCC represent just under $10 \%$ of the U.S. gross national product and include 72 small, medium, and large North American corporations that span the spectrum of electronics and information systems.

MCC's experience has demonstrated that doing good research is not sufficient to create commercial value from innovation. One strategy that has proven successful for MCC is the creation of spin-off companies to commercialize MCC-developed technology. MCC members preferred that technology developed by MCC be delivered through supplier companies that provided hardened, supported products. Therefore, MCC established a mechanism to facilitate the creation of new companies to be the suppliers, and in doing so produced opportunities for member companies to share in equity appreciation and investment return, as well as in the product's success.

This report details the findings of this review. For comparative purposes, Section 2 provides an introduction to a typical set of commercialization practices that has proved to be successful in the non-government environment; it is intended to serve as an introduction to the findings of the MVI Review Team. Section 3 gives brief introductions to the commercialization practices that the MVI reviewers and Los Alamos personnel found to be in operation at other DOE laboratories that parallel Los Alamos. Section 4 discusses the current Los Alamos situation in general terms, including brief summaries of several recent instances wherein Los Alamos technologies were commercialized with varying degrees of success.

The heart of this report is provided in Sections 5 and 6. Based on MVI's extensive review activities, Section 5 presents a listing of over twenty issues which appear, at present, to have negative effects on the capability of Los Alamos to allow and support commercialization of technologies developed within its laboratories. For each issue, an explanation of its impact on commercialization is given, along with one or more avenues which appear to be available to Los Alamos for reducing or eliminating the effects of those issues. Section 6 then provides two explanatory scenarios showing how commercialization of Los Alamos technologies can be greatly enhanced when the principal limiting issues are properly mitigated.

Supporting the findings reported in Sections 1 through 6, Appendices A through N provide background information that is also of relevance to the commercialization of Los Alamos technologies. Appendix A provides a summary of and representative materials from a major technology workshop, "New Frontiers of Technology Commercialization," held jointly by MCC and Los Alamos in Santa Fe, NM, on March 7 and 8, 1994.

Appendix B provides a discussion of the general factors that are critical to the nurturing of commercialization in a given geographic area, as well as an assessment of the current state of those factors in the Los Alamos and New Mexico areas. Appendix C is a representative licensing agreement used in commercial technology licensing situations; and Appendix D presents a typical set of screening guidelines for use in selecting technologies which are good candidates for commercialization.

Appendix E presents detailed reviews of key Los Alamos documents which the MVI Review Team has studied as part of its review process, focusing primarily on the impact of those documents on commercialization of Los Alamos technologies by emerging small businesses. These reviews have provided much of the base for the issues discussed in Section 5. Appendix F provides a bibliography citing those additional references which the Review Team has found to be of particular relevance to its assessment of commercialization both in general and in specific relation to Los Alamos. 
Appendix $\mathrm{G}$ contains speaker presentations and other detailed information from the Joint MCC/Los Alamos National Laboratory Technology Conference held in Santa Fe, New Mexico on March 7-8, 1994. Appendix $\mathrm{H}$ includes interviews and other background information obtained from a visit to ARCH: The Argonne National Laboratory/The University of Chicago Development Corporation. Appendices I and J contain similar material obtained from visits to the Tennessee Center for Research and Development, located at the Oak Ridge National Laboratory, and The Ames Center for Advanced Technology Development.

Appendix $\mathrm{K}$ includes examples of selected Los Alamos licensing procedures. Appendix $\mathrm{L}$ contains copies of the slides that were presented to Los Alamos by MVI during the monthly MCC/Los Alamos contract review meetings. Appendix $\mathrm{M}$ is a technical paper which presents a Generalized Entrepreneurship Model. This paper focuses explicitly on issues surrounding commercialization of technologies developed by public institutions.

Appendix N contains a memorandum authored by Christopher Lane Davis of O'Sullivan Graev \& Karabell on the subject of "Receiving Equity for Technology." The memorandum also includes sample bonus incentive planning procedures for involving members of the scientific staff in equity rewards.

\subsection{Objectives of the Project}

The principal objectives defined for the MVI review project have been to:

(a) Assess and report on the current climate for and past history of technology commercialization at Los Alamos;

(b) Assess and report on the technology commercialization practices at other government laboratories and in the commercial sector; and,

(c) Assess and report on the options available to the DOE and to the University of California, in its capacity as operator of the Los Alamos National Laboratory under contract to the DOE, for commercialization of technologies that are developed at Los Alamos and which may have useful applications in the U.S. electronics and/or computer industries.

To accomplish the tasks listed above, MVI assembled a team of experts in the various areas of policy, procedure, and technology which related to those tasks. This group, referred to as the MVI Review Team hereafter, has jointly authored this report.

\subsection{Statement of Work for the Project}

The study efforts upon which this report are based were guided by a statement of work (SOW) defined at the beginning of the project. Under that SOW, MVI and Los Alamos agreed that this final report would address MVI's findings regarding factors that influence technology commercialization at Los Alamos, focusing on commercialization via U.S. small businesses, and including the following specifically identified factors:

(1) A summary of the limitations and obligations imposed by the contractual, statutory and regulatory requirements applicable to the operations of the University of California at Los Alamos;

(2) A summary of the limitations and obligations imposed by the internal practices and procedures of the DOE and the University;

(3) A summary of the financial, marketing, regulatory and other business factors that must be taken into account by private investors and U.S. businesses, par- 
ticularly small businesses, as part of the due diligence process used to determine how to use, manufacture, distribute and otherwise exploit new technologies in the areas listed above (see Section 1.1);

(4) A description of a variety of model procedures for establishing and financing small businesses based on technologies developed at Los Alamos in the areas listed above;

(5) A summary of the unique difficulties and advantages applicable to the commercialization process, faced by prospective licensees and other transferees of technologies originating from Los Alamos in the areas listed above;

(6) A report on processes within the DOE complex as those processes relate to commercialization of Los Alamos technologies by small businesses to the extent possible given MVI's access to the necessary information.

(7) A summary of elements of a technology maturation program that would be created, funded and executed by Los Alamos, and which would be dedicated to the maturation for commercial exploitation of early-stage technologies in the areas listed above that are identified as having particular application in the U.S. electronics and computer manufacturing industries, which technologies may or may not be subject to pre-existing licensing commitments to U.S. companies serving the electronics and computer industries;

(8) A description of appropriate procedures for spinning-off small-businesses based on Los Alamos technologies in the areas listed above that would be useful as Los Alamos develops a dedicated commercialization program; and

(9) A summary of how other contractual arrangements between the University, and licensees and other transferees of Los Alamos technologies in the areas listed above might be utilized to enhance the commercialization process;

\subsection{Table of Compliance}

As an aid to readers of this report interested in specific areas of the statement of work given in the preceding section, the following table relates those areas to the various sections of this report.

\begin{tabular}{|l|l|}
\hline \multicolumn{1}{|c|}{ Work Item from the SOW } & \multicolumn{1}{|c|}{ Related Sections of This Report } \\
\hline 1: UC/Los Alamos Regulatory Requirements & Sections 4 and 5, Appendix E \\
\hline 2: DOE/Los Alamos Practices and Procedures & Sections 4 and 5, Appendix E \\
\hline 3: Business Factors re Commercialization & Section 2, Appendix D \\
\hline 4: Model Procedures for Commercialization & Section 6, Appendices C and D \\
\hline 5: Unique Los Alamos Issues & Section 4, Appendix B \\
\hline 6: Processes within the DOE Complex & Section 3 \\
\hline 7: Technology Maturation Program & Sections 5 and 6 \\
\hline 8: Spin-off Procedures & Sections 5 and 6 \\
\hline 9: Other Contractual Approaches & Sections 4 and 6.2, Appendix E \\
\hline
\end{tabular}




\subsection{Summary of Commercialization Practices in the Non- Government Business Environment}

The practice of commercializing new technology in the non-government business environment is characterized by a high degree of flexibility and individuality. The process of creating and funding a start-up is a complex, high-risk endeavor which demands patience, persistence, and a high degree of business management ability. Each start-up is unique-no two are alike - and while an individual start-up may develop along lines which might be described as a "process," each will demand special attention and time, and will go through a series of problems and opportunities specific to that particular business.

While there is a typical "process," with certain well-established, commonly-practiced steps that almost all technology-based new businesses go through, the detailed development of every start-up is unique and highly individualized. Furthermore, the basic ingredients necessary to the formation of a successful new business are far more important than the process. Hence, the practice of starting a successful new business focuses on trying to be certain that the necessary elements are in place, rather than on following any kind of rigorous step-by-step process.

\subsection{Major Considerations in the Formation and Capitalization of Start- ups}

The key ingredients that are absolutely essential in creating a successful technology-based start-up business consist of:

1. Management: considered by most practitioners to be the most important ingredient of a successful technology start-up. An outstanding, experienced management team can usually correct problems (and every start-up will encounter problems, any one of which can prove to be fatal) and find a successful business strategy even if the initial strategy proves to be incorrect.

2. Markets: consist of customers who have a need, and are willing to pay to satisfy that need. Successful new ventures are based on serving large and growing markets.

3. Technology: leads to the development of innovative products and services that have a distinctive characteristic and which represent a substantial and sustainable competitive advantage.

4. Capital: the financial resources needed to take the business to a point where it is self-sustaining (that is, capable of sustaining a positive cash flow).

In addition, the above factors need to be combined in a fashion that provides a proprietary competitive position in the form of a business strategy that takes advantage of the market opportunity in a way that competition cannot duplicate. This is especially important to the start-up which generally begins its life with a significant disadvantage in terms of size and available resources.

Every start-up presents its own unique set of conditions and problems. Consequently, the practice of commercializing technology in the commercial environment consists of a series of steps or "gates" that must be satisfied, plus a set of tools which are employed by the parties participating in the development of the new business. However, the sequence of these steps, and the assortment and quantity of the tools employed, varies widely from start-up to start-up. 


\subsubsection{The Generic Enterprise Creation Process}

The general process for creating a new technology-based business is relatively standard regardless of the technology content or where the subject technology originates. This section discusses a generic model that is used in many situations and organizations, and then discusses what modifications and additions should be made to this basic process to fit it to Los Alamos' situation.

The generic process consists of the following steps:

- Identify and characterize the market opportunity.

- Identify a marketable technology capable of producing products to satisfy the identified market need.

- Develop a commercialization plan. A commercialization plan is very similar to a business plan, and in fact, it is often used as a preliminary business plan.

- Bring the technology to a commercial state (maturation) where it can be visualized and designed into a product, and/or where sufficient proof of product concept can be demonstrated in order to obtain the financing necessary to start a company.

- Form a company to exploit the new technology.

- Recruit/form a management team.

- Revise the commercialization plan, adding the additional details and sections to turn it into a full-scale comprehensive business plan.

- Secure start-up financing-sometimes referred to as "seed capital."

- Begin operations.

The sequence, emphasis, and timing will differ markedly from case to case-there are no hard and fast rules, and frequently several steps are worked on simultaneously. For example, often it is difficult to obtain full commitments from the required members of the management team until initial financing is in place. At the same time, it is difficult to obtain commitments for the necessary financing until the members of the management team are identified and committed.

In many start-ups, the process of initial capitalization is accomplished through a carefully orchestrated process of presenting an investable president/chief executive officer (CEO) candidate, and possibly the principal technical individual, and identifying other potential management team members without disclosing their names or current place of employment. Often, the names of the = other potential team members who would join, subject to financing, are then revealed to those with a serious investment interest while they are performing their due diligence, and after they have signed a confidentiality agreement.

In other, more infrequent cases, investors may be willing to make commitments based mainly on the uniqueness of the technology, the attractiveness of the market opportunity, and/or the business concept represented. In such situations, the investors may have a management team in mind that they have worked with successfully before, and which they believe can be attracted to the new opportunity. In these types of cases, successful start-ups depend to a much greater degree on the skills and entrepreneurial management know-how of the investors. Some venture capital groups and certain "angels" have both the interest and ability needed to develop these types of venture opportunities.

Any new business is mainly a reflection of the people involved. An early-stage business often functions in its beginnings with 25 employees or less. It has not had sufficient time, nor does it have the size and structure, to have developed the character and stability normally found in larger, more established organizations. As a result, small, early-stage companies are as individualized as the people who manage them and those that work with them in other capacities, such as investors, advisors, consultants, and board members. 


\subsection{Major Considerations in Creating a Technology-based New Enterprise}

Secure Qualified Management: When in doubt, venture capitalists generally bet on the more experienced management team. Experience clearly demonstrates that management is the most critical ingredient in the success of a new venture. Venture capital managers generally only invest in situations which have management with a proven, demonstrated record in successfully managing similar start-up businesses. The cardinal rule is to back management teams, not technologies. Put another way, venture capitalists will invest in an " $A$ " team which has a " $B$ " business plan, but will avoid a "B" team, even though they have an "A" plan.

One of the reasons for this general policy is that the best way to reduce the substantial risk associated with starting a new business is to back managers who have done it before. Almost without exception, start-ups will encounter one or more major crises. Experienced managers who have encountered similar problems are better equipped to deal quickly and successfully with such crises. In addition, they will have already demonstrated the basic skills needed to successfully start and operate a new enterprise. These skills are different than those generally held, for example, by successful managers in large industrial organizations.

This is not to say that a management team capable of attracting investment always has to be in place before investors will take an interest. Instead, investors skilled at investing in early-stage business often will play a substantial role in helping to assemble the management necessary to develop an attractive new business concept. This is an important role that venture firms can play in addition to providing capital. However, investment organizations with the required skills and an investment strategy that places emphasis on early-stage and seed transactions are few (and seemingly becoming fewer), and knowing who is good at doing which type of deal (by stage of financing and type of business) is a matter of experience and an active, continuing involvement in the community that is helping to develop start-up businesses.

One very successful technique practiced by some industrial organizations and venture investors is to recruit a successful entrepreneurial manager with the demonstrated skills and interests, and to present that individual with the opportunity to search through an assortment of business opportunities, in the form of market and technology combinations, to identify a new business opportunity which the experienced entrepreneur thinks is worth taking on for development into a new business. In a similar fashion, a venture investment organization may employ a proven entrepreneur to write a business plan and form a company to address some identified new business opportunity that appears to special appeal. Some of the most successful venture capital-backed start-ups have been developed through variations of this approach to technology incubation.

The approach used to finding experienced entrepreneurial management candidates deserves special attention. There is an on-going shortage of management recruiting firms that specialize in dealing with search assignments related to early-stage, new venture companies. Typically the larger, better known recruiting firms do not have the database of candidates or the experience in operating in the small company arena that is important to filling positions in start-ups. A good practice is to use recruiters who have successfully completed placement assignments for other small technologydriven companies. The selection should be tempered by the type of business involved. Small recruiting firms tend to specialize, and the selection of those that have a known special expertise when dealing with specific business areas (e.g., when working on a software start-up, work with a recruiter that has developed a special interest in and completed numerous searches for software companies) will generally tend to be more productive.

Large and Growing Markets: In creating new start-ups in the private sector, investors and entrepreneurs generally prefer to focus on businesses which address large and growing markets. A recent Harvard study concluded, not so surprisingly, that the largest determinate of growth businesses was to be in growing markets. Large, successful businesses simply cannot be devel- 
small markets. To state the obvious, it is impossible to build a $\$ 100$ million business if the total market demand for the product which the subject company produces is only $\$ 50$ million. Conversely, a large, rapidly growing market presents a much different environment to the new entrant, and can make up for a number of other deficiencies that a small company may have at its inception.

Sustainable Competitive Advantage: Attractive start-ups are those which offer a significant, sustainable competitive advantage, usually by virtue of some proprietary content. In most cases, this will depend on the underlying technology and how well that technical uniqueness can be maintained and protected. This is one of the reasons why the venture community places so much emphasis on having clear control of the unique technical content that is to be exploited by a new company, whether by having the relevant patents or copyrights assigned, or at a minimum, by having exclusive licenses. In addition, the translation of the proprietary technology into products which are clearly superior to existing and potential products must be demonstrated, or the advantages offered through the use of that technology must be clearly superior in cost or performance to what is already on the market, or what could be brought to market in a reasonable time frame.

Movement of People with Technology: Attempts are sometimes made to move a complex new technology and start a new enterprise without transferring the technical people responsible for the development of the technology who have the basic underlying, intimate knowledge required to successfully continue to support successful development and commercialization. Unfortunately, as too many failed start-ups have proven, moving the technology without its authors is a risky process. Recognizing this condition, some industrial organizations have adopted a "shuttle" concept. The shuttle, which is "launched" from the developing organization, is composed of the key people and other resources (special equipment, prototypes, etc.) involved in the creation and development of a new technology or business concept. The shuttle is transferred to the organization or business unit responsible for planning and carrying out the commercialization of the technology. The shuttle often returns to its launch point, although some members of the shuttle team may stay behind with the newly started business.

In addition, the people transferred must be committed champions, with the ability to provide technical know-how, continuity, and perspective - they must be dedicated to the success of the development process, and have a strong desire to see their technical achievement turned into a successful product.

Make Sure the Technology is Ready for Commercialization: The technology found in many laboratory environments is typically not ready for commercialization, and must go through a period of maturation. The maturation process is intended to eliminate much of the uncertainty and associated risk that is inherent in "raw" technology. Technology that has successfully gone through the maturation process will have a reasonably predictable time and cost for developing and beginning to market a product. That is, in developing a business plan, the prospective managers will be able to lay out the necessary steps, including forecasts of the time and cost involved in developing an actual product or service which can be sold to customers, with a higher degree of certainty than that allowed with a less-mature technology. This implies an absence of technical uncertainty, e.g., all of the major technical barriers should be resolved, or at least clearly identified with well-formed knowledge as to how they can be resolved. This also requires an ability to demonstrate and prove the principles of the technology. This frequently means that breadboards, engineering prototypes, or a product configuration suitable for demonstration of the concept are available. In the case of software, this means that the basic concepts can be defined and that substantial work has been done on the definition of product requirements, and possibly that some programming of critical routines has been started.

Ereedom from Unnecessary Restrictions and Impediments, and Minimal Threat of Future Impediments: An important requirement in starting a new enterprise in the commercial environment is that the start-up must have full rights to make, use, and sell products based on the technology, 
without concern over the threat of a competitor introducing products based on the same technology. Successful start-ups depend on having a sustainable advantage. Much of that advantage in a technology-based company comes from the underlying technology, but only when coupled with the company's continuing ability to turn that technology into marketable products.

In the case of licenses, often the patents or patent applications for any critical technology are assigned directly to the new enterprise. If the patents are licensed rather than assigned, investors and entrepreneurs generally expect that licenses will be exclusive and unlimited, with worldwide rights, no field-of-use restrictions, and the ability to sub-license as required. In addition to royalty payments and other forms of compensation, the licensee may be required to agree to certain conditions to ensure that the technology is actually used. This may take the form of minimum sales levels and/or commitments on time that an initial product will be brought to market. If these sales and product introduction commitments are not met, conditions are often imposed that result in the license automatically converting to a non-exclusive arrangement. As long as the licensee meets the agreed-to sales and other performance conditions, the exclusive condition of the license agreement remains in effect.

This is not to indicate that successful new enterprises are not started with semi-exclusive, or even non-exclusive licenses. However, every limitation that restricts the ability of the company to practice the technology in a free and unrestricted fashion will detract from the company's ability to obtain sufficient financing and commitments for other necessary resources.

Another requirement is that license compensation arrangements recognize the financial condition of most new enterprises. Up-front cash payments are generally avoided, and, if agreed to, often royalty payments are deferred until the company has sufficient cash flow to permit payment without taking away cash needed to support growth. In many cases, patents are assigned and licenses granted in return for an equity interest in the start-up, with the objective of helping the licensee to conserve scarce cash resources during the start-up and growth phases of the business.

\subsection{Common Business Policies and Practices for Investing in and Developing Commercial Start-ups}

Dependence on Equity Financing: Small, rapidly growing business must be financed with "patient" money that is prepared to wait from five to ten years or more for a return. Likewise, small technology-driven companies cannot and should not be financed with debt. The types of private equity investors who are candidates for participating in a small-business start-up include: wealthy individuals with some relevant business experience, frequently referred to as "angels"; as well as venture capital investment firms, including a range of firms according to the amount of capital they manage, their investment strategy, and their elected class of business focus. Institutions seeking to facilitate the commercialization of their technologies need to assist emerging companies based on those technologies in identifying appropriate investors for their new companies.

Use of Partnering Arrangements: In appropriate situations, a new enterprise can gain significant advantage by partnering with a larger, more established organization. Partnering with another company to gain the benefit of a superior distribution organization, or to find an inexpensive way to penetrate foreign markets, or to take advantage of low cost manufacturing, can make a great deal of sense for an early-stage company.

Often partnering may be the only effective means to introduce exciting new products when the market is dominated by a few entrenched competitors. A larger partner may have established a superior marketing organization, but it may lack the technology to refresh the product line and may be lacking the new products needed to keep the marketing organization motivated and effective. In other cases, an industry participant may have manufacturing capacity which includes specialized equipment that a start-up cannot afford or justify. 
The critical challenge is to correctly determine what the newly created company can and should do for itself, while at the same time making sure that the new company has sufficient control and is not overly dependent on another organization to the extent that it loses its identity and is no longer viewed as sufficiently in control of its destiny. Start-ups that become subjugated to large partners are generally unable to obtain financing and often end up being absorbed by the larger company on a basis that is unfavorable to its management and investors.

Active Management Support and Board Participation: Successful private equity investors that deal with early-stage technology-based companies spend a great deal of time and energy working for and with their portfolio companies. Board meetings are one of the means (but not the only one) for this active involvement. Formal board meetings are generally held monthly, and often less formal meetings occur randomly as required by circumstances-sometimes on a weekly or daily basis. It is not unusual to find one of the investors assuming a temporary, full-time management role in situations where it has become necessary to make a change when a replacement has not yet been identified or is not readily available.

Some of the functions that successful early-stage investors often perform include introductions and assistance in penetrating key customer accounts; advice on the development of the business' overall strategy and direction, especially regarding what is happening in the market and competitive environment; assistance in recruiting for key positions; helping to identify sources of additional financing and in making presentations to prospective new investors; dealing with difficult financial and accounting issues; facilitating partnering and distribution arrangements; and a selection of other specialized tasks where an investor may have unique skills or special contacts that management may not. This close working relationship is one of the main reasons why successful early-stage investors generally invest in companies that are within easy travel distance (preferably within a 1 to 2 hour driving range). While Los Alamos may not be in a position to assume board responsibilities, it can work through an organization to which they can entrust their "investment" interest.

Providing Pre-qualified Support Organizations Familiar with the Problems of Technology-driven Start-ups: As in the case of recruiting firms, selected business support organizations are significantly more adept at working with early-stage companies. The qualification and selection of an accounting firm, a corporate law firm, a patent attorney, or a public relations firm to work with a small business is largely based on the reputation and experience in dealing with such firms. Firms experienced in dealing with early-stage companies are frequently willing to take a portion of their compensation in equity in cases where cash is short.

Provide Sufficient Financing to Carry the Business Through the Next 12 to 18 Months: For a small business in its early years, fund-raising can be a constant activity and can consume excessive amounts of time of the key people, often at the wrong time. Starving a small company at its inception is not a wise thing to do, and venture firms now generally look at financing packages to make certain that sufficient initial funds are in place to support a year or more of operations, even with low-end revenue projections. This is a two-edged problem, however, in that the costs of operation during such periods may be high enough to dissuade potential investors. Asking for too little is not an alternative, and the availability of a year or more of operating capital as part of the start-up process enables both staff recruitment, facilities acquisition, and management with a reasonably long-term view rather than constant pressure to accomplish too much, too soon. Institutions interested in commercializing their technologies through the start-up process should be prepared to assist those start-ups in acquiring sufficient initial capital as well as in acquiring appropriate amounts of capital at later stages of financing.

Invest at a Reasonable Valuation with Plans to Step-up to Additional Rounds: It is important to avoid over-valuing a start-up during the early rounds of investment-this will only result in "step downs" during later rounds. This is a difficult problem for "seed" investors: their investment often becomes diluted after additional rounds of investment, especially if the company does not do 
well. This could be a particular problem for Los Alamos since they will not be "investing" during the later rounds and will be relying on the position they established at the start-up's formation instead. In the software business, this may serve them well; in a hardware business that requires a bigger capital investment and multiple investment rounds over a longer development and growth cycle, this may prove to be a problem.

Use the Business Plan as a Continuing Working Document: The initial business plan should be considered as a living document which projects the operation of the business into the future. As actual operations differ - for better or worse-from the initial plan, it should be revised as necessary. The management of the company and the funding organization should both participate in the review and revision of the plan by looking for ways to help. The funding organization will act as a teacher, or mentor, rather than as a policeman or inspector.

Replace Management if that is the Only Way to Solve a Serious Problem: Assuming that good management was put in place at the beginning, the best choice is normally to support them even if the business is not meeting expectations. Replacement always enforces a period of adjustmentfew small companies have the qualified staff to promote to a management role from within, and a new manager needs time to learn the situation before he or she can begin corrective action. A better approach is to provide assistance, support, and even training to the managerial staff that is in place. If, as a last resort, a managerial change is decided upon, swift and decisive action is mandated, with clear information being provided to all affected parties. Losing key technical staff members during a managerial change is often a second-order coup de grace to a small company.

\subsection{Adapting the Generic Commercialization Model to Los Alamos}

Los Alamos faces some fairly unique problems in seeking to apply the generic commercialization model typically used in industry. ${ }^{1}$ Under current conditions, it is difficult for Los Alamos to use many of the tools and techniques commonly employed in starting technology-based businesses in other environments. This is due to a number of existing restrictions, principal of which are the following:

- Restrictions and obligations imposed by the University of California M\&O contract. As a government-owned, contractor-operated (GOCO) facility, Los Alamos is subject to the restrictions shared by all GOCO laboratories. In addition, Los Alamos is affected by the fact that the current manager, the University of California, raises related issues which do not affect those laboratories managed by industrial corporations. ${ }^{2}$ The single most important benefit to commercialization of technology that Los Alamos derives from its relationship with the UC as the M\&O contractor is the inheritance of an academic environment in which cutting-edge research can flourish. The recent trend among large U.S. corporations to focus on short-term profits through incremental advances to technology or products at the expense of long range research and development places a premium value on technologies developed by laboratories such as Los Alamos since they have the potential to represent a significant, sustainable market advantage over those products based on incremental extensions.

- DOE and other governmental policies and regulations. The DOE expresses a desire to see technology commercialized through the creation of small businesses because they are an appropriate means to exploit technology-based business opportunities. However, the various rules and regulations imposed on these small businesses by DOE, UC, and Los Alamos make it very difficult to

1 For detailed explanations of these issues see Section 6 and Appendix E.

2 See also Section 3.3 of this report. 
obtain technology and know-how from DOE laboratories to generate a new business. Many of these rules and regulations are subject to interpretation, and much depends on the mind-set of the various field offices and the advice they receive from the local general counsel. A valid question is: which does DOE really wish to do-promote new business formations as a means of technology commercialization, or strictly follow the established rules without any attempt to recognize the special problems related to start-ups? Are those in authority willing to recognize that the risks associated with attempting to begin a new business justify the superior rewards that a few successful entrepreneurs are able to gain, and that if the proper arrangements are made to participate in these successful start-ups, the government can share in these same gains?

- Management policies, administrative conditions and the "culture" at Los Alamos. Even without the impediments posed by DOE and other governmental and UC restrictions, the prevailing organizational attention, historical mission, management style, and general culture at Los Alamos serve to work against the formation of start-ups. The time scale of task completion at the Laboratory is not synchronous with that of small businesses. Whereas a small business thinks in terms of completing tasks and reaching decisions in days, or even hours, time horizons at Los Alamos appear to be much longer. In the early years of a start-up, managers often work 12 to 14 hours per day, 6 or even 7 days per week. A start-up is heavily goal-oriented, whereas the national laboratories (and many larger companies too) tend to be task-oriented.

Los Alamos is perceived to follow intellectual property policies which tend to be similar to those found in a university environment where it is regarded as more important to publish rather than to protect important new discoveries. In addition, the overall goals of the Laboratory tend to discourage entrepreneurial initiatives-especially under conditions that have existed over the last 3 to 4 years. Those who show entrepreneurial tendencies are not supported and may be subjected to a combination of envy, scorn, and questions about their ability and willingness to fulfill their Laboratory assignments.

- Los Alamos' location and the available infrastructure. In comparison to other geographic areas that have been active sources of new business formations, the area around Los Alamos suffers from a lack of the necessary infrastructure for spawning start-ups. This includes an absence of sources of private equity risk capital; the lack of available, experienced entrepreneurial management; and the shortage of suitable facilities in which to house new companies. Also, Los Alamos' remote location is an added handicap to attracting an outsider's involvement in local area start-ups.

The foregoing comments are not meant to imply that it is impossible to successfully launch startups with technology from Los Alamos; but it will be more difficult than in the normal commercial world, and it is harder than it really needs to be. Those seeking to form a new company to commercialize Los Alamos' technology are faced with problems similar to navigating a mine field while trying not to get blown up.

\subsubsection{The Los Alamos Enterprise Creation Model}

Some of the modifications which will need to be considered in attempting to improve the process for successfully developing spin-out companies based on technology from Los Alamos include the following: 
- Develop and install better techniques to identify and document technologies as they are developed, and provide a system to maintain this information in a readily-accessible database which can be shared among those within Los Alamos who have an interest in commercializing technology from Los Alamos. Procedures should also be established to update this information as new technical and evaluation information is created.

- Develop improved intellectual property procedures, including: more rigorous, Laboratory-wide maintenance of laboratory notebooks and other methods used to document discoveries; make decisions on which discoveries to protect based not only on technical considerations, but also based on marketability and the potential for commercialization; continue the development and maintenance of a database of all applications and patents, including summary information on potential applications; and develop and install a copyright generation policy and licensing system.

- Develop and apply a screening process to select those technologies which represent the best opportunities for successful commercialization through the creation of new, small business start-ups.

- Consider the circumstances, approvals, and administrative procedures that are necessary to enable principal investigators (PIs), on their own time, to selectively use laboratory resources to explore the prospects for starting a spin-off business that makes use of technology from Los Alamos.

- Reinstitute some form of entrepreneurial leave or a "new business sabbatical" program to encourage qualified PIs with well-developed, and potentially successful, plans to obtain a leave of absence.

- Speed up and simplify the licensing procedures used when small companies are attempting to obtain some form of exclusive rights to Los Alamos' technology. Establish a mechanism for quickly obtaining the necessary approvals and/or waivers in cases involving a start-up where existing or former Laboratory employees and/or consultants are, or expect to be, principals in the spin-off company.

- Establish Los Alamos' ability to accept and administer minority equity interests in small companies that are using Los Alamos technology, or that have received support from Los Alamos. Develop a stock appreciation rights (SAR) program similar to that used within industry to permit Los Alamos' management and professional employees to share in the returns realized for equity holdings in companies to which they have made a direct contribution.

- Institute an expanded internal communications program to educate Laboratory management and PIs as to the requirements, risks, and opportunities represented by attempting to form a new business venture using technology from Los Alamos. Included in this should be a carefully developed policy statement regarding the Laboratory's goals and intentions with respect to promoting and assisting such small companies. There are at least three programs which are already in place at Los Alamos that would provide a natural setting for disseminating this kind of information. These are the monthly Innovator's Forum, the Software Developer's Group Meetings, and the Technology Transfer Overview Seminars, all of which are offered regularly by the IPO. It will still be necessary to broadly advertise the importance of the material that is to be added to these forums and to demonstrate strong management support for attendance by 
PIs and management alike since participation in these forums has largely been voluntarily in the past. Experience and careful monitoring of attendance will determine whether additional steps need to be taken.

In instituting new practices with respect to small-business commercialization of Los Alamos technology, it should be recognized that spin-out opportunities may originate through a variety of possible sources and means. Some of the anticipated sources which should be taken into account include:

- Initiated by PI or other employee. This assumes that a more effective process has been instituted to reward those involved for their efforts in documenting and protecting intellectual property, and for participating in the development of spinoff opportunities.

- Initiated by Los Alamos' Industrial Partnership Office (IPO), as a direct result of an active program to identify and develop comprehensive commercialization plans for those technologies with high commercial potential. To be successful, this requires that successful programs have been created to identify and classify technologies, and that an educational process has been put in place to encourage those with new business ideas to work with IPO. This will require improving communication and understanding between the divisions, and making it clear (from the director's office on down) that the Laboratory favors and will assist those interested in attempting to form new businesses based on technology developed by Los Alamos.

- Entrepreneurial request initiated by an outside entity (small company or qualified entrepreneur). This could be either a self-initiated inquiry or one in response to a publication or other information that is disseminated on technology developed by Los Alamos. This approach requires the successful development of broader communications with the entrepreneurial and early-stage private equity investment communities, and a demonstration that Los Alamos is a "friendly" source to work with.

- Other. While IPO has initiated numerous programs directed toward assisting and transferring technology to small businesses, and a majority of the licenses granted by Los Alamos have been gone to smaller companies, there are still many additional opportunities for IPO to engage the entrepreneurial, new venture, small business community in an attempt to attract their attention to opportunities available at Los Alamos. However, efforts to be more active in working with smaller, entrepreneurial businesses will only be successful if some of the existing impediments, discussed later in this report, are successfully resolved.

Historically, Los Alamos has not been required to give any significant thought to making a return on their "investment" in technology. Increasingly, such considerations will probably become valid concerns. Earning a greater cash return on technical assets will help to justify the continuation of valuable programs and could support additional work in areas where Los Alamos has a unique contribution to make. Licensing alone will not produce adequate returns; thus, other forms of compensation/participation must be considered.

\subsubsection{Typical Start-up and Early-stage Business Arrangements}

There are a number of sources of capital available to early-stage, technology-based businesses. Each has its own advantages and disadvantages with respect to how they may serve the formation, growth, and development of a small technology-based business. 
- Personal resources: founders, family, friends, relatives. This is the most frequently used source of financing for most start-ups, especially in the earliest stages of their development. Funds are usually limited in amount and are generally only sufficient to get started. Depending on individual circumstances, this may be the easiest money to raise, especially within a short time frame. In some instances, this may be sufficient for a small business, especially those involved in small niche-market applications software, to get to a point where they can "bootstrap" continued growth.

- Angels. These are wealthy individuals who have elected to invest a portion of their capital resources in risky, early-stage business opportunities. Many of these individuals have business management backgrounds and can be very helpful in advising a small company. However, often these people have very finite resources to invest in risky opportunities, and consequently they tend to limit their exposure in any given situation. The result is that sometime they are unable to contribute additional capital at a crucial point even though the company may be on schedule and doing very well. This source may prove to be the best alternative for use in funding Los Alamos spin-outs in view of the current absence of any organized local venture capital sources in New Mexico.

- Venture capital funds. Organized venture investment firms follow a variety of investment strategies. Some focus on pre-seed (investments made in some form to help in the actual formation of a company) and seed investments, including those firms that will help to incubate a new company by working along with, or actually being a founder of, a company. Often firms that invest at the seed stage will be the only outside investor at that point. Others investors focus on later rounds of investment. Those who are willing to invest in the next round (after the company is up and running, with a management team in place and a product under development) are generally considered to qualify as earlystage investors. Other firms, often larger in terms of the amount of money under management, focus on still later rounds. The number of firms willing to do early-stage, technology-based investing has declined significantly over the last decade as venture investment capital has tended to become more concentrated in fewer large firms, and as some senior venture capitalists have left the business.

- Corporate partners. Finding a corporation willing to enter a partnership with a new, technology-based business is often a good source of capital. This can also be a strategic partnership that provides sales and distribution channels and support, and/or manufacturing and other facilities that a small company cannot afford to build on its own. Additionally, some corporations have investment groups that function much like independent venture capital firms.

- Grants and other contractual arrangements. Small Business Innovation Research (SBIRs) Program grants, etc. can also be a source of initial capital.

- Use of non-capital sources. Other sources of funding can be developed by obtaining extended credit from suppliers and by receiving advanced payment or progress payments from customers.

- Capital equipment leasing. A select group of specialty firms focus on leasing capital equipment to venture-capital backed companies. This has come to be referred to as "venture leasing." 
Typical arrangements made with outside investors are generally based on the company's stage of development; its perceived potential for success; the qualifications of the management team; the size and attractiveness of the potential business opportunity represented; and the objectives, motivations, and negotiating skills of the parties involved.

- Most early stage investments are made in return for equity participation in the company. Form of equity given to private investors are generally: convertible preferred stock with predetermined conversion rates and conditions, preference on liquidation, board positions, the right to control certain decisions, and information rights, among other considerations.

- The valuation of the company determines that portion of the equity going to early stage investors vs. the portion remaining in management's hands. Sometimes an "incentive" arrangement is made whereby management can maintain a greater share of the company on the condition that certain predetermined performance targets and milestones are met.

Generally early-stage investors will seek to obtain a controlling position in the company, especially when they are being asked to back an unproved, or relatively inexperienced, management team. There is also a need in many early-stage companies, especially in the case of those started with an incomplete management team, to consider the amount of additional stock that must be reserved to attract additional management. Early-stage investors must also consider how much total capital will be needed during succeeding rounds of investment, and at what point that capital will have to be raised, in order to anticipate how those future rounds will affect their potential return on investment. In cases of capital-intensive businesses, some early-stage venture investors have found that they did not receive an adequate return on their investment due to the dilution they experienced during later investment rounds.

In the commercial environment, most technology-based start-ups begin with the assignment of any patents related to the basic technology which will be used by the business. Often the original patents are held by one or more of the founders of the company. If, for some reason, the patents are not assignable, then normal practice is for the company to obtain exclusive worldwide rights (including the right for unlimited sub-licensing). The license agreement will also include rights to any enhancements or improvements on the technology. This is not to say that companies are not formed with less than exclusive licenses; however, that is rare and tends to occur in cases where the technology is extremely broad and/or the underlying market and business opportunity is exceptionally attractive.

Compensation arrangements offered to members of the initial management group tend to be within a fairly narrow range from one start-up to another, and generally consist of a reasonable salary (possibly including a modest cash bonus based on the achievement of certain higher-than-planned goals), plus an equity participation. When an experienced CEO is recruited to head a start-up, their annual salary will typically be in the $\$ 100,000$ to $\$ 130,000$ range and include $5 \%$ to $10 \%$ of the equity. If the CEO is also a founder and developer of the underlying technology, the equity share will be adjusted upward according to the number and relative contributions made by other members of the founding group. In total, that portion of equity retained by management after the initial outside investment in a start-up varies widely. Management and other employees can expect to retain anywhere from $25 \%$, up to as much as $70 \%$ (or in some rare cases, more, or even less), depending on conditions affecting each particular situation. 


\subsection{Summary of Technology Commercialization Practices at other DOE Laboratories}

As part of the MVI review process, visits were made to several U.S. national laboratories other than Los Alamos. Those visits were focused on learning what approaches those other laboratories were taking in order to facilitate the commercialization of technologies that were developed at their sites.

\subsection{Practices at the Argonne National Laboratory (ANL)}

A team of MVI and Los Alamos personnel visited the Argonne National Laboratory on January 18, 1994. The purpose of the trip was to review with both DOE and Argonne National Laboratory personnel how they handle technology transfer, intellectual property protection, and their relationship with the Argonne/Chicago Development Corporation (ARCH). The attendees were Steve Girrens (Los Alamos), Merlin Schulze (MVI), and Lyle Welty (MVI). While at Argonne they met with Stan Borys (ANL), Charles Pietri (DOE), Robbie Dalton (DOE), and Bob Fisher (DOE).

\subsubsection{The Argonne Industrial Technology Development Center (ITDC)}

Stan Borys is the head of ANL's Industrial Technology Development Center (ITDC), a position he has held for three years. ITDC employs 16 to 17 full-time staff members; it also has 8 to 10 parttime personnel who generally are retired ANL researchers who do technology evaluations. The part-time personnel must be employed less than 100 days per year (they are typically used about 40 to 50 days during the year). The ITDC staff includes two full-time patent attorneys. They also use outside attorneys for patent prosecution.

Another of the primary responsibilities of the ITDC is negotiating agreements such as CRADAs. They sign about one such agreement per week (this includes their superconductivity agreements). To-date, they have about 54 pilot center agreements and in excess of 30 CRADAs.

\subsubsection{The Argonne/Chicago Development Corporation (ARCH)}

Originally, the University of Chicago (the operator of ANL) tried using UPI (University Patents, Inc.) to provide technology commercialization. This approach proved unsatisfactory, so ANL formed their own seeding organization to fund technology commercialization. Forming an effective organization, the Argonne/Chicago Development Corporation (ARCH), took two years. ARCH was formed in 1986 and actually began operations in January, 1987 as a not-for-profit subsidiary of the University of Chicago. The initial agreement was that if the university elected to commercialize an item of intellectual property, it was assigned to ARCH for commercialization. They later changed this to a dual series process under which ARCH gets the IP rights to some technologies (referred to as series 200 projects) and ANL retains IP rights to the remainder of the technologies (referred to as series 100 projects). In all, ANL manages approximately 250 projects with a total budget of approximately $\$ 500$ million. At the initiation of each new project, decisions are made concerning both funding and IP ownership rights as follows:

- Series 100 projects are those which require industry cost sharing (approximately $70 \%$ of the projects are in this series), and,

- Series 200 projects which are fully funded by DOE projects; ARCH gets all IP rights for these projects.

ARCH has had about seven start-ups since 1986. Illinois Scientific was the first; it is now publicly traded. ARCH can also license technologies it owns. 
Within ARCH there is approximately $\$ 9$ million in capital available for supporting start-up projects. The capital comes from a combination of University of Chicago funds, State of Illinois funds, Illinois-based pension funds, and other sources. The University of Chicago and ANL supply approximately $\$ 1.2$ million to $\mathrm{ARCH}$ each year for administration costs.

\subsubsection{ITDC's Priorities for Commercialization}

The five priorities established for ITDC's commercialization activities are:

- Exploit synergy with the research and development (R\&D) activities of ANL,

- Provide transfer of technologies from ANL into commercial situations,

- Generate goodwill for ANL both internally and externally,

- Manage all Conflict of Interest (COI) issues during the commercialization process, and,

- Generate financial revenue from the commercialization activities.

With regard to the latter priority, the current ANL royalty distribution scheme provides the following divisions of royalty income between interested parties:

\begin{tabular}{|c|c|}
\hline Series 100 Projects: & Series 200 Projects: \\
\hline $25 \%$ to Inventor & $25 \%$ to Inventor \\
\hline $75 \%$ to ANL & $75 \%$ to ARCH \\
\hline
\end{tabular}

The Associate Laboratory Directors (there are four of them) decide how to utilize the funds coming into ANL as Series 100 royalties.

\subsubsection{Equity Handling at ANL}

While at ANL, the review team discussed whether or not inventors could ever have equity in the - companies started with ANL technologies in a fashion similar to the way they currently receive a share of all royalties. There was a very strong affirmation that this would never happen at ANL.

\subsection{Practices at the Ames Laboratory}

\subsubsection{Center for Advanced Technology Development}

Ames Laboratory's Center for Advanced Technology Development (CATD) was founded in mid1980 s during a regional recession, with a $\$ 3.5$ million grant from the Department of Commerce (DOC). Its purpose is to help bridge the gap between fundamental research done at Ames Laboratory and other Iowa State facilities and the commercialization of that research. The overall organization is the Institute for Physical Research and Technology (IPRT) of which Ames Laboratory is a part. The director, Richard F. Gaertner, joined in late 1987, and for approximately two years was the sole CATD employee. Growth was slow the first few years; it took two to three years to develop some working prototypes and get them in the pipeline, as well as to establish working relationships and some methodology.

The Center applied for funding from DOC and the State of Iowa; DOC funding has now stopped and CATD is actively seeking other sources funding to continue operations of CATD. The associated Research Park was created in 1987 and acts as an incubator. It is funded by the state and university alumni and is growing rapidly -it is now trying to attract private money. 
Richard Gaertner, the Executive Director, was with GE for eight years first in Schenectady, and later Pittsfield (Noryl Thermoplastics Division; Chemical and Metallurgical Division) where Jack Welch (GE's current chairman and CEO) was the GM. Later he became director of research at Owens-Corning, then headed up their diversification efforts as head of corporate development and planning.

Lisa Kuuttila came from Harris and AMI, and then moved to California where she was a consultant to Stanford University doing licensing (she worked with MIPPS, Sun, etc.). Later she joined a consulting division that had been formed as a part of Regis McKenna to do technology commercialization. She also consults for Iowa State (Wallace Technical Transfer Foundation).

Robert Harris came from Battelle with a background in information sciences. He worked in the international division (Asia/Europe) for ten years. He helped set up an internal organization similar to CATD for internal technical development.

Everyone in CATD has an industrial background, but has learned the university viewpoint towards research and the educational process. CATD is organized into two groups: contract research and technology commercialization.

\subsubsection{Office of Contract Research}

Funding is supplied through a cost share mechanism using state money. It is political and concerned with job creation, which is an important metric.

\subsubsection{Ames Laboratory}

Ames Laboratory is a single purpose laboratory with about $\$ 30$ million in funding. CATD attempts to bring marketing inputs into the development process by bringing in companies early or by hiring consultants to do value-added research. The company has a well-established process for protecting intellectual property rights; it insists on laboratory notebooks (this is a written policy). Ames does its own patent literature research through a library, which handles two to three searches per week. When a technology is selected, the PI signs a contract with the company to produce a deliverable product and there are due-diligence standards that have to be met. There is a proactive search for technologies: a project is proposed and then a market analysis is done by the PI. They also have management control over intellectual property.

\subsubsection{Research Foundation}

The Research Foundation received $\$ 12$ million worth of proposals, it funded $\$ 2$ million of those. They may have up to twenty projects at a time; an informal review process is used to kill projects if it becomes clear that a market does not exist or large technical hurdles are identified. The foundation keeps graduate and post-doctoral students even if their project is canceled.

\subsubsection{Exploratory Research Program}

The Exploratory Research Program was developed for those projects that lack proof of concept. This program provides $\$ 25,000$ to $\$ 50,000$ per project to demonstrate proof of concept. It challenges researchers and has resulted in some of the most successful programs.

Commercialization plans are updated every three months and replicate an industrial team approach. The PI handles technical aspects and CATD provides marketing. All information is on a server shared by the Foundation and CATD.

Active databases and communications are important, since it is easy to miss filing dates for foreign patents. It is a complex problem to control intellectual property, so they see all legal correspondence. The university cannot hold intellectual property and consequently must hire attorneys. 
There are problems in financing small companies, strategic partnering is often the only solution. They are very selective on foreign filings because of the expense.

\subsubsection{Commercialization Plans}

These are updated every three months and replicate an industrial team approach. The PI handles technical aspects. CATD provides marketing research for servers shared by Foundation and CATD.

\subsubsection{Licensing}

With their licensing, they try to limit exclusivity by using fields-of-use restrictions and/or limiting the period of exclusivity in order to satisfy freedom of access requirements. The CorpTech database is used for targeted mailings, it contains 3500 technology-based companies. Iowa companies are given first preference, then regional companies in the midwest and then national. They contract with companies to do testing and hire graduate students.

They worked with 150 companies this past year; all signed confidentiality agreements. They have begun 55 CATD projects over the past six years. Out of this number, 15 licenses have been granted for 20 of the projects. Eight start-ups were formed: one failed and two are barely hanging on.

One license, assigned to Engineering Animation, has been a great success. This company was formed in 1988 in the Research Park and now has 70 employees. It obtained corporate financing to license visualization software and operates as a service center: markets include courtroom use to recreate accidents. A second license was obtained for modeling the human skeleton, for this they received Advanced Technology Program (ATP) money from the Department of Commerce. The technology is being used by customers like Johns Hopkins and the Mayo Clinic.

Iowa State University's policy had been lenient on conflict-of-interest issues-only two faculty members and two graduate students made up the review board. Concerns about the lenient policy were raised by a colleague; subsequently, an audit was done by the University and the policy was changed. An oversight committee is appointed to deal with conflict-of-interest cases. They have requested only one waiver from $\mathrm{DOE}$.

The oversight committee is a recent development allowing an individual to devote up to $65 \%$ of his or her time to outside interests while still maintaining benefits at the laboratory. Most scientists keep up some involvement both for security and as a fallback (continue some research, "what you can negotiate"). Employees can consult with a start-up one day per week.

\subsubsection{CATD's Entrepreneur's Forum}

CATD's Entrepreneur's Forum is held every month with a speaker on various issues associated with start-ups. This provides a forum for both successful and future entrepreneurs to interact. One of the lectures featured the Vice-Provost speaking about conflict-of-interest.

\subsubsection{Prospective Spin-Offs}

Several venture capital groups have visited CATD, including Ampersand, AMT, and two Minneapolis-based groups. None have made an investment. Edge Technologies was one of the more visible spin-outs; it has not been very successful. Problems were largely the result of unqualified management and a board that was unable to correct the problem. It was undercapitalized and also had CEO problems. Investors included a beer distributor and trucking company, which were mismatched for a technology company. A Des Moines insurance company and the university were involved, and the situation became a political problem. CATD has relicensed the 
technology for magnetic materials manufacturing, which has helped to take the technology into the marketplace.

Full Spectrum produces medical optical fiber made of a new glass composition for laser surgery. It obtained commitments for a $\$ 500,000$ investment and obtained free assistance from consultants and sources of materials. They are trying to organize a management team and begin production runs. A surgeon funded the work and was the founder, state money was also added. Full Spectrum is now recruiting a CEO. They have a good working relationship with the director of Ames Laboratory, as well as close support there. Additionally, $40 \%$ of their funding actually goes back to Ames.

One of the new business opportunities is a process to manufacture heat sinks that are injection molded with powdered metals. This process allows for extremely complex shapes because it is very flexible at an inexpensive cost. They are now working with two large electronics manufacturers.

Another small company offers photo-acoustic detection products. The company was founded in 1988 and is a "lifestyle" business, i.e., the owners are not interested in maximizing growth), the business has sales of $\$ 1$ million a year.

\subsection{Practices at the Oak Ridge National Laboratory (ORNL)}

The Oak Ridge National Laboratory (ORNL) is operated by Martin Marietta Energy Systems (MMES). Technology transfer policies implemented at ORNL reflect the influence of both MMES and DOE policy and management style. There are essentially three DOE complexes at Oak Ridge designated as ORNL, Y-12, and K-25. Y-12 is as a high-technology job shop with small-volume, complex, high-quality component manufacturing capability. $\mathrm{K}-25$ is primarily an environmental plant. It houses the Center for Environmental Technology and Waste Management. They are trying to develop a basic testing capability and eventually provide an "Underwriters Laboratorylike" capability.

The Office of Technology Transfer (OTT) located at ORNL is a component of MMES. The OTT provided the following patent, licensing, and CRADA information:

\begin{tabular}{|l|c|c|}
\cline { 2 - 3 } \multicolumn{1}{c|}{} & $\mathbf{8 4 / 9 3}$ & $\mathbf{9 3}$ \\
\hline Invention Disclosures & 1403 & 160 \\
\hline Copyrights & & \\
Granted & 27 & 9 \\
Licensed & 17 & 2 \\
\hline Patents Filed & 267 & 79 \\
\hline ISSE & 114 & 27 \\
\hline Licenses Executed & 90 & 17 \\
\hline Royalties Received & $\$ 2.3 \mathrm{M}$ & $\$ 376 \mathrm{~K}$ \\
\hline Commercial Sales & $\$ 70.9 \mathrm{M}$ & $\$ 20.6 \mathrm{M}$ \\
\hline Government Sales & $\$ 12.8 \mathrm{M}$ & $\$ 1.13 \mathrm{M}$ \\
\hline CRADAs & $116(\sim 163.2 \mathrm{M})$ & $53(\sim \$ 79.7 \mathrm{M})$ \\
\hline
\end{tabular}


The OTT does not attempt to generate spin-offs in the same way that Los Alamos is planning. They have little interest at the moment in transferring technology via new, small business. Instead, they have decided that they will be more productive by trying to license to larger business (i.e., $>\$ 100$ million/year).

"Spin-off" at OTT means carving out a piece of the facility, technology, and people that are either outside, or on the edge, of the fence and leasing this total capability. There are currently four areas that they are considering spinning out, one of which is a Y-12 training division. DOE will retain ownership of this lease for national security reasons.

\subsubsection{Licensing}

They have procedures in place for the Principal Investigators (PIs) who are developing new technologies to formally disclose the invention. However, ORNL has the same problem as Los Alamos in that the PIs are more interested in publishing their material than protecting technology through the disclosure process.

ORNL has a group that meets monthly to review disclosures. This group makes recommendations as to which disclosures are either worth pursuing further, need more work, or are ready for patenting. This could be considered as their first screening process. Those disclosures that are "elected" have patent applications prepared and filed.

Fairness of Opportunity (FOO) has not been much of a problem because they canvas such a wide area. FOO compliance is facilitated by working with non-profit organizations. For exclusive licenses, the OTT often makes a public announcement in order to cover FOO (exclusive licenses do not require DOE approval). The company who was originally interested in obtaining the license can lose the potential license at that time if they are not the high bidder. If the business is going to be located locally, the OTT can waive the exclusive license up-front fee, or use forward averaging or other measures. They can also do similar things with royalty fees. No favoritism is given currently to small businesses; however, there is an OTT manager who is putting together a small business program for approval.

OTT's outreach program will be primarily through advertising to get businesses to come in and talk about their problems. One example was given for Coca-Cola, $\mathrm{Co}$ : they saw the OTT advertisement in Financial World magazine. They called the OTT, and as a result, the OTT sent them a description of 60 technologies in their areas of interest. Coca-Cola selected 15 technologies to explore further. They are going to ORNL the week of April 11th to spend three days reviewing these technologies.

OTT's experience has been that discussions are more open for vertically-oriented alliances than for horizontally-oriented ones. Those companies do not want to release any information that could interfere with their ability to be competitive. Arranging alliances between manufacturers and users works much better because they have common problem(s).

Royalties are paid as follows:

- $25 \%$ to the inventor

- $25 \%$ for technology maturation

- $50 \%$ goes to OTT

The royalties (other than those paid to the PI) belong to Martin Marietta Energy Systems (MMES) to use as part of their OTT contract-this is quite different from the royalty situation at Los Alamos. One of the things that OTT uses the royalties for is advertising in trade journals since they are not allowed to use DOE funding for this purpose. 
It is only recently (within the last year) that they have started paying close attention to licenses. Before that, they would issue the license and pretty much forget about it. They were somewhat surprised to learn that they had issued the most licenses to California companies (28), followed by Eastern Tennessee (21), and then Texas, and then the Boston area. OTT does not try to restrict the licenses to their own geographic area. They view this as being counterproductive to their overall technology transfer mission.

An example was given of ABXIS Co., whose three founders were interested in the medical area. They came into ORNL and looked at several technologies in that area and found some relating to blood testing. ABXIS does blood diagnosis, from a single drop of blood, using technology licensed from ORNL. Currently this company has raised in excess of $\$ 70$ million in initial public offering funding.

OTT has helped to relocate small businesses to the area in order to assist them in utilizing Oak Ridge's technology (four companies within the last three months). One of their reasons for this is to add to the local infrastructure by attracting more small businesses.

\subsubsection{Tennessee Center for Research and Development (TCRD)}

The Tennessee Center for Research and Development (TCRD) is a 501.C3 non-profit organization originally started as a biomedical technology consortia. It has evolved to that point now that it has several centers: Power Applications (in support of EPRI, the Electrical Power Research Institute), Technology Application, and a Commercialization Center/Beta (the Beta Center is for-profit). TCRD was founded by the Tennessee Valley Authority (TVA), the University of Tennessee, and Martin Marietta Energy Systems (MMES). It has three levels of membership: \$100K, \$25K, and $\$ 5 \mathrm{~K}$. Funding for it is approximately $\$ 11$ - to $\$ 15$-million per year. The Beta Center has $\$ 2$ million in seed capital which the state matches 3:1 (Joe Brandon is in charge of funding for the state).

MMES has learned how to exploit strategic partnerships, e.g., with not-for-profit partners to reduce DOE overhead taxes. By flowing requests to do Work-For-Others through the TCRD, MMES has been successful in getting the DOE overhead and depreciation taxes waived.

\subsubsection{Tennessee Resource Valley (TRV)}

The TRV was established as a marketing center and is primarily supported by the area's Chamber of Commerce. Eastern Tennessee is the state's high technology center: $70 \%$ of the technology, and $60 \%$ of the manufacturing capability, are located in this part of Tennessee. $24 \%$ of the Knoxville/Oak Ridge economy comes from state and federal dollars.

TRV's secondary mission is the "Technology 2020" effort. Its purpose is to help technologybased start-ups. This effort began with a $\$ 1.5$ million grant from DOE and MMES. OTT will be co-located with Technology 2020 in the near future (it will produce tools). Technology 2020 does have Internet access.

Saturn's automobile plant is an example of a local forward-thinking company. Saturn requires that any vendor must be able to talk with them electronically (even tertiary suppliers) because they do not want to have more than one day's worth of inventory on-hand. Consequently, Saturn's telecommunications requirements have helped to push Eastern Tennessee into fiber optics.

OTT stated that the most important thing for Los Alamos to understand was the strategic importance of partnerships and alliances. George Kozmetsky of Austin's IC2 group was helping them put together a Tennessee Capital Network similar to the one he started in Texas. This network would be made up of "angels," seed money, banks, and venture firms. 


\subsubsection{Principal Investigator}

MMES does not have the two-year PI problem that Los Alamos has. ORNL will allow a PI to take a two-year sabbatical with full benefits paid by ORNL. At the end of two years, if the PI does not return to ORNL, that person is terminated. If they do return, they are guaranteed a job. Additionally, the PI has the right-of-first refusal of excess (surplus) property at reduced rates. While they are out on sabbatical, their service years continue to accumulate.

\subsubsection{Tennessee Innovation Center (TIC)}

The TIC is run by Tom Valunus (615-482-2440, or contact their attorney, Mel Koon). This center is a for-profit entity that OTT intends to change into a non-profit center within the next 60 days. They would like to be more similar to Technology Ventures Corporation (TVC) (their sister facility at Sandia National Laboratories). TIC makes seed investments (their total funding is \$2- to \$3million per year); if the technology they are investing in is DOE technology-based, they cap their earnings at $8 \%$ plus the cost of money. They would like for TIC to emulate the best parts from TVC and Kozmetsky's IC2 group in Austin. They would also like to focus on international markets in order to get royalties from off-shore sources.

\subsubsection{Conclusion}

It appears that it would be very difficult for Los Alamos to attempt to emulate the MMES technology transfer process. Some of the reasons are:

- $\quad$ MMES is not interested in starting new, small businesses.

- Because of the proximity of large businesses, the geographic area has much more infrastructure in place than exists at Los Alamos.

- It would almost be impossible for Los Alamos to attract medium size companies into the local area because the land is just not available.

\subsection{Sandia National Laboratory}

Sandia has few known instances of technology being spun-off through start-ups. Part of the problem is that no one has kept track; consequently, there is no active historical record. In the instances when some anecdotal information exists, there was no interest generated unless the company came back to Sandia for help. Another factor was the extremely conservative posture of the prior M\&O contractor, AT\&T. Historically, the laboratory and AT\&T focused on classified programs, with little attention to commercial opportunities. Martin Marietta has a different approach - they are more interested in technology transfer. Spin-outs and TVC were a key part of the Martin Marietta proposal. ${ }^{3}$.

Sandia's technology commercialization strategy has mainly focused on cooperative research agreements (CRADAs), although recently more emphasis has been placed on intellectual property. People who have recently joined the technology transfer department are surprised by how few patents the laboratory has been granted. ${ }^{4}$ On unclassified subjects, the tendency has been to publish externally rather than to protect IP; there has been no incentive or encouragement otherwise. As a result, very significant technologies, such as strain-layer super lattices, were placed in the public domain (apparently this one was presented as an application, but DOE had run out of funds for patents that year), and the Japanese were more aggressive and successful in exploiting it than

3 TVC is seen as a means to pull together all of the resources needed to make a business, and to help a company to obtain financing.

4 Documentation of their potential intellectual property is good. Laboratory notebooks are widely and consistently used (a probable influence from AT\&T). 
U.S. firms. This technology is now the basis for advanced lasers and high-capacity field emission transmitters.

Many variables affect technology transfer at each individual laboratory. These include the attitude and support of the laboratory director and management, as well as that of the M\&O contractor; and the attitude and emphasis of the DOE field office and the way their general counsel interprets the regulations and policies of the local Inspector General's (IG) office. Sandia's director gives total support and is active in the technology transfer process. The laboratory is still undergoing a significant intellectual change.

Sandia does not currently have an entrepreneurial leave policy, but they are working on one. They have a leave of absence, but plan to tailor something more to the needs of a spin-out opportunity. They are thinking about a 1- to 2-year leave with guarantee of a job upon return, with benefits and credit to retirement time continuing while on leave. The strategy would be to openly offer the opportunity and to promote it throughout the laboratory. The laboratory director is personally behind this. ${ }^{5}$ Sandia is also thinking about taking equity positions in spin-outs, but they are not as far along in developing a policy as Los Alamos is.

On Fairness of Opportunity, they plan to follow much the same drill as the other laboratories, e.g. Commerce Business Daily (CBD), various conferences; check back over visitors who expressed an interest; occasionally conduct workshops for industry. However, if a company comes to them with an idea for the use of a technology, they do not need to advertise that enhancement or improvement.

Sandia has the same problem as Los Alamos with the 2-year rule on granting exclusive licenses to former laboratory employees and consultants. However, they have applied for waivers and have received them.

Sandia has a "technology transfer leave of absence" policy to permit people to leave the laboratory and work with a licensee, with the understanding that they can come back within a negotiated period if they wish to return to the research environment. They are also trying to develop some sort of "halfway house" program (they agree that a better name is needed). Their thinking is to help prospective entrepreneurs to develop their plans and mature technology before they leave the laboratory-and to give them some exposure to the realities of the commercial world before they - leave. This is separate from what TVC may do to help Sandia's researchers.

They do not have a user facility arrangement, although Los Alamos is helping to develop one. Sandia also has a joint-venture cost sharing agreement which works within the normal procurement process. They use DOE program funding, advertise for and select a prospective partner, but it sounds like it is focused more towards larger companies.

More attention is being devoted to intellectual property development and resources have been added to that group. They have hired two more patent attorneys, but more importantly, Sandia has created 6 full-time "patent agents." These are senior, highly respected scientific personnel recruited out of different areas in the laboratory that are going through an intensive training program. They are expected to take the same exams as patent attorneys, and although they are not allowed to handle litigation, they will be able to write patents. One sign that this will work is that these people are already being called on for help in disclosures and developing possible patentability for given technologies. Proposed patent applications go through a screening process based on a scoring system which includes market analysis data.

5 DOE/ALO (the Albuquerque Liaison Office) has added the metric of small business spin-outs to laboratory performance. 


\subsection{Summary of Technology Commercialization Practices at Other Laboratories}

None of the organizations interviewed appears to have developed a solution to the commercialization problem that is well-suited to the needs of Los Alamos. Later sections of this report will discuss in detail the unique opportunities and impediments to commercialization that characterize Los Alamos and a statement of those issues is postponed. However, the following brief list of examples are provided to support the conclusion stated above.

- None of the organizations interviewed have solved the COI problem as it manifests itself at Los Alamos, especially when the PI tries to obtain an exclusive license to his own technology,

- A solution for Los Alamos' lack of an entrepreneurial support and technology maturation capability was not found,

- The intellectual property management issues which are raised in Section 5 remain to be solved. No direct remedy was discovered that results in the identification, classification, and evaluation of commercial potential of Los Alamos technologies.

Other laboratories are faced with similar problems, and in some cases have found ways to deal with their impediments to commercialization. As a specific example, CATD is closest to having an answer, but there are some conditions that are unique to their situation which do not apply to Los Alamos. For example, CATD has a well-established process for protecting IP rights. When a technology is selected for commercialization, the PI signs a contract with the company to produce a deliverable product. This process includes a mandatory due-diligence component with standards that must be met. Commercialization plans are maintained on-line and are updated every three months. CATD has a marketing group dedicated to this process.

Each of the DOE complexes are unique due to factors such as the makeup of their field offices, amount of oversight from $\mathrm{DOE} / \mathrm{HQ}$, interpretation of policies and directives, contents of their prime contracts, whether they have a university or industrial M\&O contractor, management support and enthusiasm for technology commercialization, culture and historical patterns, laboratory mission and the resulting technology content, among others. Any solutions to the commercialization problem/opportunity are inherently intertwined among these differences to the extent that they are almost automatically rendered useless outside the environment in which they were created.

However, the solutions found elsewhere and documented above should not be discounted or ignored. Individual components of the solutions found at other DOE sites may serve as models or as precedents for similar procedures that could be implemented at Los Alamos National Laboratory. 


\subsection{Current and Historical Commercialization Practices at Los Alamos}

\subsection{The New DOE Technology Transfer Initiative}

The strong emphasis currently taking place within all of the U.S. national laboratories to provide broadened support for commercialization of technologies created within those laboratories is a fairly recent happening. Just last year a major DOE report 6 stated that, "Our goal must be to get the maximum value for the American public out of the budget made available to the Department. This means that every dollar spent toward meeting the Department's missions-whether for basic research, nuclear weapons stewardship, environmental cleanup, or energy production and conservation-must be examined for its potential to be leveraged toward a mutual benefit with industry, academia, or other agencies." Toward that end, DOE has established five "critical strategies," which are:

- The Department must change its culture.

- We must optimize our technology transfer partnership processes.

- We must make it easier for industry to access Departmental technology, resources, and facilities.

- We must ensure that our technology transfer process and technology development programs are guided by market-pull.

- We must develop, with industry and others, integrated program plans.

\subsection{The Los Alamos Industrial Partnership Office (IPO)}

Responding to the DOE emphasis on industrial cooperation and technology transfer cited above, Los Alamos created the Industrial Applications Office in October 1989 and later created a centralized Industrial Partnership Center in 1993 as a means of making Los Alamos a "Recognized leader and partner with industry in developing and transferring science and technology to enhance economic performance and to serve the public needs."7 Later redesignated as the Industrial Partnership Office (IPO), this Los Alamos office handles much of their intellectual property issues as well as relationships with individuals and companies interested in Los Alamos technologies, personnel, or facilities.

The IPO has initiated a variety of programs intended to increase cooperation between Los Alamos and commercial industries, including the Small Business Initiative (August, 1993); Access New Mexico (a telephone-based "single point of contact for technical assistance" in cooperation with the state of New Mexico and Sandia National Laboratories); and programs supporting DOE's Technology Transfer Initiative and DOC's Advanced Technology Program (ATP). The IPO also publishes The Bridge, a periodical report on interactions between Los Alamos and industries.

\subsection{Examples of Small-Business Commercialization of Los Alamos Technologies}

Even before the IPO was established, Los Alamos technologies were involved in several commercialization activities, albeit with varying levels of success. More than 28 new companies have "gained impetus" from Los Alamos technologies. As background material, the following subsections discuss a sampling of those efforts to commercialize Los Alamos technologies.

6 Partnerships for Global Competitiveness: A Draft Strategic Plan, U.S. Department of Energy, July 29, 1993.

7 "Industrial Partnerships-The Future," Kay V. Adams, Los Alamos National Laboratory, August 9, 1993. 


\subsubsection{Cell Robotics, Inc. (CRI)}

To get started, Ron Lohrding worked through the legal staff to create a "Chinese wall"8 and take an eight month leave of absence. In October 1988, Lohrding took a two year entrepreneurial leave, incorporated the company, and began raising money. The other founder and inventor stayed with Los Alamos and worked part-time for Cell Robotics. This later became the subject of an Inspector General (IG) audit which was critical of how the situation was handled-claiming there was a conflict of interest.

Several well-known venture capital firms looked at Cell Robotics including Oak, Kleiner-Perkins, and Asset Management. When Kleiner-Perkins turned them down everyone else backed away. This is an ever-present problem in dealing with venture capital sources. Later, the Ross Perot Group spent six months on due diligence and negotiations. Cell Robotics thought they had a deal, but it fell through (Perot was distracted by other activities). During this time, Lohrding was funding the company out of his own pocket and with bank loans.

In late 1990, Cell Robotics was introduced to Mitsui (Japan) which was looking for deals and technology in the U.S. First funding was received in August 1991, although some advances were made early in 1991. In total, Mitsui put in $\$ 4.5$ million, both in equity and with a loan. Lohrding left Los Alamos and took early retirement. The company was moved to Albuquerque from Los Alamos. Currently Mitsui owns 49\% of Cell Robotics and has invested an additional \$2 million. The current burn rate is $\$ 100,000$ per month and the company would like to find U.S. partners with some expansion capital. At the end of the fiscal year (October 1993) the company had 14 employees including three salespeople and a half-time marketing person. They are mainly selling through distributors.

In Europe, the University of Heidelberg Group has given them a great deal of help and interest in Japan is picking up as well. They expect to do roughly \$2 million this year and \$6 million next year. Cell Robotics has negotiated a small business CRADA with Los Alamos, this took three to four months to complete and it is just starting to work. Their part of the deal is to provide personnel and materials. They have done a great deal of additional work since leaving Los Alamos and are adding more imaging technology. They had 130 inquiries in September and 430 in October and were mystified by the sudden increase. After lengthy discussions, the other founder recently agreed to leave the company due to disagreements over the allocation of resources to marketing versus further research and development.

Comments: The IG investigation concerned both real and apparent conflict of interest. The report was highly critical of the financial interest and potential for gain which the principals had in the company, but disregarded the significant investment that Lohrding had made, and the substantial risk that the principals were taking. The audit report was also critical of the fact that CRI used laboratory equipment to continue development and to make customer demonstrations. Due to current restrictions, possibly imposed as a response of the IG audit results, Cell Robotics could probably not be started in today's environment.

CRI pays royalties to Los Alamos, and has negotiated a small business CRADA. Los Alamos has no other interest in the company (other than the CRADA), and the investment position held by Mitsui could result in the company being controlled by a non-U.S. organization.

\subsubsection{Essential Communications}

Michael McGowan is the Founder, Chairman, and Chief Technical Officer of Essential Communications. He was employed at Los Alamos, but left in 1990 to serve as a consultant to Network

8 "Chinese wall" is an investment banking term that means to purposefully erect a communications barrier between two interacting organizations. 
System Corporation. Essential Communications now has three employees and five consultants and within nine to twelve months expects to add twenty people. An Albuquerque-based Value Added Reseller (VAR) agreed to provide administrative support, space, and some light manufacturing in return for equity. McGowan brought in Bill Boas, who had extensive experience in sales and marketing of high capacity networking systems, as President. They are using a San Josebased software house because the necessary skills were not available in Albuquerque. They need people with communications software experience that have produced products. Essential Communications has six products and is developing a workstation adapter for a seventh. For this product, all of the hardware is done and they are now working on software.

Network Systems Corporation has proposed an investment. Essential Communications is developing all of NSC's high-end market products and is helping to sell them. Eighty percent of switch revenue is now via NSC. McGowan values the business at $\$ 9$ million; NSC has offered $\$ 2.5$ million for $40 \%$ - a valuation of $\$ 6.25$ million after the money.

Mr. McGowan left Los Alamos in 1990 because "he was tired of the lip service to technology commercialization." He did not feel that there was real commitment at Los Alamos and wanted to "make it happen." A major frustration for a PI at Los Alamos who is trying to obtain licenses from Los Alamos is that the policies and procedures for doing so are either not clearly defined and articulated, or else the inertia imbedded in the procedures makes them seem cumbersome and illdefined. This probably results from the need to obtain DOE approval prior to the issuance of an exclusive license for any technology, especially to a current or former (within the past two years) employee.

When he left Los Alamos, he obtained a one-year contract to design a frame buffer for NSC and he tried a one-year entrepreneurial leave. The income cushion from the NSC contract enabled him to start the company. Patents are not an issue-Essential Communications has not used any Los Alamos proprietary technology-HIPPI (High-speed Interactive Parallel Processing Interconnection) is an open standard. Essential Communication's strategy emphasizes design simplicity, doing things simpler and cheaper, thereby gaining a competitive advantage. He was surprised by their success with the federal government on a National Aeronautics and Space Agency (NASA) bid which has led to the potential for a high capacity, high-end PC and workstation system. The proposed standard will strengthen his plan.

He discussed his plans with venture capital firms, including Sevin Rosen and John Jaggers (from Sevin Rosen). The firms felt there were too many unanswered questions and turned down the written business plan. He looked at a New Mexico Research and Development Institute (NMRDI) grant, but decided not to work with the people at NMRDI.

Comments: Mr. McGowan left Los Alamos out of frustration over attempting to see the technology he helped to create successfully commercialized. Since the HIPPI technology was established as an industry standard, and since McGowan did not receive any intellectual property from Los Alamos, the return to the Laboratory will be zero. In addition, Los Alamos has continued to work on developing HIPPI products, using taxpayer money, which compete with Essential Communication's products. This technology is being licensed to Essential Communication's competitors.

There is probably a better way for Los Alamos to deal with similar situations, e.g., some limited assistance and support could be provided to entrepreneurial Los Alamos employees in return for an equity share in the companies they form, and some policy provisions could be implemented to limit situations where Los Alamos is in competition with a company founded with its technology and in which it may hold an interest. 


\subsubsection{Paradigm Concepts}

John Deal, President, was a Los Alamos contract employee. The business has modest revenue and is still operating at a loss. It is having great difficulty finding financing. It took twenty-seven months to obtain a restricted license from Los Alamos for selected software (exclusive, but limited field of use to Apple environment). Another company has license for PC (not selling or developing a product as far as he knows). Apple only equals 14 to $15 \%$ of the market potential.

The Industrial Partnerships Office (IPO) took six months to review and respond to Paradigm's business plan. He is meeting with Apple management and hopes to get support.

Comments: Too early to tell if he will succeed, there are a lot of impediments:

1. Lack of financing.

2. Market limited to Apple platforms.

3. Management.

The restricted field of use license granted to Paradigm is working against the company and may preclude its successful development.

\subsubsection{Amtech}

Gary Seawright, the founder and initial president, left Los Alamos in 1983 and formed Amtech in late 1984. Two earlier attempts to transfer the technology to other companies had failed, and government funding of the technology was terminated in 1982. UC and DOE waived their rights to two patents, Los Alamos lent the company demonstration equipment that was due to be scrapped, and at that time, they had a very flexible policy that allowed personnel to participate in such a venture. After a nine month search, Amtech received its first funding in November 1984 from a wealthy Dallas businessman, David Cook, who later sold out when Perot invested. The company had also received a limited line of credit from Los Alamos National Bank.

Mr. Seawright took entrepreneurial leave and went to class at UNM to learn how to prepare a business plan. He worked on the Amtech's development part-time while doing some consulting. UNM graduate students helped with the market research, financials, and spreadsheets. Entrepreneurial leave was very helpful, but the other four founders where not willing to leave until the company obtained funding. Rod Sharp did not invest, but was very helpful. Mr. Seawright's division director at Los Alamos was also supportive and lent him equipment for demonstrations. His current impression about Los Alamos is that there are many others with entrepreneurial inclinations, but they are not willing to take the risk just yet.

The importance of looking for the correct market: an example is the electronic identification business where Amtech is now the leader. They tried the cattle industry, but were not successful. They then tried advertising and received numerous inquiries. One was from Kerr McGee for coal miner identification and tracking in southern Illinois. They dusted off their old laboratory equipment and made demonstrations-Kerr McGee wanted to purchase the equipment on the spot. Rail car identification came later and was the first significant application of the technology.

Comments: This is the only known Los Alamos spin-off that has done an initial public offering and is a NASDAQ-listed company. It is the only major success story. It owes its success partly to foreign investment and support (Mitsubishi invested and obtained Asian marketing rights). Amtech had its initial public offering on November 8, 1989, selling 1.6 million shares at $\$ 13$ per share. After the offering, the company had approximately 6.2 million shares outstanding, giving a total market capitalization of over $\$ 80$ million at the time of the offering. 


\subsubsection{Prediction Company}

Doyne Farmer was with Los Alamos for 10 years. He started the Complex Systems Group (T-13) and later became a group leader in T-Division. He enjoyed his tenure at the laboratory until he became group leader, at which point he was constantly involved in a struggle to find money to keep the group going.

He left the laboratory three years ago to form Prediction. He got the idea partly from attending a conference at the Santa Fe Institute where he was exposed to several Wall Street firms. The general business concept is to use advanced neural net-based software to trade various security markets.

He initially tried to take a leave of absence, but he could not work it out with Los Alamos' attorneys. From their direction, he took great care while at the laboratory to avoid doing any work related to planning the business or developing a trading system. He talked with the "technical transfer" (sic) people about obtaining a license to the software, but found the procedures impossible to deal with, "I would have to write it up; put it out for bid; wait three months; then negotiate with the laboratory. I could not wait that long-the procedure was too complex and uncertain."

On further discussion with Los Alamos' lawyers, Farmer discovered that he had inadvertently given away the software by posting it on the public FTP, a network that allows others to access software. As a result, the lawyers said that the software was already in the public domain and therefore no longer needed to be licensed. Subsequently, he walked out with the software and exchanged letters confirming who had been given the software and obtained a confirming letter.

Farmer connected with Norman Packard at the University of Illinois who had been working on advanced trading systems. Packard spent about a year before the company was formed working on a business plan and software. According to Farmer, the University of Illinois is not as "draconian" as Los Alamos about employees working on personal activities. Originally there were seven founders. A portion of the seed financing was received from Jim Pelke, a wealthy Santa Fe entrepreneur. Along with Pelke, Farmer and another founder put up about $\$ 200,000$ to get started. Several people took no salary the first year and others received only partial compensation. Another key person is Jim McGill, a Ph.D. in Physics whom Farmer had known in college and who had helped form Digital Sound; then became the Vice President of Engineering at Telebit. He had developed business skills from these experiences and is the "businessman" on the team.

"In the past it was relatively easy to move money between programs at Los Alamos and some good science was done. It was possible to be 'fast and loose.' Now the situation is much tighter-the laboratory's fear of the Inspector General and the Government Accounting Office borders on paranoia and it is extremely difficult to get anything done." It was this sense of frustration that finally caused Farmer to leave the Los Alamos.

Because of his participation in the Santa Fe Institute conference he had made some good contacts on Wall Street and was able to talk with a dozen firms. He received offers from four or five and played them against each other. He eventually formed a partnership with O'Connor, a major options trading firm in Chicago, who introduced them to Swiss Bancorp (SBC). Prediction Company now has an exclusive relationship with SBC and has been trading for six months with real money. If the company is able to meet certain performance goals, SBC will continue to add to the capital pool for trading. Prediction trades "anything that doesn't eat, run, or grow," and is now mainly focused on futures. Major metric for measuring success is "return to risk" ratio.

They feel they are reasonably protected on their software despite the earlier disclosure. It is not user-friendly, and they have made numerous improvements. 
The employees still own $85 \%$ of the equity in Prediction. They have taken in a few other shareholders and have done a bridge loan. Four to five software people have been hired, including a neural-nets person from Siemens. There are now 13 full time employees and a part-time bookkeeper. He has found it easier to secure the $\$ 1.2$ million which has been required to fund Prediction in each of the past two years than to find money for T-13. SBC funded much of the R\&D on the software.

They plan to retain their exclusive relationship with SBC. This is reinforced by the fact that O'Connor, with some 22 partners, is being acquired by SBC.

Farmer's general thoughts on the laboratory are that there are some good people-he turned away post-doctoral students from MIT, Harvard, and Cal Tech. The management, however, is out of touch and has become highly politicized and bureaucratic.

\subsubsection{Mesa Diagnostics/Los Alamos Diagnostics}

The following section outlines one perspective of the Mesa Diagnostic spin-out experience. It is included to illustrate some of the difficulties individuals have experienced in the past in attempting to commercialize a Los Alamos technology.

Background: Mesa was the first attempted spin-out under the revised Stevenson-Wydler Act. After several months of negotiation, about a dozen contracts were signed simultaneously in December of 1984 to put the Mesa Diagnostics deal together. The applicable contracts were: PruTech contracted with Mesa to develop a virus identification instrument; Mesa in turn contracted with the DOE to perform the development as a work-for-others assignment; and DOE in turn instructed Los Alamos to perform the work (within the Life Sciences Division). The progress milestones were the same in all these contracts.

The original goal was an instrument that would be placed in doctor's offices for samples of sputum or other body fluids to receive simple processing and then be placed in a flow cytometer. Each bacterium or virus would be quickly identified, allowing rapid in-office disease diagnosis.

It was believed that Los Alamos had a functional static machine (the one used for the originally published research) which was to be used to generate a library of virus signatures. Los Alamos was also to develop the flow cytometer instrument and provide it to Mesa to use as a prototype for the mass-produced machines.

PruTech employed SRI International to monitor Mesa's performance on the contract. Audits were held approximately every 3 months. All of the audits (beginning March 1985) reported missed milestones. PruTech's funding of Mesa had two components—one paid for the instrument development and the other paid for developing manufacturing capability, the marketing effort, and general and administrative (G\&A) expenses. The research and development portion was being consumed with little progress, thereby ruining the original strategy.

Mesa management was held accountable and had numerous meetings with Los Alamos people on ways to rescue the schedule. These meetings culminated in formal meetings with the Principal Investigators, Group, Division, and Laboratory management during August and September of 1985. Mesa's top managers were replaced in September 1985 for failure to meet PruTech's requirements for the contracted work. PruTech brought in a new president who worked until early 1986 when he recommended that Mesa staff-up to perform the R\&D and terminate the DOE contract, which was done on February 19,1986 . The company eventually closed down operations and the technology became the property of PruTech. 


\section{Comments:}

1. The prime motivation for Los Alamos and the PIs in doing a technology transfer was as a source of capital equipment funds for the procurement of a licensable virology laboratory and to pay for expensive apparatus.

2. The technology was oversold. Some of the original precepts (virus identification in a flow cytometer) were challenged by an outsider and this caused a major redefinition in the project (static identification from cultures).

3. PruTech was enamored with "Los Alamos," and because they were the first to get a foot in the door, their due diligence either was inadequate or very few people understood the technology.

4. The original experimental work that was published was wrong. This work reputed to show that there were optical differences between various viruses, when in fact what was observed was the optical signature of the medium in which the viruses were grown.

5. The first milestone was the installation and checkout of the modular virus-certified laboratory, and it was delayed four to five months. This work was to be done by Los Alamos' support services contractor. This was delayed in favor of higher priority work elsewhere within Los Alamos.

6. The existing static machine, upon which the published data was obtained and was to be used for generating a library of virus signatures, was faulty. It had noise and stability problems with lock-in amplifiers that were designed and fabricated by another Los Alamos division. That division did not take ownership of the problem. This problem had a low priority within the division-they would send a different person each time to tweak the amplifiers. Several months later, Mesa finally created usable lock-in amplifiers on its own.

7. The PI and other senior staff were distracted from Mesa's problems as they spent a considerable amount of time, as would be expected, preparing papers, going to meetings, and preparing proposals for other funding.

8. Los Alamos staff could not be counted on being there at crisis times, due to vacations, meetings, Los Alamos obligations, etc. Los Alamos employees annually receive 24 days of vacation, 18 days of sick leave (the average taken is reportedly nine days), and 12 paid holidays. In addition, internal and external conferences, seminars, and meetings can consume another 5 to 15 days.

9. While the project was underway, contamination of expensive and hard to get viral cultures occurred. Mesa had to build its own virus laboratory and duplicate the virus library as Los Alamos would not relinquish that portion of the work.

10. Mesa began hiring its own staff and placing them in the virus laboratory to work with the Los Alamos staff. They complained of a poor work ethic at Los Alamos. Contract cancellation was assured when statistics were taken of the status of weekly milestones and the Los Alamos ones were mostly performed by Mesa staff.

11. Mesa paid $\$ 1.8$ million (approximately) to DOE at contract signing. The contract (and the law) required that Mesa be billed monthly. The amount of the bill was to assure that DOE did no private work with public funds by requiring that DOE have in its possession enough money to cover close-out costs at any time. These costs were 
defined as money to cover procurement obligations plus the salaries of the staff for onequarter while they were reassigned. Mesa received no bills and paid no money to DOE until after contract termination and negotiations. Mesa kept a shadow set of books based upon information provided by Los Alamos's Life Sciences (LS) Division.

12. The LS Division believed that this work was a best-efforts attempt and had lower priority than programmatic work. At contract termination, the division demanded the remainder of the contract money, claiming that it was a "grant." On more than one occasion, Los Alamos people stated that the contract milestones were guidance only and that Los Alamos was not obligated to adhere to them.

13. There were about six people in the world who understood the technology (the Los Alamos PI was one of them). Another of the six was a professor at UNM in Albuquerque. Mesa hired him, first as a consultant, then in a permanent position as the chief scientist. He was very effective, and his availability eliminated the need for an association with Los Alamos.

14. Some professional jealousy was exhibited. Co-workers would no longer interact and contribute ideas. Statements were made like "he will use my ideas and make money on them." This tactic is used even more strongly against people who are trying to start up a company based on Los Alamos' technology. Los Alamos' deputy director made the statement that he "did not feel that a person had the right to profit from tax-payer funded efforts" to a group in a middle-management training class in the mid-1980s.

15. After the cancellation, a serving Los Alamos Board member was accused of using Los Alamos time or materials while on the BOD of Mesa. No one from Los Alamos talked to the Board member about what went wrong so that corrections could be instituted. There was no ownership to the problem or process, instead there was denial and avoidance.

16. There were investigations by both the Inspector General (IG) and the Government Accounting Office (GAO). It was learned that $\$ 1$ million of ISRD funds had been diverted to cover the Mesa project overruns caused by the negotiated settlement of the close-out costs.

17. Mesa learned that other companies were solicited for additional applications of the technology that was being developed under the Mesa contract.

\subsubsection{Other Selected Commercialization Interviews}

Jan Hearer: She is an ex-IPO member with a biology background. She opted out of IPO to try to be more effective in working with technology transfer opportunities in the biological sciences area. She has helped to form two new corporations.

1. Molecular Technologies, Inc. (Albuquerque): She has licensed broad core technology to various bio-technology corporations. First application area is single cell detection-one use is mapping of the human genome. This accomplishes in minutes what had previously taken days. It is based on easily understood principles.

2. Optical Biopsies, Inc. (located in Florida): Uses a laser identification system to detect cancerous cells . Can be used anywhere a light can be shined.

"Hard Core Group" meets for one hour every other week to discuss marketing and development of their technologies. There are lots of opportunities with great potential. 
Wanetta Tuttle, Southwest Medical Ventures: She is the former coordinator of the Lovelace Foundation. Her partner is Art Schulze (in Houston), he has a biomedical background. They have incubated four start-ups:

1. Indigo Medical: started with a $\$ 3$ million investment from J\&J Development. Business product concept came out of technology developed at Los Alamos and at Phillips Labs. Concept and ideas developed from work for others. Laser/ BPH treatment-_laser induced hyperthermia."

2. Patient Technology, Inc.: Technologies include preventive diagnostics, treatment for advanced cervical cancer, and wireless patient monitoring, and an eardrum thermometer. Developed from Sandia Labs technology.

3. Molecular Technologies, Inc.: Technologies include the sizing of DNA fragments. Developed from Los Alamos technology. They have a license and have applied for a patent.

4. Health Services (still referred to as Newco): A software database that measures the process of care.

General Comments about Los Alamos Start-ups: Bill Enloe (President, Los Alamos National Bank): His major objective is to avoid giving start-up companies just enough money to hang themselves, i.e., either give them sufficient funding or do not fund them at all. Many companies start with contracts doing the same work for Los Alamos that they did before leaving. Over the years the bank has been involved with 30 to 40 companies, of which 10 to 15 are very marginal. Some examples of the successful companies are listed below:

1. Galaxy Computer (Santa Fe): Security software with the potential for a major Saudi Arabian contract; could be potential winners.

2. Digital Instrument Technologies

3. ICAMP (Los Alamos): Software machine tool control. Started in the late 1980 s; still very small, but making good income for principals.

4. Cell Robotics: see Section 4.3.1.

5. Pulse Systems (White Rock): Small gas laser company run by a husband and wife team.

6. Jomar Systems: Developed and manufactured gamma detection devices. It grew to forty employees and $\$ 4$ to 5 million in sales. It was sold to Canbarra, moved out of New Mexico and absorbed.

Since 1986, there have been fewer and fewer start-up plans submitted to the bank for review. Mr. Enloe once saw one person per month with a start-up plan; now almost nothing. Los Alamos lacks facilities for new small businesses. Major problems are: labor, land, buildings (the entire infrastructure is weak); incubator; lack of active support and participation by the University of California. Los Alamos retirees have been absorbed into other small business or are doing contract work for Los Alamos-there are not many on the loose. Current Los Alamos employees are fearful that if they indicate they might leave, they could become targets and be vulnerable during the next layoff.

\subsection{Summary}

History confirms that mechanisms exist for transferring Los Alamos' technologies into the private sector via new small businesses. At the same time it must be recognized that the rate of technology transfer and the growth rate of those businesses that have been spawned are both far less than one might expect to result from a laboratory of the size and breadth of Los Alamos. This becomes even more noticeable in light of the DOE's mandate to the M\&O contractors to emphasize the transfer of laboratory technologies into the private sector. The ramp-up in new business creation activity which was hoped for has not occurred in spite of the best intentions of the DOE and the best efforts 
of Los Alamos. In fact, just the contrary has occurred-transferring technology out of the laboratory and into small businesses has become substantially more difficult over the past few years, at least in part as a result of the attention that has been focused on this activity. Some of the specific actions taken by Los Alamos in the past during the formation of business described in this section have received criticism from some government officials and have been the target of investigations by the office of the Inspector General.

Finally, the companies which have been successfully created have not succeeded in producing any substantial return on investment for the laboratory, nor have they brought widespread recognition for Los Alamos' role in creating the technology or transferring it into the private sector.

Sections 5 and 6 of this report focus attention on those commercialization policies and practices at Los Alamos which are beneficial to the technology transfer process as well as those which need to be improved in order to bring about a quantum change in the rate of technology transfer into the private sector by Los Alamos. 


\subsection{Issues Associated with Los Alamos Affecting Commercialization}

Technology commercialization can take place through a multitude of circumstances and formal mechanisms. From inside Los Alamos, for example, principal investigators may wish to move their inventions outside and create a new business based on a technology they helped to create. A slightly different scenario would involve an outside entrepreneur who wishes to export a technology from Los Alamos to begin a business based on that technology. Finally, an existing business, small or large, might wish to gain access to a Los Alamos technology as a means of business expansion or to create a new product. A host of other mechanisms allow Los Alamos expertise and technology to be transferred to small and large businesses alike.

At Los Alamos, as is the case for all of the national laboratories, commercialization activities such as these take place within an existing framework of regulations, policies, and procedures. In most cases, the basis for those regulations, etc., lie in one or more documents that relate to Los Alamos as an institution, to the University of California in its role as the operator of Los Alamos, to the DOE, or to the U.S. Government in general. In compliance with the SOW tasks 1, 2, 5, and 9, MVI has reviewed all of the documents relating to current policies, procedures, and regulations affecting technology transfer that have been provided by Los Alamos. That review has identified a number of situations in which the language of these controlling documents (or the current interpretations of that language) appears to have a significant impact on attempts to commercialize technologies developed within Los Alamos as well as on other forms of interaction between Los Alamos, its staff, and external enterprises. ${ }^{9}$ These policy issues, despite the best efforts of the Los Alamos IPO, its staff, and its managers, appear to be impediments to expanding the spin-off of Los Alamos technologies through the creation of small businesses. Examples include policies currently in place (or, in some cases perceived to be in place) which do not promote the "rapid and effective transfer of unclassified research." These identified policies appear to be making it a very slow and difficult process for a small business to obtain Los Alamos technology.

This section discusses the "problem" issues which have been identified by the MVI Review Team. Each issue is accompanied by a description, an assessment of its impact on the process of attempting to spin-off Los Alamos technology to small businesses, and, in most cases, a discussion of available alternatives that have been identified during the assessment. MVI believes that these alternatives should be considered in any attempts to resolve the issue and thereby better facilitate the commercialization of Los Alamos technology through new and small businesses. = Appendix E provides a complete list of the documents which are the basis for most of these issues, along with additional comments on the relationships between those documents and the commercialization issues discussed in the remainder of Section 5.

\subsection{The Existing COI Regulations}

Description of Issue: Legal restrictions are the major difference between the commercialization of technologies from other sources and the commercialization of technologies created at any of the national laboratories. At the center of those restrictions are the issues associated with individual conflicts of interest. Because of the complexity of these restrictions, the problems faced by small businesses interested in Los Alamos technologies are more complex than in most other commercialization situations. In fact, it appears that among the major time-consumers in technology transfer from Los Alamos is the handling of Conflict of Interest (COI) and Fairness of Opportunity (FOO) issues.

9 As discussed elsewhere in this report, in addition to its detailed review of Los Alamos documents, the MVI Review Team has also discussed policies and procedures with both laboratory personnel and outsiders, examined commercial spin-out practices at other institutions, and studied commercialization practices outside of the government, using those efforts to develop an in-depth understanding of the conditions affecting technology commercialization at Los Alamos. 
Relative to conflicts of interest, DOE's Technology Transfer Implementation Handbook (dated December 1993) states that, "all employees of DOE, as well as employees of DOE's management and operating (M\&O) contractors, are subject to conflict-of-interest provisions." Those provisions require that no individual, organization, or institution shall use their position or knowledge gained by virtue of their position for undue gain, financial or otherwise. Apparently DOE has decided to put the emphasis on the "undue gain" section of the above quotation, and the Handbook goes on to state that, "M\&O contractors are expected to develop and implement guidelines that enable a laboratory or facility employee to better determine those circumstances where the benefit to the employee is just and reasonable, as opposed to those circumstances constituting 'undue' gain."

Similarly to COI, Organizational Conflict of Interest (OCI) is defined as a situation in which:

1) A subcontractor's ability to render impartial, technically sound or objective assistance or advice is diminished because of any past, present or currently planned interest; or

2) The subcontractor is given unfair competitive advantage as a consequence of the subcontract. ${ }^{10}$

Prospective Los Alamos subcontractors are required to submit a disclosure statement describing the relevant facts concerning the related work and to identify whether the work to be performed could result in the offeror being given an unfair competitive advantage. If actual or potential $\mathrm{OCI}$ is found to exist, Los Alamos has the following three courses of action under current OCI policies:

1) Disqualifying the offeror,

2) Imposing contractual limitations that would avoid or mitigate OCI, or,

3) Awarding the subcontract if deemed by DOE to be in the best interest of the U.S.

Impact: Unfortunately, when a small company is pursuing Los Alamos technology, they rarely will have the resources to attend meetings or to develop detailed answers to questions about complex issues such as COI. Exploring and responding to these issues does not actually help them to either understand the technology of interest or obtain funding for its commercialization. It is imperative, therefore, that the Los Alamos personnel dealing with representatives of such companies understand that although they are going to get paid when they attend meetings even if the meeting is not productive, the same may not be true for the small business entrepreneur. The small business entrepreneur many times is operating on a very limited, fixed budget (e.g., a second mortgage against his or her home) and simply does not have the time to deal with the Los Alamos/ DOE bureaucracy associated with COI and other such issues. This single fact must be recognized as part of any commercialization strategy, and Los Alamos must always seek to become proactive in helping small businesses overcome such issues as they seek to obtain technology. For Los Alamos, this means, among other things, handling requests for information about candidate technologies as expeditiously as possible, as well as providing advice and support for small businesses as they seek to satisfy COI policies.

This appears to be a serious Catch-22 situation. An inverse to the story of the Little Red Hen, the COI interpretations (as well as the Fairness of Opportunity interpretations discussed in Section 5.3) combine to make the individual who "baked the bread" (e.g., the PI or the entrepreneur) the one least likely to participate in eating it.

10 Organizational Conflicts of Interests, Form 1002, Los Alamos National Laboratory, 4/91. 
Resolution Alternatives: With specific regards to COI, in order for Los Alamos to meet the spirit of the guidelines in the Prime Contract, DOE may find that they have to facilitate a more flexible position for technology transfer to small businesses. This more flexible position could take the form of a change in policies or possibly a demonstration (i.e., an experimental technology-transfer project) that precludes the forming of new businesses from "jumping through COI hoops" and allows the DOE to see if this "flexibility" actually does facilitate the creation of new businesses. This would be equivalent to a "drive it before you buy it" policy.

As a basis for discussions with Los Alamos's Model Commercialization Program personnel about the impact of the COI provisions on potential commercialization of Los Alamos technologies by small businesses, MVI identified, early in this assessment project, some representative scenarios for either an employee of Los Alamos trying to commercialize technology, or an outside new business identifying technology and trying to transfer the technology out of Los Alamos. ${ }^{11}$ As a result of these discussions, personnel from the Los Alamos Industrial Partnership Office generated a Personal Conflict of Interest Plan For The New Business Startups Project, version 1 dated March 7, 1994. This plan took the MVI scenarios, expanded them, and then tied them to the Prime Contract, the applicable statutes, and other policies of the University and DOE relating to the conflictof-interest issue.

Another approach to resolving these issues is for Los Alamos (and DOE in general) to recognize that any attempt to commercialize emerging technology has at its heart the desire for gain. COI requirements do not question the right to such a gain, but rather whether or not a gain is "undue" as a result of a real or perceived conflict of interest. Clarification of the policies relating to COI to recognize that when an entrepreneur, especially a small-business entrepreneur, invests his or her limited resources into an effort to commercialize a new technology, significant risk has been accepted as a means of (hopefully) making significant gain. If that effort proves successful, the question of whether or not a COI or OCI situation resulted in "undue" gain appears to need more specific guidelines. These guidelines should reflect the fact that holding a significant equity interest in a start-up company, especially if that interest is based on a commitment of substantial personal resources, whether in cash or by providing services to the start-up, along with the acceptance of personal risk, does not provide a basis for charging an individual with a personal conflict of interest.

\subsection{Uniformity and Discipline in Intellectual Property Procedures, Including Los Alamos IPO Licensing Guidelines}

Description of the Issue: Intellectual property management is a critical factor in enabling successful technology transfer. ${ }^{12}$ Intellectual property consists of inventions, patent applications, patents, copyrights, mask works, trade secrets, know-how, and trademarks. In order to successfully manage and protect intellectual property at any research institution, a formal system for recording and protecting intellectual property must be instituted. Intellectual property is one of the key "values" of a newly forming business. Without the proper intellectual property foundation, an entrepreneur will have much more difficulty building and capitalizing a successful company. Specifically, potential investors use the value derived from intellectual property as part of the risk/ benefit analysis. The weaker the intellectual property base, the less likely an investor will risk putting capital into the business. In some cases, public-domain technology has given rise to successful business ventures. ${ }^{13}$ However, these were unique circumstances and constitute an exception to the majority of situations. Clearly, it is critical that Los Alamos vigilantly protect and keep proprietary the intellectual property as it is developed and commercialized.

11 Detailed information on these scenarios is provided in Section 6.

12 Center for Applied Development of Environmental Technology, Intellectual Property Management Plan, CADET, January, 1993, Pg. 2.

13 Companies have been started based on public information related to the HIPPI standard. 
Managing intellectual property is critical at research institutions because the natural motivation of the researcher is to publish their work results as quickly as possible, rather than to protect it. In the world of research, publications are a critical mark of professional success. Research professionals are therefore often more motivated to publish papers than to make sure all administrative and legal requirements for protecting their ideas have been met. Essentially the requirements of protecting intellectual property are at odds with the goals and motivations of the research community, even though this same community may recognize, in principle, the importance of protecting their work. For example, if a formalized disclosure process becomes lengthy and complex (something which could potentially delay publications on the subject), a researcher may have little motivation to participate in that process. These conflicting forces must be managed successfully to meet both the objective of protecting new intellectual property as well as publishing research results in a timely manner.

Impact: While Los Alamos does have a system for protecting intellectual property once it is defined as an invention and proceeds through the process of being formally protected through patents or copyrights, the in situ implementation of the policy is apparently difficult to maintain and some technologies may not obtain proper intellectual property protection as a result. It appears, for example, that laboratory notebooks and similar forms of documenting discoveries are not uniformly used throughout Los Alamos. While difficult to document, there also appears to be some suspicion within Los Alamos that valuable discoveries are not being disclosed for protection due to indifference on the part of research staff and the lack of strong and consistent management support for the development of patents. One former Los Alamos researcher noted that his division director's only comment after he received a patent and a Research 100 award was, "When are you going to get back to work on what you're supposed to be doing?"

The emphasis within many of the Los Alamos research groups seems to be on a university-type philosophy which assigns greater importance to publishing, as opposed to protecting, novel intellectual property. This condition is compounded by the problems faced by Los Alamos patent attorneys in trying to involve a large institution populated with very skilled, but often very independent (and occasionally even egocentric) researchers in an effort to prevent the premature and unplanned disclosure of intellectual property that has potential commercial value. Some of these researchers even appear to harbor negative feelings toward the patent process itself, preferring instead the full-disclosure attitude typified by universities during the $1970 \mathrm{~s}$ and $1980 \mathrm{~s} .{ }^{14}$

The absence of a consistent, organization-wide practice of maintaining laboratory notebooks to establish the basis for patent applications and to serve as "proof of discovery" places Los Alamos in a vulnerable position in the event of conflicts over the validity of subsequent patent applications. The inconsistent and sometimes negative managerial attitude toward seeking patents, whether real or perceived, further dilutes Los Alamos' intellectual property rights and weakens its ability to maximize the commercial value of the wealth of technology being developed at Los Alamos. The conflicting priorities affecting the decision on whether to attempt to protect rather than publish new technologies presents the possible loss of rights for technologies which may have commercial value.

Resolution Alternatives: Resolution of this issue is primarily a matter of establishing clear management priorities coupled with the education of the Los Alamos staff regarding intellectual property protection. Strong direction from the top of the organization on down is needed to change attitudes and practices with respect to preserving intellectual property rights. By comparison, in most industrial laboratories, laboratory notebooks with proper recording and witnessing are mandatory. Industries enforce strong incentives for protecting intellectual property, and laboratory

14 The "university" attitude has, in most cases, undergone a significant shift toward patenting and other forms of protection and licensing of intellectual property. Institutions such as Stanford and MIT now obtain significant revenues through such practices. 
management and staff are now being judged (sometimes to the extreme) on how many patents have been applied for and issued. The issuance of papers and other technical documents is tightly controlled, and sometimes decisions are made to delay filing applications to avoid premature disclosure to competitors. Patent strategy is a key element in the development of plans to successfully exploit any important new technology.

Educating its research community and providing incentives for disclosing ideas would help Los Alamos maintain more control over laboratory notebook maintenance and help prevent premature intellectual property disclosure. These techniques are used by large companies that share similar intellectual property management challenges. ${ }^{15}$ Additionally, educating the researchers through seminars and internal training sessions would very likely greatly increase control over intellectual property. Offering cash incentives for patents or even timely disclosure of information could increase the motivation for researchers to work cooperatively with Los Alamos' IPO.

Finally, the above activities all depend on increased funding to support them. Intellectual property protection activities, such as prosecuting patents, are limited by available funds. These activities are time consuming, complex, and require a large staff. If the IP office budget permitted it, all valuable inventions, trademarks; software, and other technology would be recorded and protected. However, given the limited funding and staff, the intellectual property office must limit the number of patent applications to prosecute. Increased funding would allow Los Alamos to better implement the intellectual property policies that already exist.

\subsection{Fairness of Opportunity Requirements}

Description of Issue: As a government-funded agency, Los Alamos is required to make reasonable efforts to ensure that any transferable technology developed with public funds be made available to any interested party on an equal basis. This is being interpreted to require that available technology be broadly advertised or otherwise made available to all interested parties, and that those who may be interested in exclusively licensing the technology be allowed (required?) to compete for the license through the submission of a proposal (a "business plan") indicating how they intend to exploit the technology. Since the candidate with the "best" business plan is normally the one selected for the exclusive license, small businesses appear unlikely to have a fair chance to obtain such a license in any situation where they are forced to compete for it versus a larger, more established contender.

Start-ups and other small businesses seeking to develop unique new commercial opportunities normally wish to obtain an exclusive license to a technology upon which successful development of that opportunity depends. With Los Alamos, however, they may not be able to license the technology because they do not have the capital resources to prepare extensive business plans that can compete with larger companies who do possess the resources to invest in business plan development. Thus, current Los Alamos Fairness of Opportunity (FOO) requirements appear to make the licensing process more difficult for start-ups and other small businesses.

Fairness of Opportunity is the prime contract requirement that Los Alamos must satisfy when exclusively licensing technology or in any other type of technology transfer activity. Under current policy, Los Alamos satisfies the requirement when it takes reasonable measures to ensure widespread notice of availability of technologies suitable for transfer and opportunities for exclusive licensing and joint research arrangements. The FOO question does not arise when the parties to any such transfer arrangement have had no access to internal Los Alamos information. 16

15 Whiting, Rick, "Protecting the Power of the Idea," Electronic Business, February 24, 1992, pg. 25.

16 The FOO requirement is included in the Prime contract between the University of California and the Department of Energy in Article XII, CL11.e under the Technology Transfer mandate. See Appendix E for additional comments on that particular article of the Prime Contract. 
Issue: The problem observed with FOO, much as with the "undue gain" issue associated with OCV/COI, is that having an "advantage" is an essential part of the business plan for any start-up corporation. If such a company does not have an advantage (either obtained by being early to market or by having exclusive access to a technology), then its business plan is not sufficiently attractive to generate needed seed funding. In other words, in order for a small business to compete economically, there must be some form of unfairness of opportunity which gives that business a marketable advantage. Unfortunately, based on the Review Team's discussions with companies who have spun-out from Los Alamos in the past decade, it appears that both Los Alamos and DOE have evolved positions that are very restrictive with respect to the interpretation of the FOO and OCI/COI doctrines, interpretations which appear to be disproportionally troublesome to small businesses.

Small companies, and especially start-ups, usually have limited access to capital resources. In fact, under-capitalization of these companies is one of the primary reasons for failure during their first five years of operation. ${ }^{17}$. These classes of companies are generally forced to operate on greatly reduced time schedules, partly because of their lack of capital, but also because of competitive and market conditions. To survive, they must be more nimble and more effective in rapidly turning technology into marketable products. In addition, before being willing to provide start-up funding, most potential financing sources will expect the small company to have an exclusive license on any technology important to the success of the business. As a result, the resolution of FOO and $\mathrm{OCI} / \mathrm{COI}$ questions is particularly burdensome for small businesses and prospective entrepreneurs, in the following ways:

- The time factor: a small business cannot endure the time required to wait while a technology is advertised, and then while a reasonable time is allowed for others to prepare a proposal, and then for that proposal to be reviewed and a decision reached. While accepting a non-exclusive license can help to reduce the time involved, this presents a major barrier to securing any significant venture funding.

- Competitive conditions: the small business is at a great disadvantage in attempting to compete on an equal basis with larger, more established companies. Large companies have more financial and other resources to devote to competing for a valued license. They are also better positioned to accept the time delay and can devote the resources required to out-distance smaller companies in developing an attractive proposal.

The FOO issue presents an especially critical problem for a person who may have gained special knowledge about an attractive technology while being a Los Alamos employee or while serving as a Los Alamos consultant. Often these individuals are among the best qualified parties to successfully undertake or participate in the commercialization of a technology by a small, start-up enterprise. However, this status specifically prevents these individuals from participating in certain commercialization activities, limiting their capabilities to participate in such efforts, a situation which is potentially of great negative consequence to a small company that does not already have a pool of qualified technical talent. ${ }^{18}$

Resolution Alternatives: The small-business Fairness of Opportunity problem can be addressed in a number of ways. One solution involves giving some preference to start-ups and other small businesses for licensing considerations. Two other solutions involve creating a mechanism for

17 The New Business Incubator: Linking Talent. Technology. Capital, and Know-How Raymond W. Smilor and Michael Doud Gill, Jr., Lexington Books, Lexington Mass, 1986, pg. 13.

18 This issue is addressed in more detail later in Section 5.13, Ability of Los Alamos Employees, Former Employees, Consultants, or Companies Which Hire Them to Obtain Licenses. 
guaranteeing that small businesses can gain equal access to information about Los Alamos technologies through public channels, thereby reducing the negative impact of the FOO issue. By doing so, companies seeking to commercialize Los Alamos technologies may not be required to go through Fairness of Opportunity procedures because the technologies were obtained from the public domain and it can be assumed that all interested parties have had equal access to them.

It would seem that, considering current DOE guidelines favoring small businesses, it could be argued that preferential treatment should be given to small businesses. 19 However, this would probably require changing the parts of the Prime Contract and/or other DOE regulations. Precisely how such preference might be implemented is not clear.

In cases where an external company approaches Los Alamos with a request to license a particular technology, there is normally a presumption that the Fairness of Opportunity requirement has been satisfied. It is specifically stated that the requirement to widely disseminate the availability of technology-transfer opportunities does not apply in cases where the interaction is initiated by a company. ${ }^{20}$ The implication is that the requesting company has learned about the subject technology through some publicly available source, and that widespread public notification has been satisfied.

If, however, the company has learned of the technology through a contact at Los Alamos, or if a consultant working for Los Alamos contacts a company suggesting that a potentially valuable technology exists, then execution of the normal Faimess of Opportunity procedures would seem to be required. This is a narrow distinction depending on confirmation about how the applicant learned of the subject technology in the first place. Any number of scenarios could be constructed that create many gray areas which could be subject to a negative interpretation (e.g., that Fairness of Opportunity was not achieved).

Often only the most entrepreneurial and technically well-qualified parties will see the commercial potential of a technology at the earlier stages of its development. If the Los Alamos IPO identifies and advertises technology at an early stage before a particular commercialization plan is ready for implementation, or with the knowledge that a particular company or individual may be interested, the adverse effects of Fairness of Opportunity may be reduced. However, this does not eliminate the problem, and still leaves the imposition of the time required for advertising. The potential use of a broad communication facility accessible over Internet for such advertisement appears likely to -help to reduce the waiting time involved.

Based on current MVI understanding, it appears that there is no fully satisfactory solution to this issue, short of changing the Fairness of Opportunity regulations themselves. However, the alternatives cited above may provide opportunities for reducing the adverse effects, should a change in regulations prove to be too difficult to accomplish.

\subsection{Ability to Accept Equity and Use of Equity as Compensation}

Description of Issue: Los Alamos is currently not empowered to accept equity from a company in return for intellectual property transferred to that company. Although Los Alamos staff have indicated that they have significant flexibility in negotiating licensing terms with small, early-stage companies, the ability to accept equity, as opposed to more specific forms of remuneration, appears likely to increase the chances for start-ups to succeed. Accepting equity parallels industry

19 For example, the Los Alamos Small Business Initiative which already provides programs "to meet the special needs of our small business partners."

20 Prime Contract Technology Transfer Procedures, Article XII, Cl. 11(e) at 129. "The requirement to widely disseminate the availability of technology transfer opportunities does not apply to a specific application originated outside of Los Alamos." 
and UC practices, and has the potential for generating much greater returns on successfully commercialized Los Alamos technology than is possible through licensing alone. ${ }^{21}$

Impact: Start-ups are always short of cash, and hence are generally more willing to offer equity as payment for assets or services. By accepting equity, those providing value to the start-up also contribute to the success of the start-up by helping to conserve scarce cash resources for current operating needs that cannot be paid for with anything other than cash. For the recipient, accepting equity can also provide other advantages when compared to alternatives, e.g., royalty on a licensed technology.

In the case of royalty, if the product containing the technology is markedly successful, the intellectual property owners will receive income based on some agreed-to percentage of the income from the product. Most generally, royalty payments are made on a regularly scheduled basis. However, in cases involving small, early-stage companies, royalties are often accumulated and paid after the company is in a position to afford such cash payments (after the company has achieved a specified level of profitability or cash flow). However, if the product does not produce significant income - or if the product, for some reason, does not employ the licensed technology-the licensor may not receive the expected income stream.

In the case of an equity interest, the equity holder in a small company most generally will not receive any current income, but must instead wait until the issuing company has achieved the size and status that enables the company to provide liquidity to shareholders by either selling the company or by going public. Often this can take as long as 5 to 7 years, if not longer. However, by assuming the apparently greater risk of postponing the receipt of any income, the shareholder who has accepted equity in place of current royalty income would expect to receive much greater total compensation when (and if) the company is successful. If the company is not successful, it is unlikely that either the equity holder or the royalty recipient would receive any substantial income.

Holding an equity interest has other advantages. Equity holders have a stake in the whole company, where a licensor only has the right to a portion of the revenue coming from a single technology and the products which may be based on that technology. The equity holder's interest continues for as long as the equity is held, whereas a royalty interest is normally limited to the period that the licensed technology produces revenue.

If all parties involved-Los Alamos itself, its technical staff, consultants, investors, and management-hold equity in a start-up (as compared to other forms of interest), there is likely a better chance that their interests in the subject company will be closely aligned, at least in the earlier years of the new company's existence. Alignment of the interests of all parties involved can be an important factor in being able to quickly and successfully deal with the numerous strategic and other vital business decisions that are always encountered in attempting to start and grow a new company.

Resolution Alternatives: The easiest solution to this issue is to adopt a policy of taking equity from early-stage companies in return for transferred technology. While a draft University of California policy regarding equity participation proposes taking equity only as partial compensation for transferred technology, this is clearly a step in the right direction. ${ }^{22}$ However, to fully solve this

21 Appendix $\mathrm{N}$ contains a detailed discussion on some of the reasons that have prompted a number of institutions to accept equity interests in new, small businesses in exchange for technology. This appendix also contains a sample bonus incentive plan that illustrates some of the ways that members of an institution's scientific staff can share in the rewards from their work. The material in Appendix $\mathbf{N}$ is not intended to provide a model for a specific plan, but is an illustration of how such plans can be constructed. This appendix was provided by Christopher Lane Davis of O'Sullivan Graev \& Karabell.

22 Licensing Guidelines for Equity Acceptance by the University of California, 4/7/93. 
problem, it does not appear to go far enough. If coupled with a willingness to eliminate up-front payments and to postpone the payment of on-going royalties until a start-up has adequate cash flow, it would probably become more workable for small businesses. It would still be far more beneficial if Los Alamos were able to accept equity as full compensation for the transfer of any intellectual property. And, while it is impossible to prove at this point, it is certainly possible that this form of compensation would, in the long term, provide greater returns to Los Alamos and its numerous constituents.

\subsection{Sharing Licensing Compensation with Managers}

Description of Issue: Presently only those named on a patent share in the royalties which Los Alamos receives as a result of licensing their inventions. In reality, many others, especially the named inventors' line managers and associates may contribute to the invention, and, possibly more importantly, to its successful commercialization. ${ }^{23}$

A related issue is the potential morale problem of PIs working in close proximity, and possibly even on similar programs-but one has an opportunity for significant extra compensation from royalties or other commercial returns, while the other does not. While this situation may present some additional problems, this is regarded as a relatively minor issue in the overall need to improve the process of technology commercialization.

Resolution Alternatives: While it may require closer and more careful management attention, a viable solution is to modify the Los Alamos licensing income distribution policy to include some form of revenue sharing among line management and others that have contributed to the development and/or commercialization of a particular intellectual property. Broader distribution of compensation would be made easier by the creation of a compensation arrangement that pools the assets received. Such an approach may be necessary for successfully dealing with certain problems associated with the acceptance of equity on behalf of PIs who are not qualified investors, and as a result, are unable to accept restricted stock directly. Such a pooling arrangement could also be part of a stock appreciation rights (SAR) scheme.

\subsection{Time Required to Obtain a License}

Description of Issue: For the reasons already described in the earlier section on Fairness of Opportunity Requirements (Section 5.3), small companies rarely can afford long and uncertain licensing procedures. Materials supplied to MVI by the Los Alamos IPO indicate that obtaining a license for a Los Alamos technology can require as little as a few weeks or may require a time interval measured in years. ${ }^{24}$ The reasons for the variance are complex and include delays due both to DOE involvement in some cases (where a former Los Alamos PI wants to obtain an exclusive license) and delays due to the potential licensee's attempts to negotiate more favorable licensing terms, or to negotiate alternate wording in one or more of the existing Los Alamos agreements that typically accompany licensing negotiations. Certainly, exclusive licenses are more difficult to arrange under the faimess of access rules, and therefore require a considerably longer time to complete.

Impact: Small companies and entrepreneurs may be dissuaded from trying to gain access to Los Alamos developed technology due to the time and other significant impediments in existing Los Alamos licensing policies and procedures.

23 As one example, Gary Seawright, the founder of Amtech Corp., made a point of the fact that the support of his division head at Los Alamos was instrumental in facilitating the difficult process of creating his new company.

24 Narratives for Licensing Guidelines Flowchart, Industrial Partnership Office, Los Alamos National Laboratory, January 1994. 
Resolution Alternatives: A series of steps could be implemented to reduce the time required to award an exclusive license. This might include trying to perform more steps in parallel; developing a simplified proprietary information agreement (PIA) that more closely parallels those agreements commonly used in industry; shortening the time required to complete a PIA (do it by FAX, with one day turn-around); reducing the time required to complete other steps; developing a more standardized, pre-approved licensing agreement in a form more acceptable to early-stage small companies; or co-locating the licensing attorneys with the IPO division in an "outside-the-fence" location.

\subsection{Restrictions on Licensing and Inability to Assign a Patent}

Description of the Issue: Despite the availability of so-called exclusive licenses for Los Alamos technologies, the MVI assessment has found that Los Alamos is generally unable to assign an existing patent to an entrepreneur in a truly exclusive manner. ${ }^{25}$ The intellectual property which Los Alamos licenses originally belongs to the DOE and is subsequently assigned to the University of California, the operator of the Los Alamos National Laboratory. One condition of that arrangement is that the government retains a perpetual, royalty-free, unrestricted right to use the technology for government purposes, including the right to provide it to government contractors. These provisions, in effect, allow the government the perpetual right to license a company other than the exclusive licensee (and, possibly, a competitor), to develop and manufacture products to sell to the government and its contractors based on that supposedly "exclusive" license.

Impact: It is difficult for a company's management and investors to accurately determine the potential impact of the policy of reserving government rights to licensed technology. In many information and electronic systems markets, for example, the federal government is estimated to represent from $12 \%$ to $20 \%$ of the total U.S. market potential. When government contractors are added to these percentages, the threatened loss of such a major portion of the domestic market may become a significant problem for a small company. While the actual effect of the governmentmarket exclusion is often more limited, in circumstances where the government continues development of the technology and then later licenses or otherwise transfers a more advanced version of the technology to another company, the effect can be serious. Even if the actual impact should only be minor, potential investors in a small business may perceive the government right as another uncertainty in a situation that already presents an abundance of risks.

Resolution Alternatives: One possible approach appears to be to implement licensing policy changes that are within Los Alamos' power to implement, such as: ${ }^{26}$

- Grant the licensee rights (or at least some sort of option) to any future improvements or enhancements of the technology if it is likely that Los Alamos will continue to do work in the subject technology. A form of continuous crosslicensing giving both parties rights to any enhancements or improvements made by either party might also be used to meet both Government requirements and the potential licensee needs;

- Agree from the beginning that if the licensee can equal or exceed the offers made by other potential government vendors, that the licensee will have first chance to supply government requirements for products embodying the technology;

- Agree that in return for a grant-back of any improvements, the licensee will have first right to supply government needs unless its prices and performance are found to be unsatisfactory (non-competitive); and

25 In addition, because of the requirements involved in attempting to obtain an exclusive license, the tendency at Los Alamos has been to prefer non-exclusive and/or restricted licenses rather than exclusive licenses.

26 Clearly, Los Alamos cannot change prime contract and statutory requirements. 


\section{The Final Report of Los Alamos Contract No. 4790L0013-9Z, Volume 1}

- Provide assistance to a prospective licensee in evaluating the potential effect of the continued right of the government to make use of the technology in order to assure the licensee that if it successfully commercializes the technology, the Government will not likely license the same technology to another company.

\subsection{Knowledge and Identification of Existing Technologies}

Description of Issue: Los Alamos does not currently have a comprehensive catalog or database of technologies existing within the Laboratory, nor has the MVI assessment found any formal program for identifying technologies that might be prospects for commercial ventures. Efforts currently underway to create a resource database of technical capabilities may prove to be helpful, but do not appear likely to be completely sufficient for identifying and screening candidate technologies.

Impact: The screening and selection of Los Alamos technologies to be evaluated for commercialization must start from some base of information on what is available. Unfortunately, at present it appears that sufficiently detailed knowledge about technologies worthy of consideration for commercialization resides primarily in the heads of individual scientific staff members and division managers, making it difficult for interested parties to become aware of those technologies other than through personal relationships with Los Alamos staff, a situation which exacerbates the FOO and $\mathrm{OCI} / \mathrm{COI}$ issues.

Resolution Alternatives: Since much of the necessary information is held by any number of individuals, developing a catalog of Los Alamos technologies will undoubtedly require an extended process of interviewing and networking among current Los Alamos scientific staff members and managers, and possibly recent retirees and consultants. (The type of information required is outlined in Appendix D, Technology Screening.) The main question to be resolved here is how extensive and how deep the screening should be before starting the process of attempting to mature and actually commercialize specific technologies found by the screening to be of high promise. The availability of such a technology database, if made generally accessible both within and without Los Alamos (as on an Internet server), would also help to address the Fairness of Opportunity issue.

Ideally, a complete database covering all potential technologies in sufficient depth to permit a comprehensive evaluation and selection of the most attractive candidates would be desirable. However, it is anticipated that a less optimum process of simultaneous identification, data collection, cataloging, and evaluation will be required, as a starting action, to demonstrate results more quickly. Selections of technologies for commercial development may need to be made (and realistically, can be made) in parallel with the process of collecting information and constructing a Los Alamos technology database. The only possible negative feature of this approach is that the most commercializable technologies may not be identified first, although there are many other factors which will affect the initial selections, such as time-to-market, cost of maturation, market readiness, etc.

One potential source of information about the commercial potential of Los Alamos technologies is the DOE Record of Invention (see Appendix E). This document is filled out by the principal investigator when disclosing a new invention. The form requires the PI to discuss the commercialization potential of the technology being disclosed. That information could be readily incorporated into a technology database. Given such a database, initial ideas about commercial applicability could readily be made available to market experts who could independently judge the commercial value and viability of those ideas. Establishing a mechanism for making that information available to the entrepreneurial community will increase the likelihood the PI's commercial idea will be explored. 


\subsection{Current State of Los Alamos' Commercial Knowledge and Market Orientation}

Description of the Issue: As a research institution historically devoted primarily to the development of defense systems and military weapons technology, Los Alamos has had little need to be concerned with commercial markets and the selection of technology on the basis of its suitability for commercial applications. Furthermore, with the federal government as its primary "customer," there has been little need for the Laboratory to develop the commercial market orientation normally present in industrial research organizations. As a result, Los Alamos lacks, to a large extent, the basis for evaluating and directing the development of technologies based on their potential for commercialization in commercial, non-military applications, and people in the organization, in general, appear to have insufficient knowledge of industrial markets and marketing.

Impact: Within Los Alamos, it appears that key decisions as to what to work on, or what to patent $\longrightarrow$ or how to go about taking advantage of perceived commercial applications-are frequently made without sufficient understanding of non-defense market opportunity or market and customer requirements. For example, the question of market potential is not a significant factor in selecting those technologies to patent.

Resolution Alternatives: Becoming more market oriented and developing marketing skills within its technical and managerial staff is likely a major, long-term cultural challenge for Los Alamos. Some initial steps to solve this problem have been taken in the form of educational and other programs directed toward key staff. However, much more needs to be done with visible direction from executive management. Other steps to solve this problem might involve including marketrelated criteria in decisions on what intellectual property to protect, and the incorporation of market and applications information in decisions affecting the allocation of discretionary development funding.

As a start, such additional information could be supplied by qualified outside consultants. Also, as they become available, openings in the Los Alamos IPO could be filled by individuals with strong commercial business development, marketing and market research backgrounds. For the entire Los Alamos management organization to acquire the required degree of market orientation will probably only occur with the accumulation of significant experience in successfully commercializing Los Alamos-developed technology.

\subsection{Lack of Knowledge about Small Business Commercialization Practices at Los Alamos}

Description of the Issue: As discussed in Section 4.3, only a handful of successful small companies have been created as a result of the transfer of technology developed at Los Alamos over the past ten years, and depending on how "success" is defined, the number could be as few as four to six companies. The only known publicly traded company is Amtech Corporation. Other successful companies include Cell Robotics Inc., ICAMP, ${ }^{27}$ and Essential Communications Inc. Additionally, with the infrequency of Los Alamos-spawned new company formations, and the recent high turnover in management of the Los Alamos IPO, there is a lack of any significant experience base or historical knowledge with respect to the creation and development of spin-out companies based on Los Alamos technologies. Further, as more attention has been focused on commercializing technology through small businesses, that process appears to have become more difficult due to the increasingly burdensome policies and regulations imposed as part of that focus.

27 ICAMP is a spinout from Los Alamos which was formed in the late 1980s. Their primary product is a software tool which aids in the analysis of mechanical parts to ensure that they comply with design specifications. ICAMP is profitable, but its founders do not plan to grow the company much beyond its current market. 
Impact: Despite the announced goals for broadly expanded commercialization on the part of DOE, there is little tangible evidence that more small business commercialization has taken place in the past five years.

Resolution Alternatives: A viable near-term solution to the commercialization problem appears to be to turn towards experienced outside organizations to help jump-start the process of commercializing Los Alamos technologies through the creation of small companies, and then to retain that experience in several internal "commercialization" teams organized and properly motivated to carry on the small business commercialization process following the initially supported commercialization activities. Another possibility is to continue to have this service provided by one or more outside organizations, which should be easier to do once a successful process has been demonstrated.

\subsection{Lack of Availability of Recent Successful Small Business Spin-off Role Models}

Description of the Issue: While significantly greater resources are now being devoted by DOE and Los Alamos to the spin-out of technology to small companies, the only two significant new business formations based on Los Alamos technology have originated several years in the past-one in 1984 and the other in 1988. No more recent examples have been identified by the MVI assessment, and only one or two others are presently known to be in process within Los Alamos.

Impact: The lack of recent examples of successful spin-offs appears to be exerting a dampening effect on the further formation of Los Alamos-based start-ups. Successful role models are needed to encourage others to take the risk.

Resolution Alternatives: There is no known resolution except the rapid creation of several successful start-ups to serve as demonstrations of "how to do it" to prospective entrepreneurs both inside and outside of Los Alamos. One knowledgeable long-term Los Alamos employee stated a belief that once a spin-off process is successfully demonstrated, others will follow in rapid succession. In other words, "Nothing succeeds like success!"

\subsection{Availability of Funding for Maturation of Commercially Viable Technologies}

=Description of Issue: While many of the technologies developed by Los Alamos represent significant scientific achievements, few have been developed to a level which can directly yield marketable products, or even demonstrable prototypes. In such cases, the lack of demonstrated technical maturity appears to prevent such technologies from being successfully presented to potential seed investors. Unfortunately, Los Alamos has no formal program to assure entrepreneurs that funds will be available to mature candidate technologies for commercialization. To attract potential investors, funding for maturation will be needed to develop potential products to the point where their commercial viability is clarified, including, where applicable, the demonstration of engineering prototypes. Given the risks associated with business plans based on immature technologies, consideration appears to be needed for a program through which Los Alamos itself could participate in the costs associated with maturation of promising technologies as a means of spurring further investment from the venture community.

Impact: It is unclear that, at present, sufficient internal funding will be available at Los Alamos to bring prospective technologies to a mature enough state so that commercialization can be planned and the necessary seed funding secured from outside investors. The lack of maturation funds to make technologies more marketable to investors will likely impair the ability of Los Alamos to successfully commercialize its technologies. With this uncertainty, it is difficult to justify the effort to develop commercialization plans for candidate technologies that may require significant maturation funding. 
Resolution Alternatives: There are several possible solutions to this issue:

- Los Alamos may choose to rely largely on external, non-government financing for maturation. This would imply that only the most attractive technologies, those which are already close to productization (of which there appear to be very few), or those which are easily visualized in product form, will obtain funding and be commercialized.

- Locate source(s) of maturation funding within Los Alamos. Possible sources could include royalties, LDRD funds, and possibly later on, cash realized from the sale of equity interests in companies started with Los Alamos technology (assuming that Los Alamos is allowed to take equity interests).

- Locate some other, as yet, unidentified source.

- Make increased use of developmental licenses, and include provisions for technology maturation in the license arrangements (although because such licenses do not guarantee exclusivity, this may not be a completely satisfactory solution).

\subsection{Ability of Los Alamos Employees, Former Employees, Consultants,} or Companies who Employ them, to Obtain Licenses

Description of Issue: In many cases where a technology is moved from the R\&D environment into a commercial company with products based on that technology, one or more of the researchers who were involved in the development of the technology move along with it. Similarly, companies seeking to commercialize a technology often hire, either as a full-time employee or as a parttime consultant, one or more of the researchers who participated in the development of that technology. These situations are especially true in an area such as Los Alamos where, because of its geographic isolation, a ready pool of experienced technical and managerial talent does not exist alongside the technical staff of the Laboratory.

Unfortunately, the University of California COI policy is currently interpreted by Los Alamos to preclude the granting of an exclusive license for a UC technology to anyone who is an employee of the University of California ${ }^{28}$ or has been an employee of UC in the last two years without DOE approval. ${ }^{29}$ Some Los Alamos agreements include specific language that prohibits the issuance of an exclusive license to a former employee, e.g., the Exclusive Software License Agreement. It is our understanding that similar specific language is being considered for addition to the exclusive patent agreement. Naturally this clause is negotiable; however, we are not aware of any instance where the restriction has been waived. ${ }^{30}$

Neither the exclusive or non-exclusive patent licenses contain such a clause, nevertheless, $\mathrm{COI}$ policy would determine that a potential licensee for an exclusive license that employs a former Los Alamos employee who worked for the UC within the past two years would have a conflict of interest. In order to mitigate this conflict of interest, the company would have to obtain approval from the DOE, which would be an arduous and time-consuming process. A second approval could be required for FOO for this technology as well. Although it is not impossible for a company employing former UC employees to obtain an exclusive or non-exclusive license, it is

28 Most individuals who work at Los Alamos, except contractors, are full employees of the University of California. Exceptions include visiting military or DOE personnel.

29 It is assumed that if an employee were actively trying to commercialize a laboratory technology, the employee would be part of the company he/she establishes. That company would then negotiate for the license.

30 Exclusive Software License Agreement, dated 3/8/93, Cl. 28.5, pg. 16. 
highly unlikely that a company in this position would be able to successfully obtain the DOE waivers in such a way to be consistent with a successful commercialization time table.

Impact: In many cases, the ideal candidates to receive a license and join, or possibly even lead, the formation of a spin-out company based on a Los Alamos technology are current or recent Los Alamos employees and consultants. The current COI policy may preclude these people, or companies that want to hire them, from obtaining an exclusive license, a step which, as stated earlier, is often an essential element for obtaining venture financing. This policy removes from consideration many organizations that are ideal candidates for commercialization of technologies which originated at Los Alamos, in that those organizations may be precluded either from obtaining an exclusive license or from hiring a former Los Alamos employee who understands that technology. More importantly, this would seem to preclude the possibility of one or more employees leaving Los Alamos along with the transfer of technology, even though the transfer of people along with the technology is almost always a mandatory requirement to obtain venture capital financing for commercializing advanced technologies. 31

Resolution Alternatives: Presently, the only possible solutions that have been found through the MVI review are to obtain a blanket DOE approval for licensing to Los Alamos former employees or companies employing such individuals, possibly with some stated restrictions on the size or stage of the business they are involved in, or to change/waive this policy with respect to such individuals involved in small businesses and spin-offs. As the policy stands, it appears to be a serious limitation to commercialization activities.

\subsection{Availability and Conditions for Entrepreneurial Leave}

Description of the Issue: The ability of a Los Alamos employee to take a leave of absence without pay for up to two years was an important factor in the formation of Amtech Corporation. If still in place, this policy could continue to play an important role in encouraging entrepreneurial employees to participate in the formation of new businesses without completely risking their employment at Los Alamos. Unfortunately, however, it is understood by the MVI Review Team that Los Alamos is no longer granting entrepreneurial leave (EL).

Impact: The lack of a readily available entrepreneurial leave program discourages the participation of Los Alamos employees who might be interested in helping to form and develop spin-out companies. Because the involvement of experienced technical employees is so critical to the spinout process, their exclusion from the process appears to adversely impact the success of commercialization activities.

Resolution Alternatives: Los Alamos should consider re-instituting an entrepreneurial leave program incorporating up to two years of unpaid leave, plus other terms similar to those contained in the former policy. The MMES at ORNL has developed and proposed an entrepreneurial leave policy, although not yet been approved and implemented, which could provide a model for Los Alamos. Sandia is also investigating a more aggressive entrepreneurial leave policy.

\subsection{Effects of Los Alamos Organization on Would-be Entrepreneurs}

Description of the Issue: In many instances, Los Alamos management appears not to have been strongly supportive of the entrepreneurial efforts of staff members working under their direction. Not too surprisingly, under current policies there are conflicting objectives and motivations which separate division management and would-be entrepreneurs. One senior Los Alamos official is reported to have remarked that he is completely opposed to the spin-off of any technology developed with taxpayer money. Further, reports are that staff members who express an interest in

31 This requirement on the part of many venture capital sources was confirmed at the Los Alamos/MVI sponsored technology conference, which is described in Appendix A. 
leaving to start new businesses, or who devote any significant time to non-program activities are occasionally criticized, or even ostracized, within the Los Alamos community.

Impact: The real and perceived management opposition to entrepreneurial initiatives of Los Alamos staff members is a major barrier to generating successful spin-off businesses.

Resolution Alternatives: This is essentially a management issue. To improve it, Los Alamos management must be seen as permitting and supporting entrepreneurial activities, but the atmosphere must be such that those working on spin-off opportunities have sufficient commitment and determination that they do much of such work on their own time-and that they understand that normal obligations to Los Alamos must be fulfilled at the same time. If Los Alamos truly wishes to offer greater encouragement to commercialization activities by its employees on the prospect of sharing in the rewards of a spin-off business, then consideration could be given to a controlled application of paid laboratory time to the development of new business initiatives. It is assumed that this would require the establishment of some account to charge such time to, and that this time would be "capitalized" on the formation of the spin-off.

\subsection{Rights of Others to Use Technology Licensed from Los Alamos/UC}

Description of the Issue: Under existing licensing policy, the government retains unlimited rights to continue to use any licensed technology. ${ }^{32}$

Impact: This aspect of the existing licensing policy has several effects:

- The government may elect to have another company manufacture products for use by the government and government contractors in direct competition with a Los Alamos licensee. The licensee, in effect, could face competition with access to the same technology, even though the licensee holds an exclusive license. It is unclear what the effect would be if the manufacturer, as a result of its production activities, develops enhancements and improvements to the original technology.

- Los Alamos may continue to develop enhancements and improvements to the licensed technology. This improved technology could be licensed to another competing company.

- Software presents a slightly different problem. A complete package of any software developed at Los Alamos must be supplied to ESTSC, which then publishes that information, supplying it, on request, to any government agency or contractor. The contractor is only supposed to use software obtained through ESTSC on government-related work, but this restriction is virtually impossible to enforce. Even U.S. subsidiaries of foreign corporations who are serving as U.S. government contractors can qualify to receive software from ESTSC. Despite attempted restrictions, it is likely that software so supplied is sometimes relayed on to the foreign company's headquarters, thus reducing the overseas market prospects.

The actual potential threat of this issue is hard to predict; its appearance may be worse than it actually may be. If an exclusive licensee successfully exploits the technology in an aggressive

32 The license agreement also requires that the licensee provide to UC, upon demand, any enhancements made to the software including derivative works, documentation, and extensions. See Appendix E.4.3 and the Exclusive Software Agreement, Cl. 2.7, pg. 5. This could mean that the entire product line based on the original technology could be disseminated to a government contractor; possibly a competitor. No historical precedent exists in which the UC has exercised this option and personnel in Los Alamos' IPO believe that it is highly unlikely that it would ever be enforced. 
fashion, it should be in the best position to be the preferred supplier to the government, and should be in the best position to continue to develop enhancements and improvements. Despite this, the effect of this loop-hole on prospective investors and others is that the "exclusive" licensee may, nevertheless, face competition based on the same technology, and that the company could be excluded or face significant competition in a substantial part of its intended market. ${ }^{33}$

Resolution Alternatives: Los Alamos and DOE may choose to consider procurement policies that offer small company licensees the first right to supply the government with products containing the licensed technology. This right may be conditioned on the licensee being of a certain maximum size, along with some protection on price and performance. For software, it is likely that most users would require the type of documentation, product support, and maintenance that is normally provided by a commercial organization. Here again, if the software licensee effectively develops and markets its product, government procurement officers will naturally gravitate to them, rather than attempting to obtain less well-supported software through ESTSC. Again, the best solution is for the licensee to aggressively work the market, precluding any desire on the part of prospective users to acquire an inferior version of the product from ESTSC.

\subsection{Dual-benefit Requirements}

Description of the Issue: DOE has made it clear that preference will be given to technologies that have the potential to serve both government and commercial market needs.

Impact: In theory, technologies which cannot be shown to have dual-use application will be of less interest, and hence will receive less support as candidates for maturation and potential commercialization at a DOE laboratory such as Los Alamos, thus limiting the opportunities for small businesses focused on non-government markets to adopt commercially attractive technologies which do not have potential application for other DOE/government needs.

Resolution Alternatives: This problem will need to be addressed on a case-by-case basis and can result in many different solutions. Hopefully, both commercial and government use will be possible on many of the technologies that have clear commercial potential. Consideration could also be given to providing assistance to small businesses in identifying and opening government markets for their products.

\subsection{Substantial U.S. Manufacture Requirement}

Description of the Issue: Los Alamos licenses include a clause requiring that products made under the license be "substantially" manufactured in the U.S. The definition of "substantial" is not clear, but would probably be judged based on relative value added and/or manufacturing employment.

Impact: The impact of this requirement is believed to be minimal, especially during the earlier stages of a company's development and growth. There is no restriction on the manufacture of products outside the U.S. that are subsequently sold in foreign markets.

Resolution Alternatives: It is apparent that there is sufficient latitude in the application of this clause that many businesses will not find this to be a barrier to their initial development. Therefore, it does not seem that any steps to resolve this issue are demanded now.

33 Almost all of the research agreements (CRADAs, Work for Non Federal Partners, etc.) give the U.S. Government certain rights to subject inventions developed under government contracts. These rights allow the government to license the technology to any government contractor for government purposes. The U.S. Government has exercised that right in the past to the detriment of the original contractor who developed a technology, but who was not awarded the production contract. See Hazeltine Corp. v. United States 820 F.2d. 1190 (Fed. Cir. 1987). 


\subsection{Indemnification Language in Licenses and Contracts}

Discussion of Issue: In many cases, small businesses seeking to commercialize a Los Alamos technology are required to indemnify Los Alamos against product liability for products derived from such technologies. Los Alamos licenses and other contracts contain specific indemnification language requiring the recipient to indemnify the Government and the University of California in any suits involving the use of the technology. The likelihood that most small businesses would be able to indemnify Los Alamos fully against any type of significant lawsuit is unrealistic. DOE and Los Alamos personnel say there have been no such lawsuits; therefore, small businesses should agree to the indemnification clauses. However, when a small business is trying to obtain funding from professional funding sources, the requirement for indemnification is an impediment to such funding - the funding providers do not want to see their capital tied up by a lawsuit.

Impact: To large companies, the indemnification clause is probably not a significant barrier. However, to small companies which are less familiar with this type of legal clause, and which often lack the financial resources to afford qualified legal counsel, the inclusion of this type of language may represent a significant problem. ${ }^{34}$

In high-technology industries, the importance of intellectual property in determining the competitiveness of products has lead to an increased number of lawsuits in the last few years. At the same time, we are not aware of any instances where a small company in the computer and electronics business has been involved in a lawsuit where this type of indemnification would have caused a problem. ${ }^{35}$

Resolution Alternatives: It appears that Los Alamos should explore the possibility of modifying or eliminating the indemnification clause from contracts with small businesses, or the provision of some limit to that liability for small businesses.

\subsection{Assignment of IP Rights Originating from Work for Others}

Description of the Issue: Intellectual property rights resulting from joint agreements between Los Alamos and an industrial partner are typically assigned to the industrial partner who pays for the work, e.g., see the modular CRADA, User Facility Agreement, or Proprietary User Facility Agreement. However, the reimbursable Work For Others (Funds-In) Agreement includes two options, one of which can result in IP generated by employees of the UC being assigned to the UC. Current practice at Los Alamos can result in this option being selected if the industrial partner elects only a partial reimbursement of costs, i.e., the partner does not reimburse DOE for overhead and depreciation.

Impact: In some cases, it may be possible to locate outside financing for an early-stage company that wishes to have unique work done by Los Alamos. However, this is unlikely if there is any question about ownership of the resulting intellectual property.

Resolution Alternatives: Los Alamos should take the responsibility to advise any potential industrial partners-especially small businesses who may not have legal services available to themwhat the consequences of these joint agreements could be for ownership of intellectual property.

34 In high-technology industries, the importance of intellectual property in determining the competitiveness of products has lead to an increased number of intellectual property-related lawsuits in the last few years. Whiting, Rick, "Protecting the Power of the Idea," Electronic Business, February 24, 1992, pg. 25.

35 Of some concern to the MVI Review Team is the strong possibility that small businesses executing technology-transfer agreements with Los Alamos may not be fully aware of the potential consequences of the indemnification language contained within those agreements, including the possibility of personal liability for the officers and board members of those companies. 


\subsection{Copyright Policy}

Description of the Issue: Los Alamos currently lacks a comprehensive copyright policy. Intellectual property protected by copyright is explicitly excluded from the provisions on small business CRADAs and the acceptance of equity. In the exclusive software license agreement, the University of California also specifically disclaims any warranty that the software being licensed does not violate someone else's copyright.

Impact: There is uncertainty as to how to effectively transfer rights to software to outside organizations, and as to exactly what rights and obligations are involved in obtaining rights to copyrighted software obtained from Los Alamos.

Resolution Alternatives: Develop and institute the use of a Los Alamos copyright licensing procedure consistent with UC/DOE policies, and which will be viewed as being acceptable to those familiar with copyright agreements commonly used in industry.

\subsection{Internal Los Alamos Infrastructure Issues}

Description of the Issue: One of the significant potential strengths of the Los Alamos organization in helping to form attractive new technology-based business opportunities would be its power to bring together multiple technologies drawn from several different divisions throughout the organization. However, Los Alamos is reported to lack the necessary organizational mechanisms to accomplish cross-division bundling of multiple technologies to satisfy an integrated solution.

Impact: Since many of the best candidates for technology commercialization involve the application of multiple technologies to commercial or governmental problems, the lack of an effective internal infrastructure for addressing such problems may be limiting the capability of Los Alamos experts to participate in commercialization opportunities.

Resolution Alternatives: Los Alamos could develop, through the IPO, the ability to bundle technologies to serve identified market needs. Once a specific market has been identified that might need multiple Los Alamos technologies, an ad hoc task team could be assembled across the appropriate divisions to determine if a product can be developed.

\subsection{Litigation in Case of Alleged Infringement}

- Impact: Companies with exclusive licenses from Los Alamos must be prepared to litigate for potential patent infringement entirely on their own. While the costs of the litigation can be deducted from the royalty payments normally paid to the University, nevertheless, a small business would not often have the resources to conduct meaningful patent-infringement litigation. If patent infringement does occur, and another company directly competes with the small business licensee, the licensee may find that it has no practical means to defend its intellectual property rights or its products and market share.

Resolution Alternatives: As a means for providing much-needed support for small licensees of Los Alamos technologies who are faced with potential infringement of the rights granted under those licenses, Los Alamos should consider participation in the costs of litigating such potential infringements. Having such "big brother" participation as part of its portfolio of licensed technologies would appear to be of major benefit to small companies seeking seed financing based on the marketability of those technologies. 
The Final Report of Los Alamos Contract No. 4790L0013-9Z, Volume 1 


\subsection{Alternative Procedures for Commercialization of Los Alamos Technologies}

Procedures for commercializing Los Alamos technologies must operate in accordance with a substantial body of law and policy. These include statutes of the U.S. Government and the States of California and New Mexico, policies and regulations of the University of California and the DOE, and local implementations or interpretations of these statutes and policies by officers of the Los Alamos National Laboratory.

In addition, a second substantial collection of factors (which are essentially unrelated to the statutes and policies above) affect procedures for commercializing Los Alamos technologies due to its geographical location in New Mexico.

Either of these two sets of factors insert formidable (but not unsolvable) obstacles along the various paths which lead to commercialization of Los Alamos technologies. The procedures described below offer several viable strategies for creating successful new companies and products based on Los Alamos technologies.

This section of the report includes three major subsections. The first of these, Section 6.1. provides a brief overview of a generalized entrepreneurship model for the commercialization of public-sector technology. Section 6.2 introduces the concept of scenarios which make explicit the most likely avenues that individual entrepreneurs will follow in their attempts to commercialize Los Alamos technologies, and introduces the unique impediments to commercialization which arise from the statutes and policies of those organizations which govern the operation of Los Alamos. The last subsection, Section 6.3, describes a model commercialization process which is uniquely tailored to the Los Alamos environment.

\subsection{Models for Enterprise Creation}

Creating successful enterprises from public-sector technologies requires a working partnership between the technology source and the collection of individuals and businesses which transfer the technology into commercial products or services.

In this section we divide the activities into those that are the responsibility of the technology source and those that are the responsibility of the commercial venture and provide a brief overview of each.

\subsubsection{Technology Source Responsibilities}

\subsubsection{Technology Maturation}

Technologies developed by public sector laboratories, e.g., those funded by the Department of Defense (DOD), DOE, NASA, and the National Institute of Health (NIH), are often not well matched to the commercialization process for several reasons. Some of these are:

1. The laboratory's primary mission may be basic research, not development,

2. The research may be directed at technologies which must be manufactured, regardless of the expense, for military or social purposes, and,

3. The technologies involved are intended for exotic missions that do not yet have a large public market, e.g., space travel.

Despite these limitations, many of the technologies developed by these laboratories can still be evolved to a state from which they can provide the basis for commercially successful products, but the process of that evolution is often both difficult and time-consuming. 
In the past, government-funded laboratories have not included commercialization of their technologies as part of their basic mission. As a result, there is not a widespread understanding within those laboratories of the technology maturation efforts required to close the gap between basic technologies and products based on those technologies. This is reflected both in the complexity of the policies that govern the transfer of technology from the public laboratories into the private sector, as well as in the lack of funding allocated to the maturation process by the laboratories themselves. Any reasonable model for the creation of new enterprises based on technologies developed at the national labs will have to address the technology maturation issue.

\subsubsection{Protection and Identification of Intellectual Property}

Commercial enterprises emphasize the identification, documentation, and protection of their intellectual property; perhaps as strongly as the national labs emphasize the protection of secret military information. While it is possible to base the creation of a new enterprise on intellectual property that has been placed in the public domain, this is not the usual model for success.

It is essential that the technology sources have in place a vigorous training program to ensure that there is grass-roots support for identifying and protecting intellectual property. This subject is revisited in Section 6.3 which provides a "Model Commercialization Process" tailored to the needs of the Los Alamos National Laboratory.

\subsubsection{Envision Products and Services}

Raw technology must be converted to products and services that can be manufactured and delivered at a reasonable price. Commodity manufacturing, market analysis, commercial sector customer needs, and distribution of products or services are examples of skills that are required by this activity. Ultimately, the enterprise that is created to exploit the technology will have the responsibility for these activities; however, the technology source has the responsibility for envisioning these opportunities initially and bringing them to the attention of those in the business community with the resources to create new enterprises.

\subsubsection{Determine Role of Inventors}

The pressure to avoid even the appearance of a conflict of interest has motivated the U.S. Congress, the State of California, the DOE, and the University of California to either enact legislation or establish policy that provides guidance to officers at the national labs on ways to avoid a COI incident. While these guidelines are well intentioned, they may stifle the initiative to transfer technologies from Los Alamos into private sector enterprises; especially when the enterprises are small start-up companies intended to commercialize the technology of a particular inventor.

For many technologies, full-time participation by the inventors and/or key members of the staff that developed the technology may be required if a successful start-up venture is to be established. This usually means that these individuals become employees of, or principals in, the new venture. Conflict of interest regulations that limit or prohibit these relationships can represent show-stoppers for small, new companies. These restrictions are discussed in detail in Section 6.2 which describes two commercialization scenarios.

\subsubsection{Determine a Commercialization Strategy}

A commercialization strategy must balance a collection of forces and circumstances which are external to Los Alamos and therefore beyond its control. These include product definitions that satisfy public demand, sources of components which make up the products, identification of staff and funding, competition, market trends, etc. Historically, these issues have all been resolved by the Laboratory's programmatic mission(s). The partners in the negotiations have all been govern- 
ment agencies or government contractors and the marketplace was largely determined by the needs of the military.

It is essential that the public technology sources and their commercial counterparts establish working relationships that encourage collaboration during the process of commercialization strategy planning. Existing instruments that encourage joint public/private sector projects represent steps in the right direction (e.g., CRADAs, User Facility Agreements, etc.), but other forms of cooperative agreements need to be established that recognize the special needs of small spin-out companies based on public sector technology.

\subsubsection{Public Sector Responsibilities}

The public sector component of the model for enterprise creation includes a collection of individuals and businesses. The roles which these participants play comprise the next four subsections.

\subsubsection{Creating a Venture Package}

To move from a raw technology stage to a venture package stage, the target technology must be discovered, assessed, extrapolated into products or services, and mapped into a business plan. This business plan must consider and resolve all of the forces that may affect the trajectory which carries the business from the current immature technology state to acquisition of the new venture's market share.

The business plan provides a basis for structuring the venture and the team that will launch and operate it. For example, should the venture be cast as an expansion of an existing firm or should it be a new firm? What relationships should be established with partners and suppliers? Will the inventor provide the technical knowledge required or will it be provided by another individual with appropriate skill? Will this be done with the inventor working as an employee or through joint projects with the technology source?

Negotiating the intellectual property rights and some form of joint technology maturation agreement follows next. Only after these steps have been completed successfully can the seed capital or other early-stage resources be secured.

\subsubsection{Establish the New Enterprise}

With seed capital or other funding, it is now possible to acquire product development and/or manufacturing facilities, bring a development and management team on board, enhance the technology prototypes through alpha and beta testing stages, negotiate strategic alliances, and refine initial product targets, etc. As this stage progresses, it may be necessary to expand the facilities and acquire additional product-oriented staff (e.g., quality assurance, distribution, and training staff). These expansions and acquisitions may require additional capital.

Several rounds of financing may be required before the new enterprise becomes profitable, or even before it has established a positive cash flow.

\subsubsection{Establish Initial Market Presence}

During this phase, all of the components must converge to an operational enterprise; one with sales and support staff, advertising campaigns, and possibly hot-lines for bugs and trouble reports, competitor tracking, etc. If the product line is successful, a ramp-up in all facets of the operation may be required. Some of these, such as the acquisition of new manufacturing facilities, may require long lead times and/or significant capital for a successful ramp-up. 


\subsubsection{Steady-State Operation}

Once the new venture has reached a stable state, plans must anticipate possible new directions for the business. These include new product lines, entry into foreign or other new markets, exit strategies for the investors, and growth management, among others.

\subsubsection{Interface Issues}

Several of the issues that are included in the sections above require cooperation between the government-owned technology source and the private sector entities which commercialize these technologies. In some cases, cooperative activities are in danger of running afoul of the statutes and regulations that govern collaboration or technology transfer between the public and private sectors. Section 6.2 addresses these statutory and regulatory issues and impediments in detail.

\subsection{Introduction of the Scenario Concept}

The extensive collection of statutes and policies that govern the transfer of Los Alamos technologies into the private sector creates an environment in which no single strategy is effective for commercialization of all Los Alamos technologies by any commercial company. Each individual instance of technology transfer will require a procedure specifically tailored to circumstances that surround the technology, the inventors, and the company seeking to commercialize the technology.

As a result, we have found it useful to identify and describe commercialization scenarios which navigate specific paths through the maze of laws and regulations. These scenarios are intended to capture the essence of the circumstances most often encountered during the technology transfer process at Los Alamos.

The two scenarios we describe can be thought of as the internal and the external model. The internal model addresses issues which arise when the inventor of a technology, and/or some of the inventor's key associates choose to spin-out with the technology-in other words, to leave Los Alamos and become employees of, or principals in, the venture seeking to commercialize the invention. The external model addresses the issues which arise when Los Alamos is approached by a potential licensee and the inventors of the technology do not choose to acquire any financial or other interest in the licensee (other than the normal royalty stream or equity position allowed by the University of California for all inventors).

$=$ In addition, in order to reduce to a manageable level the sizable collection of issues and choices that arise during technology transfer, we have tailored the scenarios to focus on the issues that have the largest impact on a small or new business that is attempting to acquire rights to and create products from a Los Alamos technology. The key areas of impact can be divided into six categories:

1. Conflict of Interest: The relationships that exist among UC employees, e.g., the Los Alamos inventors of a technology, and the company that desires to commercialize it.

2. Intellectual Property Rights: Licensee selection criteria, type of license desired, costs of acquiring a license and how those costs are paid.

3. Fairness of Opportunity: The requirement placed on Los Alamos to ensure that reasonable attempts have been made to broadly advertise the existence of a technology.

4. Technology Maturation: The work required to evolve a technology that exists only in the demonstration or prototype state into a sufficiently developed state to make the risk of transfer acceptable to the receptor. 
5. Legal Issues: Liabilities any licensee or participant in one of the joint project agreements must assume in order to conduct business with Los Alamos, e.g., product or patent infringement indemnification.

6. Bureaucratic Oversight: The approval processes required by the various government organizations that oversee operation of Los Alamos.

These categories are not always separable; they are interrelated in ways that are sometimes very complex. For example, conflict of interest, or even the appearance of conflict of interest, can affect the steps which must be taken to insure fairness of opportunity, actions required during the licensing process, the kinds of licenses which can be granted, and even which companies are allowed to compete for licenses.

Because of the special nature of the relationships required among the inventors of a technology and the startup company that attempts to commercialize it, and as a result of the strict interpretation of the conflict of interest policies of the DOE, the state of California, and the University of California, conflict of interest issues represent one of the most troublesome problem areas that any commercialization strategy must overcome. As a result, a substantial portion of any strategy for commercializing Los Alamos technologies will be determined by techniques for avoiding or for mitigating COI.

\subsubsection{Scenario A: Los Alamos Employee Spins-out with Technology}

This section describes a scenario based on the internal model wherein a Los Alamos inventor chooses to leave Los Alamos and assume a position with a vendor seeking to commercialize the inventor's technology.

There are numerous mechanisms available at Los Alamos which allow the inventor and key associates to become involved with the commercialization process while remaining employees of the University of California at Los Alamos. These include the CRADA, User Facility Agreement, Technical Consulting Agreements, among others. However, all of these agreements place limits on the amount of effort the inventor may devote to the joint effort. In addition, there may be little or no reward for, or even animosity directed towards the inventor for this kind of effort.

The scenario described in this section assumes that the inventor and/or key associates want to terminate their employment at Los Alamos and become employees of, or principals in, the new business which seeks to commercialize the inventions so that they can devote full time to the commercialization effort, and possibly to reap significant rewards if the venture is successful.

\subsubsection{A Three Stage Scenario}

The model technology commercialization process described in Section 6.3 of this document includes the following three formative stages (and, of course, the final stage in which the company becomes profitable):

1. Technology identification, screening, and selection.

2. Maturation and commercialization planning.

3. Business creation and spin-off.

Each of these stages contains a number of interrelated activities which must eventually converge into a set of deliverables or input to the following stage. Figures 1 through 3 (on the following pages) correspond closely with the three stages listed above. The boxes that populate each diagram 
correspond to the activities that occur during each stage. The approach we have taken for describing these activities is to associate each box or activity with a generic title or brief description and to illustrate interactions among the various activities with singly-or doubly-directed arrows.

The accompanying text describes the activities in some detail, lists the problem areas that may arise, and suggests some alternate strategies for managing the problems.

\subsubsection{Technology Identification, Screening, and Selection} Earlier sections of this report described the benefits that accrue to a company which routinely conducts or implements a uniform and aggressive training program in the management of intellectual property. The stage one activities illustrated in Figure 1 assume that such a program has been put in place so that it becomes natural for each new invention to be brought to the attention of the IPO.

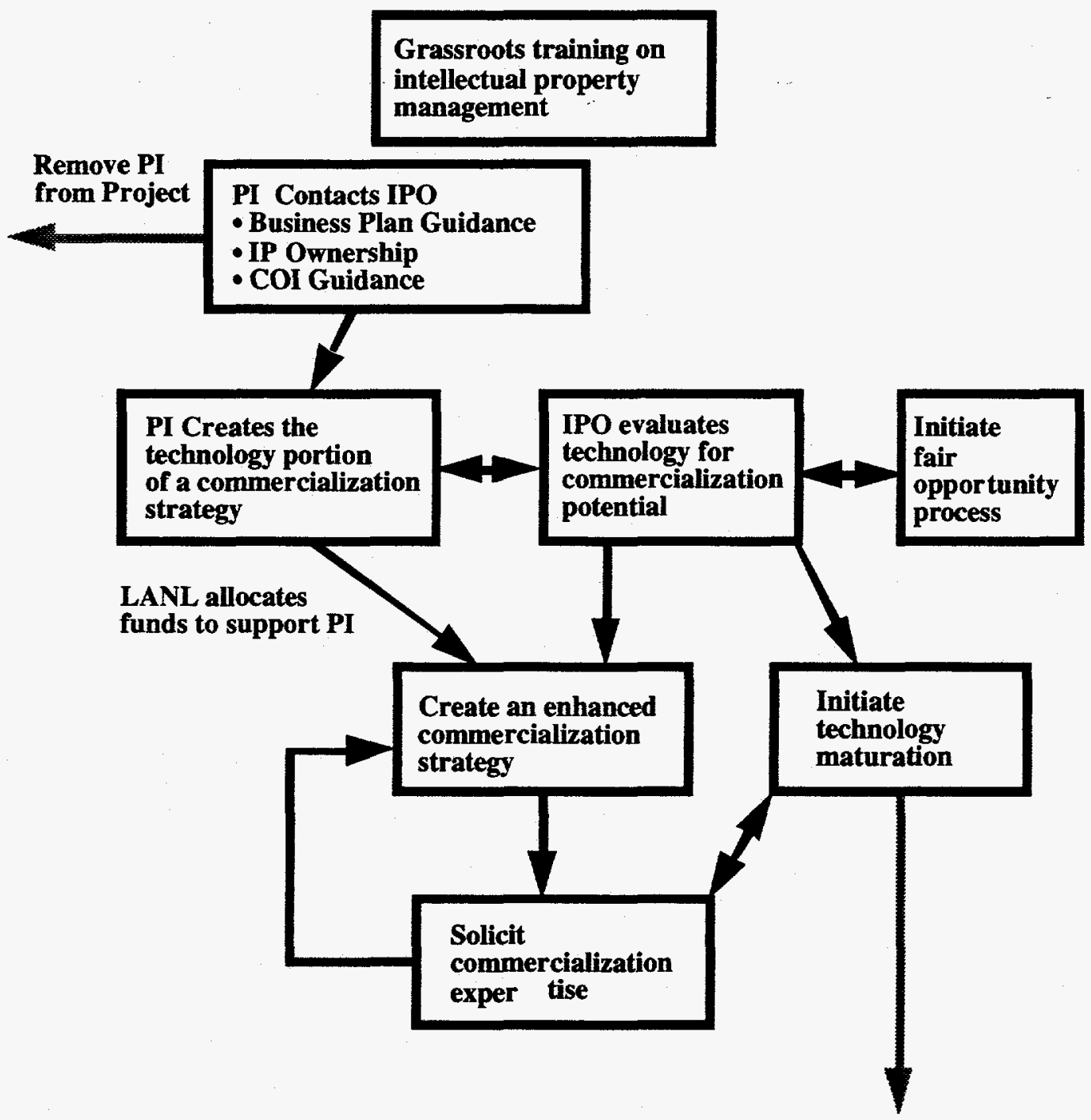

Figure 1. Stage One: Initial technology screening.

\section{PI Contacts IPO}

The first step in the screening process occurs when the inventor notifies the IPO of the invention and also of his/her intent to help form a spin-out company to commercialize the invention. Note 
that at this stage of the process, the inventor may not be prepared to announce the intent to spinout. Instead, this may be only one of the options being considered by the inventor. However, we assume the inventor notifies the IPO of this possibility so that any conflict of interest mitigation steps that need to be taken early are not postponed.

The immediate effects of such an announcement include removal of the inventor from the project that is developing the technology. In addition, project officials must be notified of the apparent conflict of interest. Note that these same actions are taken even if the inventor chooses to remain at Los Alamos but also elects to either work for (or hold a financial position in) the company that is attempting to commercialize the technology.

In some cases this may not be a serious problem if the inventor's key associates choose to remain at Los Alamos and are capable of continuing a successful technology maturation activity. In those cases where the technology has already been developed to an alpha or beta test state, removal of the inventor may also be a non-issue.

\begin{abstract}
Allocate PI Support Funds
In those cases where the inventor's participation in technology maturation is critical, the ability of a small new business to successfully commercialize the technology may be cast in doubt. The small business simply may not be able to afford the other alternatives, e.g., to hire the inventor and to continue the maturation either internally, or through one of the Los Alamos joint agreements. One solution to this problem might be the establishment of a separate DOE fund which supports the inventor during technology maturation (perhaps in exchange for equity in the new business). Figure 1 illustrates this form of funding which allows the inventor to continue to participate in establishing the commercialization strategy (including technology maturation).
\end{abstract}

\title{
Fairness of Opportunity
}

Since the PI will hold a position with the company that will be seeking a (possibly exclusive) license to the technology, the "fairness of opportunity process" now presents a dilemma. An aggressive advertising campaign can overcome any hint of conflict of interest. However, by drawing attention to the new businesses plans to commercialize the technology, the chances for success may be diminished since competitors of the new business will gain advanced warning and may even compete for license to the technology.

The gap between raw technology and commercial products can be quite large. If fairness of opportunity is established while the technology is in an early state of development, there will be less risk that the new businesses product plans can be deduced from their interest in the technology alone. Figure 1 illustrates this case where the existence of a technology is advertised early in the commercialization process and before technology maturation has begun.

Those who are planning to form a new company to license and commercialize the technology would like the intellectual property rights issues to be settled early as well. If a competition for licenses develops and the new venture is unable to obtain the kind of license required for a successful startup, they may choose to abandon further pursuit of the technology. If this happens, the inventor may be left in an awkward position. If the inventor is not able to resume a career at Los Alamos in a relatively seamless way, e.g., to resume a position as the project's principal investigator, the results are likely to produce a chilling effect on other potential Los Alamos entrepreneurs.

\section{Create Enhanced Commercialization Strategy}

Assessing the potential market size of any technology requires an analysis of what products or services the technology can be used to create or enhance. At this stage of the screening process, it may not be necessary to have in hand a comprehensive business plan, but some metrics are 
required to place at least a partial order on the collection of all potentially commercializable technologies since there are likely to be too many to commercialize simultaneously.

If the inventor is intent on spinning out with the invention(s), this screening and evaluation may only result in Los Alamos deciding whether it is profitable to pursue protection and licensing of the technology to the inventor's company (or some other) or whether they should abandon pursuit of the technology and leave any protection of the intellectual property to the discretion of the inventor.

Those technologies that receive high scores from the analysis of market potential may be further screened and prioritized. It is very likely that this secondary screening will require substantially more mature business plans than were used in the initial screening. The source of these business plans could be an organization internal to Los Alamos that is created and funded to produce them. Historically, this has not been a high-profile activity at Los Alamos, and as a result, the current personnel at Los Alamos may not be as well prepared to do this job as those from the financial community who are very skilled and well-versed in market issues.

The last activity listed on Figure 1 suggests that solicitation of expertise in commercialization planning is appropriate. This is very likely to include people who are not employed at Los Alamos. The source of funds which support the consultants or other participants during this part of the process is unclear and may require DOE or Los Alamos budgetary initiative.

\section{Initiate Technology Maturation}

In parallel with the secondary screening and planning processes, we have shown an activity box called "initiate technology maturation." In some real sense, the secondary screening and planning work could be considered part of technology maturation and thus must be funded separately from the programmatic work that produced the technology originally. Those technologies which are judged to be "dual benefit" provide an example of a borderline case. Los Alamos is justified (and possibly even required) to continue maturation and development of the technology. However, great care must be taken to guarantee that any development is motivated by programmatic needs and not solely as an attempt to enhance the chances for success of the commercial spinout (and the size of the resulting royalty stream that may accrue to the inventors).

This "apparent conflict of interest" seems to be inherent in the system that results from a combination of dual benefit concepts and the desire to move Los Alamos technologies into the private sector. We are not aware of any conflict of interest mitigation plans that are required for this case other than: 1) removal of the PI from the project if he/she plans to join the licensee, or 2) prohibition of the PI's participation in the license negotiation process otherwise.

\subsubsection{Maturation and Commercialization Planning}

The transition from the first stage, technology screening, to the second, maturation and planning, is not abrupt but has a certain "more of the same" flavor to it. However, there may be an abrupt change in the group of individuals who conduct the planning activities as stage two proceeds. This is because of the special skills, knowledge, and access to financiers and market analysts that will be required of those who conduct the detailed product definitions, manufacturing and marketing strategies, etc. In order to bring outsiders into the planning process so that their expertise can be exploited, it will likely be necessary to execute a Proprietary Information Agreement (PIA).

It is essential that the inventor, and possibly many of the key associates, participate in the planning process since they are the ones who can best answer questions such as: 1) which products can be made or enhanced with the technology, 2) what special manufacturing support may be required, 3) whether or not environmental issues may become paramount, and 4) what supporting components or products may be required and who the suppliers are. Current conflict of interest policies do not appear to preclude such participation, but the source of funding to support the work required may 
require some action by Los Alamos to tap discretionary funds or by DOE to create new sources of funds.

We note that the technology maturation process continues throughout the second stage described below (and in Figure 2) and do not mention it further except to note that information exchange between the commercialization planning processes and the maturation activities are almost certain to elevate the chances for a successful transfer of the technology into the commercial marketplace. The flow of information in one direction describes the results of alpha or beta tests (how well the system performs), manufacturing requirements, etc. The flow in the other direction may describe features that are found to be desirable or which add value to the commercial product expected to be produced.

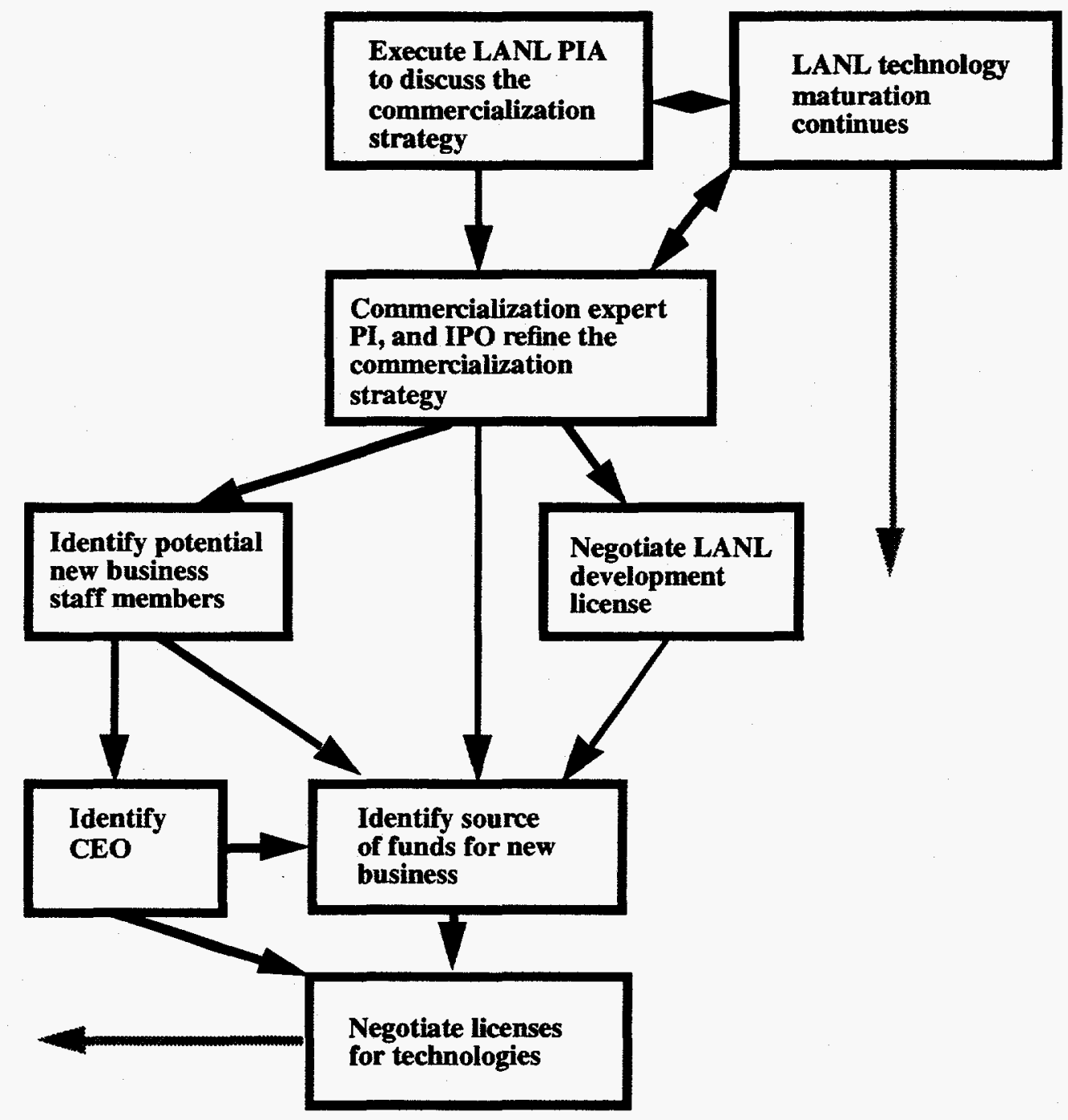

Figure 2. Stage Two: Commercialization planning.

Proprietary Information Exchange

Neither the staff at Los Alamos, nor the outside experts who are brought in as consultants, want to give away their valuable knowledge about emerging technologies or markets. The PIA provides a mechanism that allows frank and productive planning activities to proceed. In some cases that have been described to us, outsiders have been unwilling to accept the exact wording of and pro- 
tection afforded by the Los Alamos PIA. When this happens, lengthy delays can result because of the negotiations required between the legal staffs of the two organizations.

In some cases, DOE or Los Alamos agreements have been modularized so that alternate choices for wording exist. This approach can streamline the execution of any agreement whenever the two parties can find agreeable wording among one of the choices. The current Los Alamos PIA is not in a modular format. If history (or future experience) suggests that the PIA execution process is unacceptably long, a modular form of the PIA could provide some resolution.

\title{
Commercialization Planning
}

At this stage of planning, the foundations are being laid for the creation of a new enterprise. This includes not only a definition of the new business' intended markets and products, but the development of sales and support plans, facility requirements, a determination of the types and numbers of personnel that will be required, and the careful estimates of schedules and cash flows, among other topics. Those who have started successful businesses are naturally more likely to produce better plans and estimates than those who have not. As a result, an important component of this activity is the identification of individuals who are skilled in the targeted technologies and markets as well as experienced in running a business. This includes not only the CEO, but the other key officers as well.

A second activity required during the commercialization planning stage is the location of possible sources of funds to provide the capital needed to nurture the business through the very risky early phases. It is very likely that the management team will have to be a part of these negotiations. Funding sources will also be concerned about intellectual property rights. It is common practice for financiers to insist that the new business have some advantage in intellectual property over and above what the potential competition has, that is, an exclusive license to a technology (possibly restricted to a field of use).

This presents a potentially serious problem for the scenario we are describing since the inventor has chosen to join the company seeking license to the technology. The level of seriousness of the problem depends on whether the inventor is a principal in or just an employee of the company and whether the company is requesting an exclusive license or some more limited rights.

\begin{abstract}
Negotiation of Licenses
$=$ If the inventor is a principal in the company and an exclusive license is requested, then a written justification of the fairness of opportunity procedures must be presented to DOE for approval. Prudent business practice suggests that this action would have been taken very early in the stage one technology screening process, i.e., as soon as the inventor announced the possibility of becoming a principal in the venture. If the technology is software, a modification to the current "Exclusive Computer Software Agreement" will have to be negotiated since the current form of the agreement requires the potential licensee to assert that no director, officer, or other principal of the licensee has been a University of California employee for the past two years. ${ }^{36}$
\end{abstract}

If the inventor is an employee of the company, or if a non-exclusive license is being requested, the usual license negotiation procedures can be used; however, the inventor should have removed himself/herself from the technology project very early-on and should have notified the project's officials of the apparent conflict of interest. In addition, the inventor is precluded from entering into any license negotiations while still a Los Alamos employee.

Serious problems can arise for the inventor at this stage of the scenario. Two troublesome aspects are that the inventor's career at Los Alamos has been placed in limbo (or possibly the inventor is now unemployed) and the licensing process can extend over a large interval of time. If the DOE

36 Exclusive Computer Software Agreement, Clause 28.5. 
(or Los Alamos) has instituted a mechanism that allows the inventor to continue to contribute towards technology maturation during licensing negotiations, or if the conflict of interest and fairness-of-opportunities have been dealt with quickly and early in the process, then the risk to the inventor can be reduced.

Even in the best of cases there is likely to be a gap between the moment the inventor leaves Los Alamos and the moment he/she begins to receive a commensurate salary from the new venture, since at this stage, the business has not yet been formed, and may not have funds to support the inventor during the transition phase. This kind of risk is not unusual.

A final aspect of the Los Alamos licensing policy (which is not peculiar to either of the two scenarios described here) is that part of the licensing policy which generally retains a non-exclusive license to practice or have practiced any technology that the government licenses. In some cases (e.g., the Exclusive Software License), the licensee is required to make available to the government (via the UC, on demand) all enhancements and derivations to the original technology. This can place the licensee's entire product line that is based on the licensed software at the government's disposal. While this policy can have a significant impact on the size of the market the new venture may expect, the most serious consequence may be the reduction in comfort level it causes for potential investors in the company.

\section{Miscellaneous}

A number of other issues arise in the negotiations that occur during the licensing process which are not directly related to this scenario, but which can undermine the success potential of a small new venture whose success is based on commercialization of Los Alamos technologies. The DOE/UC indemnification policies are one example of this. The small business is not likely to have the resources to provide any significant indemnification even though they may have signed a legal contract to do so. But the requirement that businesses sign such agreements as part of the licensing process, or as part of other joint project agreements, may provide cause to dissuade investors from backing the new company.

Many of the technologies developed at Los Alamos include a software component. Policies and procedures for dealing with copyrights at Los Alamos are not nearly as well developed as those for dealing with patented technologies. This lack of firm policy usually translates into lengthy delays that occur when the DOE must be included in the licensing process.

\subsubsection{Business Creation and Spin-Off}

Some of the activities that occur during stages one and two include the possibility of government funds being applied to commercialization activities, e.g., technology maturation and commercial planning. The beginning of stage three marks the end of government support for any of those activities (see Figure 3 on the next page). All further commercially oriented work is funded by external sources. The new company may still continue a close relationship with Los Alamos for a variety of reasons, especially if the technology falls in the dual-benefit category, then Los Alamos may wish to purchase products or services from the new company. Or the company may wish to execute one or more of the agreements which allow cooperation between Los Alamos and private enterprises.

In the first case (in which Los Alamos attempts to purchase products or services from the company), Los Alamos purchasing regulations include a thorough analysis and justification procedure that guarantees the purchase to be in the best interest of the government and is free from conflict of interest. The requirement for a justification results from the inventor's status as either an employee or principal of the supplier who formerly worked at Los Alamos on related technologies. ${ }^{37}$

37 "University of California DOE National Lab COI Requirement," Draft, October 13, 1993, Section B $(3,4,5)$. 


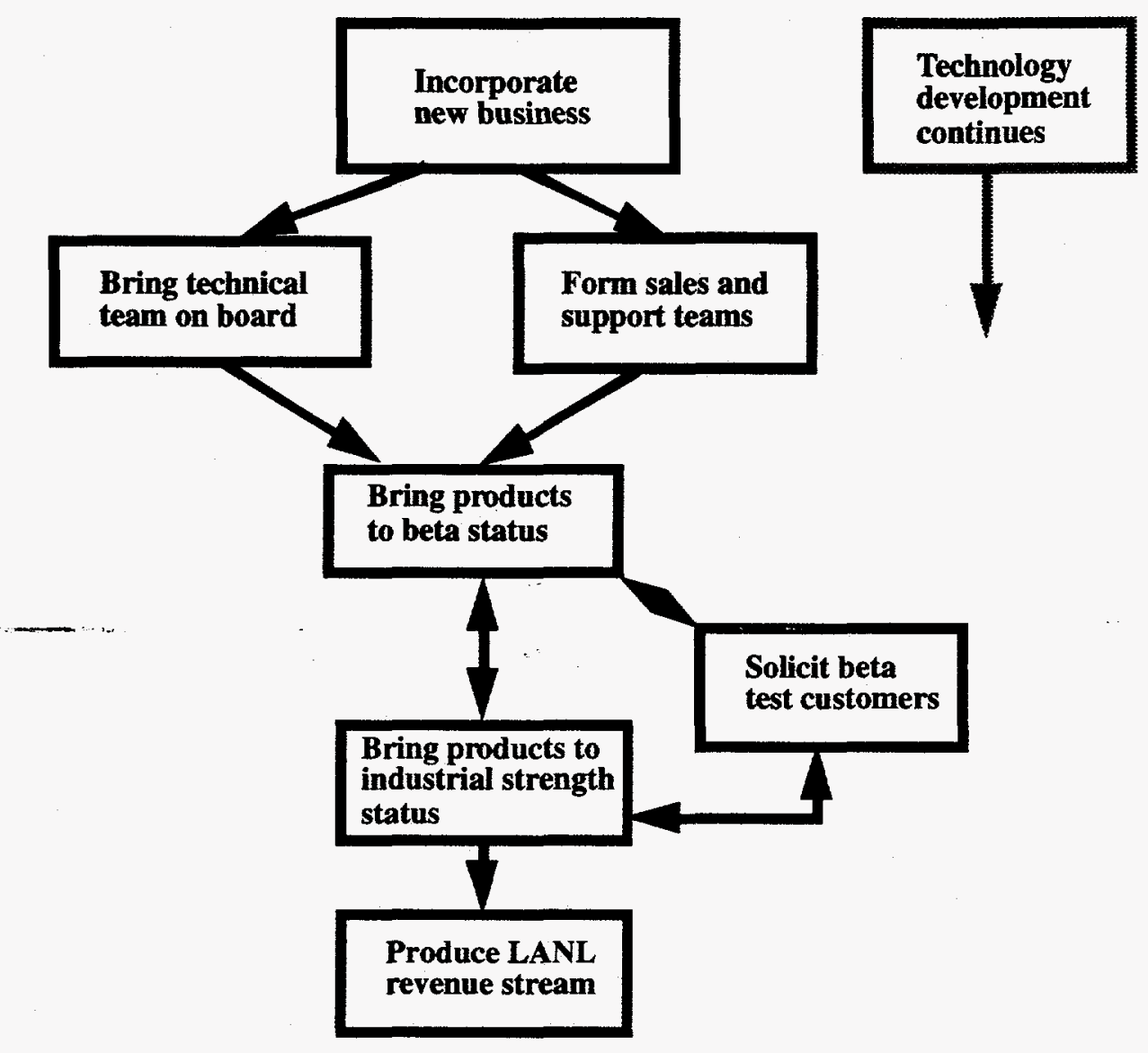

Figure 3. Stage Three: Create new venture.

In the second case, in which the new company attempts to execute one of the joint project agreements with Los Alamos, some problems can arise. For example, the current version of the Technical Consulting Services Agreement requires the commercial participant to certify that no former Los Alamos employees serve as principals or directors in the company. The approval process for waiving this clause is not specified; however, it is likely that DOE approval is required. Fully reimbursable agreements like the CRADA, User Facility Agreement, or DOE Work For NonFederal Partners Agreement are not explicitly bound by this restriction.

Since the remainder of the activities illustrated for phase three are conducted externally to the Los Alamos management structure, discussion of them will be postponed until Section 6.3.

\subsubsection{Scenario B: Entrepreneur from Outside Los Alamos \\ Laboratory Spins-out a Los Alamos Technology}

This section describes a scenario based on an external model; an entrepreneur from outside Los Alamos National Laboratory identifies a technology to spin out into a new business.

This model makes a set of assumptions regarding the status of the technology, and the resources and qualifications of the entrepreneur. These assumptions were created to demonstrate that under certain circumstances, it could be possible to successfully spin-out a technology from Los Alamos and start up a small company. Success of the venture means that Los Alamos, the entrepreneur, and the New Mexico community benefit from the endeavor and that all participants are satisfied with the process from technology identification to spin out. 


\subsubsection{Scenario Assumptions}

The Principal Investigator Receives Only Royalties for the Technology being Transferred By receiving royalties only, the principal investigator will avoid any problems based on conflict of interest or the appearance of conflict of interest. Receiving equity as compensation is not a common technology transfer practice at Los Alamos, and could appear to create a conflict of interest. The principal investigator would have even more problems with conflict of interest if he or she were to become a principal in the company. Therefore, it is assumed that only royalties are received as compensation.

The Technology Chosen by the Entrepreneur was Advertised in the Public Domain

The entrepreneur will avoid lengthy fairness of opportunity requirements by finding and exploiting technologies that were advertised in the public domain. If the technology is in the public domain, then it will not appear that the entrepreneur had some kind of unfair access to the technology. If the entrepreneur is attempting to obtain an exclusive license, then this requirement is even more important, because fairness of opportunity requirements are triggered by requests for exclusive licenses.

\section{Capital Considerations: The Entrepreneur does not have Significant Capital Resources}

This is assumed because, in all likelihood, most entrepreneurs will not have large amounts of capital available. This assumption has a number of implications. First, it implies that Los Alamos must be sensitive to the this situation and strive to make sure Los Alamos requirements do not exacerbate the lack of capital problem by creating extra requirements or significantly stalling the commercialization process. By being sensitive to these characteristics of the enterprise, Los Alamos can help ensure that lack of capital does not prevent a well-conceived venture from succeeding. Lack of capital has some specific implications for the Laboratory as well. For example, the entrepreneur will need funds to help develop the commercialization plan and pay for the licenses. Los Alamos can help in this area by providing some support through IPO staff to at least make comments on the business plan. The licensing officer can work out some alternative payment plan for the license fees. Licensing fees can be reduced or made payable over a certain period of time to avoid taking valuable cash resources away from the entrepreneur.

\section{The Entrepreneur does not have the Resources to Mature the Technology}

The success of the business plan will depend in part on the state of the technology itself. If the technology is not mature, which is more than likely with Los Alamos technologies, then it must be matured and tested so it may be incorporated into a product. The state of the technology in terms of development for commercialization will depend on the nature of the technology itself, and on the commercial idea of the entrepreneur. The difficulty the entrepreneur faces is in obtaining funding to commercialize the technology. However, in order to reflect the reality of the commercialization process, this scenario will assume that the entrepreneur does not have sufficient maturation funds.

A critical criteria for creating a successful business plan-one that will be funded and gain the necessary licensing approval-is that the product concept must be defined along with that product's potential markets. Clearly, in order to define a product and its market potential, the entrepreneur must have significant expertise in that industry segment and/or access to that kind of expertise. Los Alamos does not typically have this kind of information and expertise and cannot necessarily help the entrepreneur find this information. The scenario assumes the entrepreneur is a strong candidate with a combination of personal experience and characteristics necessary to make the endeavor successful.

The Technology the Entrepreneur wishes to License is Fully Protected either by Patent or Copyright

If the technology were not yet protected through these mechanism, then the entrepreneurial process would be prolonged and the risk that information would be disclosed could be higher. Although it is likely, in some circumstances, that the entrepreneur's interest may instigate patenting activities 
for some technologies, it is assumed that intellectual property is available for commercialization and fully protected.

The New Business will Fully Accept the Product Liability Indemnification Clause and Substantial U.S. Manufacturing Clauses in the License to be Negotiated

In order to facilitate the licensing process, the new business must accept these clauses even if it is not necessarily the best business decision. This is assumed because the labs are not currently at liberty to negotiate those clauses as they are required by the University of California prime contract.

\subsubsection{Commercialization Stages}

The model follows a four-step outline. Each step of the process includes a sub-set of activities that are listed below and described in Sections 6.2.2.3 through 6.2.2.5 (see Figure 4).

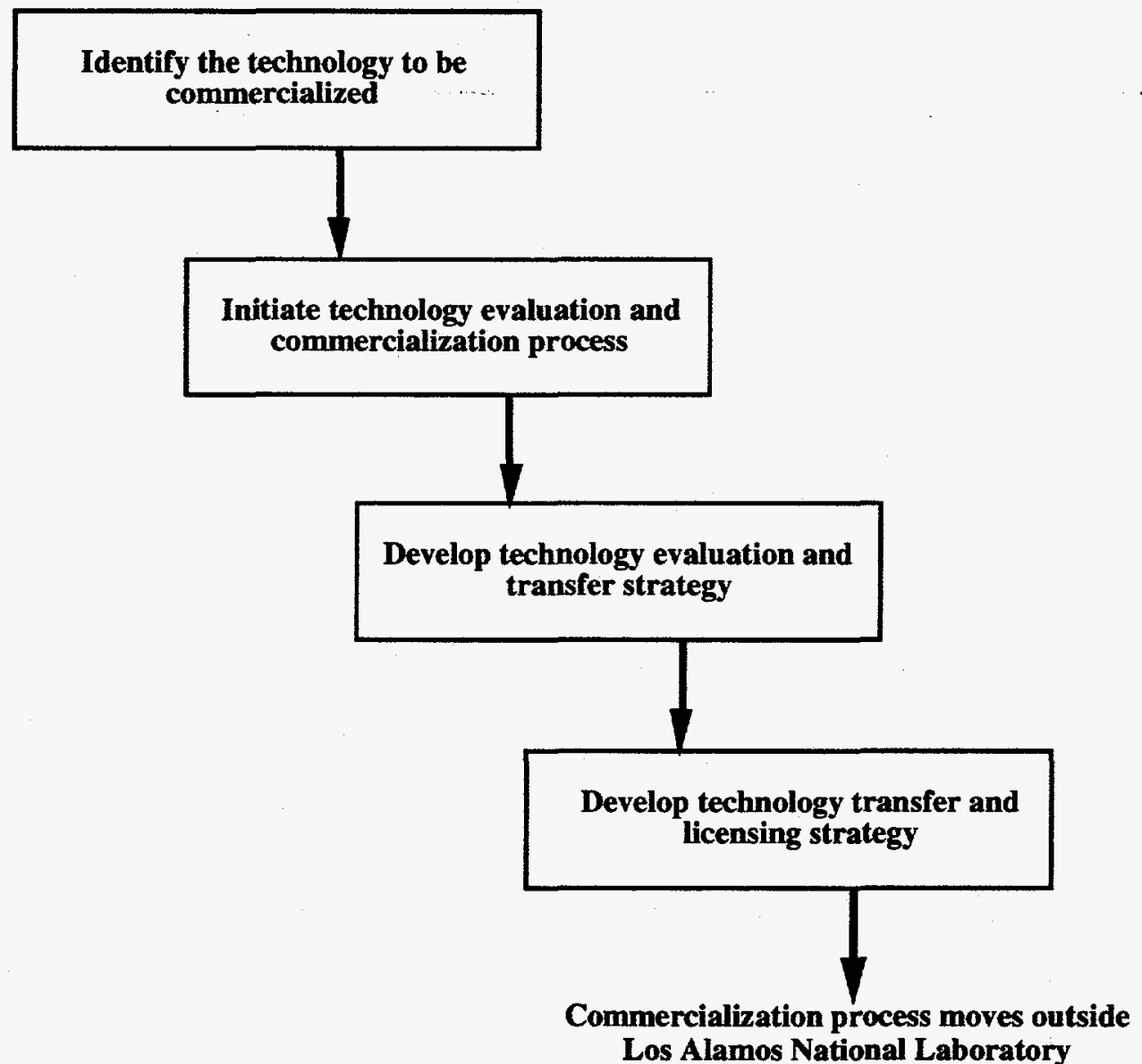

Figure 4. Overview of the commercialization process at Los Alamos National Laboratory.

1. Identify the technology to be commercialized. The first step is that the entrepreneur must identify a technology that has commercialization potential.

2. The entrepreneur begins the technology evaluation and commercialization process. This stage involves considerable Los Alamos involvement and its success depends in part on how quickly these activities can be accomplished. 
3. The entrepreneur develops the technology evaluation and transfer strategy. The activities in this area depend considerably on the nature of the technology itself. Depending on the state of the maturity, funding available, intellectual property status, the entrepreneur and the IPO can determine the best means for moving the technology out of Los Alamos and into the company.

4. The entrepreneur works with Los Alamos to negotiate and finalize all formal arrangements for maturing and licensing the technology. Once these major stages are accomplished, the Laboratory is no longer directly involved in creating and driving the commercialization process. The entrepreneur has the tools at this point to turn the technology into a viable business. Success will depend on the quality of the transfer and the abilities of the management team in the new business.

\subsubsection{Technology Identification, Screening, and Selection and Initial Commercialization Planning}

The early stages of commercialization by the outside entrepreneur begin with the initial identification of the technology (see Figure 5). After identification takes place, the entrepreneur works with or screens the technology to begin setting the framework to actually move into a commercialization process. These activities will cover conversations with the principal investigator and the IPO. The discussions will range from technical feasibility of the idea, to how to test and implement a strategy.

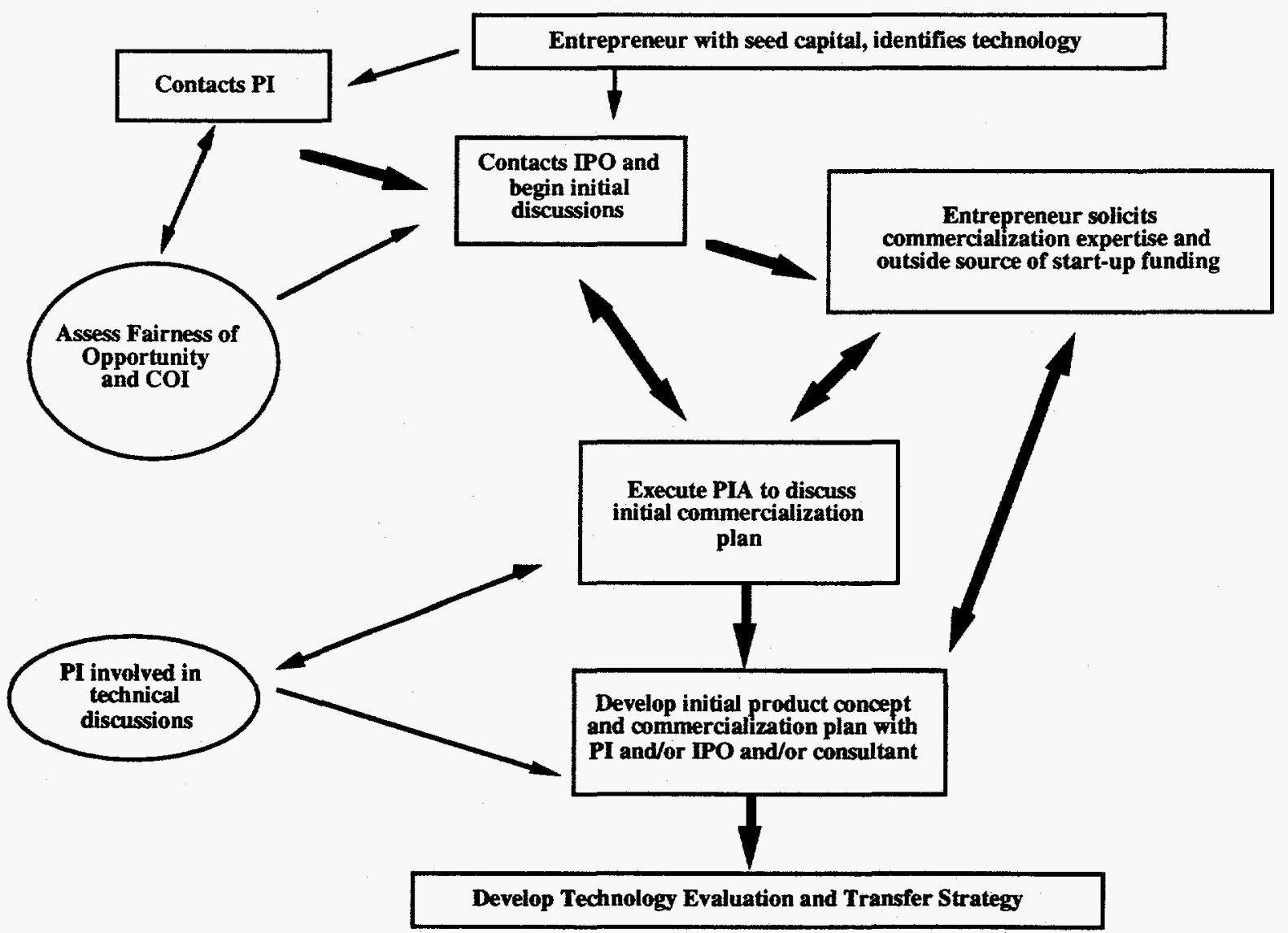

Figure 5. Initial technology selection and commercialization process. 
The Final Report of Los Alamos Contract No. 4790L0013-9Z, Volume 1

\section{Technology Identification}

Identification of the technology by the entrepreneur can occur through a variety of mechanisms. Seminars, technical publications, discussions, and technology searches can all provide the entrepreneur with the means to become familiar with Los Alamos' technologies. Los Alamos is beginning to understand the need to facilitate technology searches and access through database search capabilities. Although some access is available, the program has not yet been fully developed. In fact, the information to be entered into the database to make it suitable for identifying and selecting technologies with superior commercial potential has not yet been specified nor has any substantial collection of the necessary information been completed. In order to avoid fairness of access problems, an entrepreneur will be in a better position if technology access can be done through a public domain means. If the entrepreneur can show that the technology or technologies were discovered through public domain means, then the entire commercialization process will not be unduly prolonged by a lengthy fairness of opportunity investigation.

\section{Technology Screening}

Once the technology is identified, the entrepreneur will contact the principal investigator and/or the IPO office. It is more likely the entrepreneur will want to discuss the technology with the principal investigator at first as part of the screening process. These discussions will further increase the entrepreneur's understanding of the technology, explore the feasibility of the commercial idea, and determine in part whether the technology can be feasibly commercialized via the entrepreneur's idea. Because the commercial idea itself could be considered proprietary, the entrepreneur will want to establish a proprietary information agreement to protect any information revealed during those interactions.

\section{Allocate PI Support Funds}

It is possible that the entrepreneur will need a certain amount of participation from the PI to complete the initial technology screening process. Los Alamos does not currently have a fund to support PI commercialization activities. Although the entrepreneur may be able to use a technology transfer mechanism such as a CRADA, a Funds-in Agreement or a Technical Consulting Services agreement, it is unlikely at this stage, that the venture will have resources for these activities.

\section{Faimess of Opportunity}

Once the entrepreneur has contacted the PI, and subsequently the IPO has become involved in the process, fairness of opportunity activities will begin. In essence, the IPO will begin to look at the

* technology identified by the entrepreneur to decide whether it has been sufficiently available to the public to guarantee that fair access has occurred.

\section{Conflict of Interest}

During the initial conversations, the IPO will advise the entrepreneur about conflict of interest, how it arises and whether it is a problem during that particular commercialization idea. Typically, if the entrepreneur has not been an employee of Los Alamos in the last two years, the venture does not involve a Los Alamos employee, and there will be no apparent conflict of interest.

\section{Initial Commercialization Process}

While the entrepreneur is going through the technology screening process, simultaneous commercialization activities outside Los Alamos will be pursued. The entrepreneur must solicit business expertise and begin to develop a plan for soliciting funding of the venture. Because obtaining funding and investment depend on the quality of the business plan, and the business plan is not yet developed, these activities will only be initiated at this point. Formal business plan submission will not occur until the technology commercialization and productization plans are developed later on in the process.

If the entrepreneur has been successful in generating some initial funding at this early stage, it is likely the funding source will be involved in this initial commercialization process. For example, if 
the entrepreneur has found some support within a venture capital organization, that organization may provide some consulting services during the commercialization stage to contribute to these initial discussions and processes.

\subsubsection{Develop Technology Evaluation and Transfer Strategy}

This part of the process includes two separate activities: the Technology Evaluation Strategy and the Technology Transfer and Licensing Strategy which will be further outlined below (see Figure $6)$.

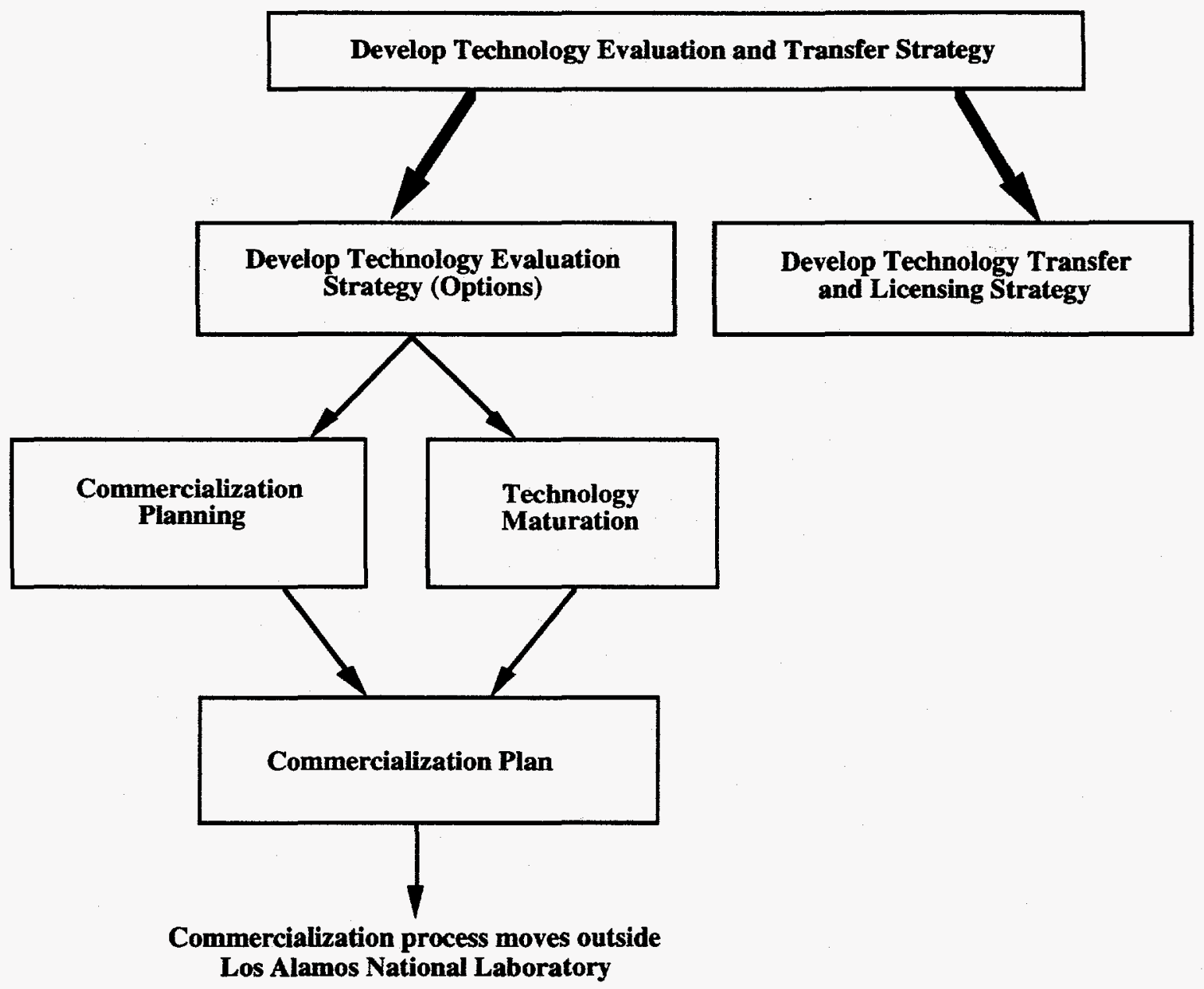

Figure 6. Develop technology evaluation and transfer strategy.

Technology Evaluation Options (see Figure 7 on the next page)

The technology evaluation stage can be conducted through a number of formal mechanisms that Los Alamos has developed to allow an entrepreneur to work with a technology. By working with a technology, an entrepreneur can better understand its technical components and evaluate whether the commercial idea based on that technology is technically feasible. For example, the entrepreneur may wish to obtain a User Facility Agreement to do some initial testing of the technology using Los Alamos' facilities and equipment. Another mechanism for exploring commercial potential is the development license agreement. The Laboratory also has industrial staff member agreements which allow an individual from industry to come into Los Alamos as a staff member and work on a project for an extended period of time. A detailed discussion of these mechanisms can be found in Appendix $E$ of this document. 


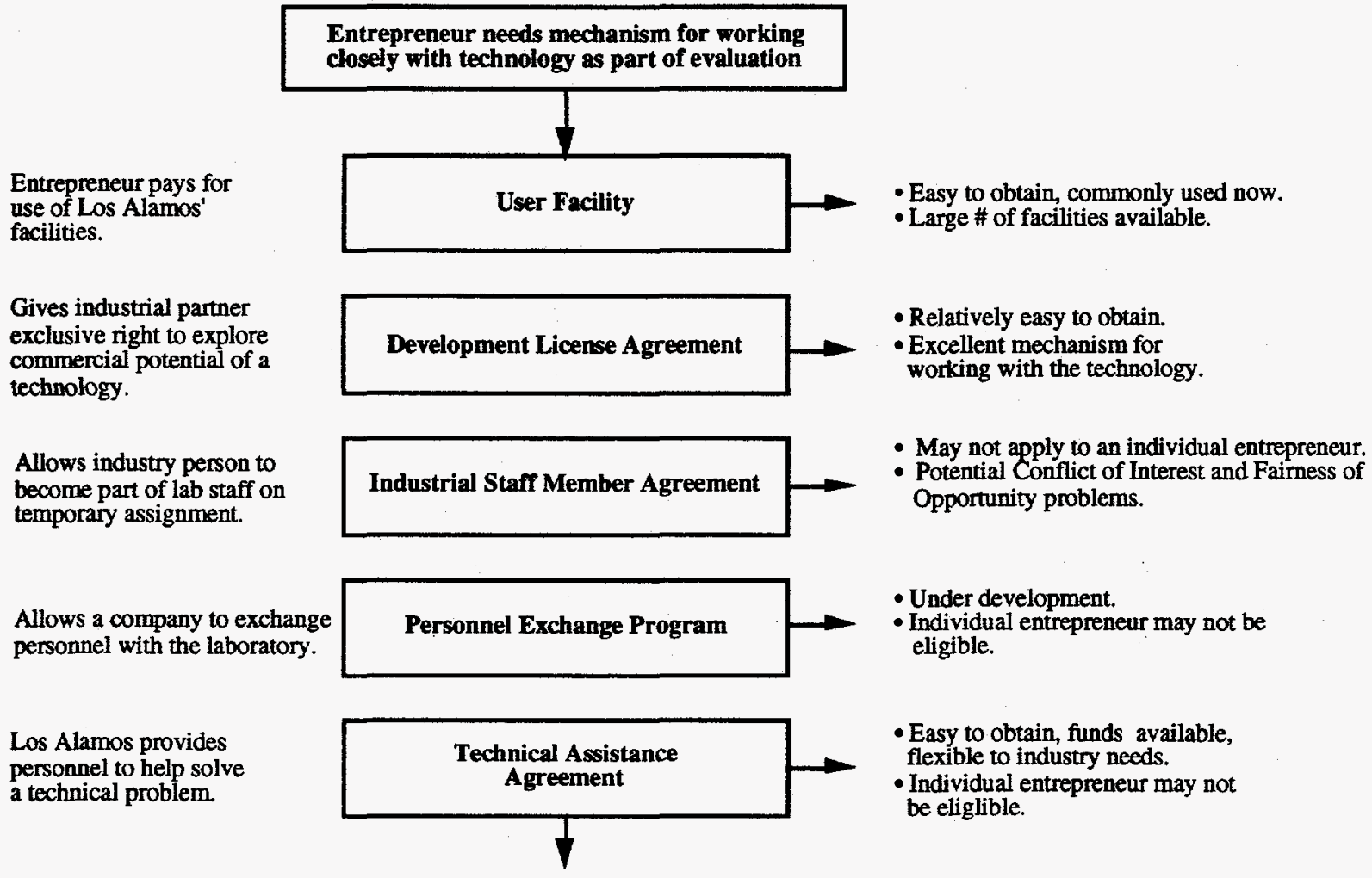

Figure 7. Technology evaluation options.

Commercialization Planning

At this point, the entrepreneur will begin establishing the foundations of the new business. This activity will include the definition and size of potential markets and products, manufacturing and facilities requirements, development of sales and support plans, recruiting of the major management team, and obtaining financial support of the enterprise. The management team search will identify individuals who are skilled in the targeted technologies and markets and who have the business expertise for handling the operations of the venture.

Securing the financing to launch the venture is a critical element of this process. Finding the capital to cover the very risky early stages of business creation will determine the potential success of the enterprise. Potential investors will be very concerned about intellectual property, because the intellectual property owned by the new business is one of its only sources of investable value. The timing of these activities is very critical and difficult to manage. In order to obtain the licenses needed to bolster the value of the new business, it is important to have the capital backing to make the business plan a strong candidate for obtaining a license. The licensing office will only grant licenses to those plans that have the greatest chance of success in turning the technology into a viable product or business.

Clearly, sufficient financing is a defining factor of future success. This dilemma must be balanced carefully. While working with capital investors, the entrepreneur must also be undertaking the intellectual property negotiations necessary to secure an exclusive license. In essence the entrepreneur must continually work to reduce the perception of risk for both the investors and for the licensing office at Los Alamos. Ultimately the licensing office will likely grant the exclusive license once it seems like sufficient financial backing will occur. At the same time, the financial community will make the investments once the chances of obtaining the license appear very high. 
The initial commercialization planning process ends when a technology has been selected for commercialization. The product of this stage will be an executed proprietary information agreement, and an initial product concept and commercialization plan.

\section{Technology Maturation}

Technology maturation comprises a continuum of technically focused activities that seek to bring a technology from an applied research state to an embodiment which allows the technology to be presented as a marketable product. Maturation actually begins with a commercial assessment of the technology followed by a product concept definition. The viability of the product concept is evaluated through a series of prototype design, build, and test activities. When pursued to completion, maturation results in a demonstrable product complete with performance specifications and manufacturing plans. The results of both the commercialization planning and technology maturation phases will be incorporated into a commercialization plan complete with advanced market research and prototypical product specifications.

By necessity, technology maturation is commercially focused and therefore may have objectives that are not compatible with the programmatic mission that funded the original technology development. If maturation objectives to commercialize a technology are not programmatically required, a new funding source must be identified.

Once the initial maturation/testing phase has been completed, and the product concept sufficiently proven valid, then a source of funding for more costly and in-depth maturation must be found and the staff necessary for conducting the activities must be assigned to the project. Maturation activities in this more advanced stage will include developing product specifications and building prototypes. The result of both the commercialization planning and technology maturation phases will be a complete commercialization plan including advanced market research using some product prototypes, and capitalized and staffed business.

\subsubsection{Technology Transfer and Licensing Strategy}

The technology transfer and licensing strategy development is conducted in parallel with the commercialization planning and the technology maturation (see Figure 8 on the next page). The entrepreneur must formalize the mechanisms for obtaining the intellectual property and technical support needed from Los Alamos to make sure the commercialization idea can be realized. A number of mechanisms for transferring technology, conducting technical projects, and securing intellectual property rights exist at Los Alamos. New businesses can use a number of these mechanisms in a variety of combinations to bring a technology from its research stage to being the product of a business. The strategy adopted will depend on a number of factors that most likely hinge on the technology selected and the product concept envisioned.

\section{Negotiate the Licenses}

As described above, obtaining the license for the selected technology is crucial to creating a business. Unfortunately, the license negotiating process can be long and complex. Los Alamos has produced an outline of its licensing processes which details the sequence of events and activities and the usual time frame in which they occur. The flowcharts identify approximately 48 steps in the process and a total elapsed time of 16 to 123 weeks or more to complete a license.

The mechanisms available for obtaining licensing rights are:

- Development License Agreement

- Non-exclusive License Agreement

- Exclusive or Field of Use License

- Exclusive Software License 


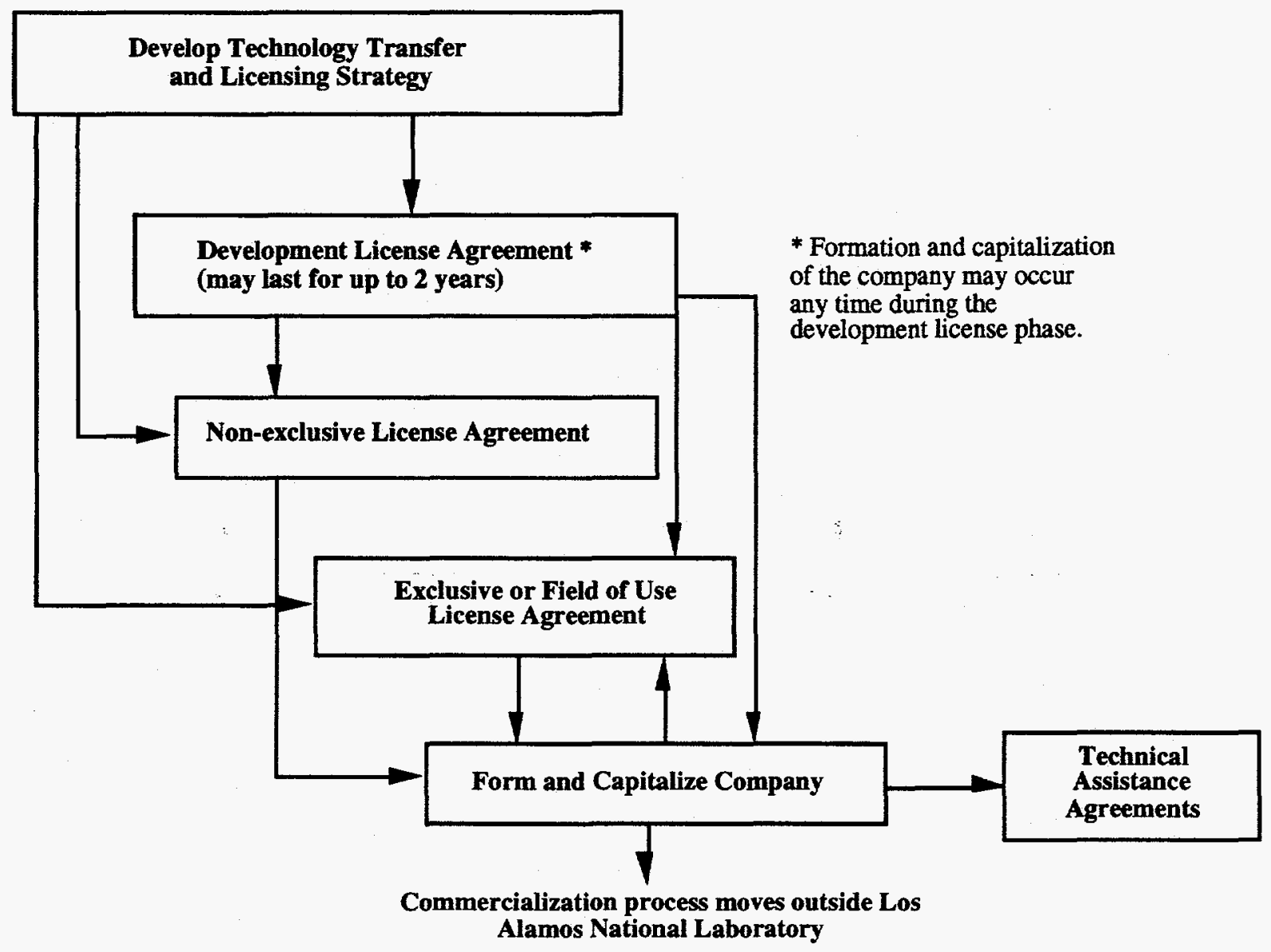

Figure 8. Develop technology transfer and licensing strategy.

Depending on the status of the technology, an entrepreneur may decide to first try to obtain a development license as a means to explore the commercial potential of the license. From the development license the entrepreneur may decide to move into negotiations for an exclusive or a non-exclusive license. A more detailed discussion of the advantages and disadvantages of the different licenses is contained in Appendix E.4.

Once the above stages have been completed, the business start-up process moves outside Los Alamos. The start-up will continue to interact with Los Alamos, but will no longer be in a precommercialization mode. Instead, the start-up will do business with Los Alamos like any small business. For future technical needs, the start-up will use technical assistance agreements and other mechanisms designed to support small businesses and assure successful technology transfer.

\subsubsection{Summary of Contractual and Policy Support for}

\section{Commercialization at Los Alamos National Laboratory}

The two scenarios presented above identify the contractual and policy instruments and mechanisms that either support or impede the commercialization of Los Alamos' technologies. These scenarios demonstrate that Los Alamos' contractual arrangements are sufficient to allow commercialization of their technologies to proceed. A number of issues which result from the implementation of statute and policy have been identified because they tend to increase the threshold of risk as perceived by potential investors in the commercialization process at Los Alamos. Some minor enhancements to existing policy have been mentioned because they could provide a way of lowering risk to both in- 
vestors and technical staff members alike, e.g., a more robust Entrepreneurial Leave policy and the acceptance of equity as payment for intellectual property.

However, the largest impediments to the commercialization of technologies from Los Alamos do not appear to originate from their contractual arrangements, but rather from the existing culture and practice within Los Alamos and from missing infrastructure elements external to Los Alamos. As a result, the degree to which their existing contractual arrangements can support a robust and active commercialization process have not yet been tested.

\subsection{A Model Commercialization Process}

Any process which has as its goal the commercialization of technologies from a large government installation such as the Los Alamos National Laboratory will probably include the activities described in the following sections. Naturally, variations in content and emphasis will occur since each attempt at commercialization of a technology developed at public expense represents a unique exercise that must be tailored to fit many regulations and circumstances.

The three phases of the model commercialization process described in this subsection correspond to: 1) finding, cataloguing and filtering candidate technologies; 2) mapping out a commercialization strategy for some subset of the technologies; and 3) creating or spinning out the commercial organizations that will bring the technologies to market.

Los Alamos must take an aggressive leading role in the first two of these activities as will be seen from the detailed breakout of the components of the activities described below. The third phase will become the primary responsibility of those individuals that oversee and manage the establishment of the new venture as well as those individuals and organizations that fund and staff it. Los Alamos can play an important role even in the third phase if the target technologies fall under the dual-benefit category.

\subsubsection{Technology Screening and Selection}

The first phase of the commercialization process focuses on finding, analyzing, documenting, and extrapolating to products those technologies that are most promising. There are three key outputs that result from the first phase activities. These are:

1. A demonstrated and refined methodology for collecting, organizing and analyzing information to assess the commercial viability of technologies developed at Los Alamos, including the types and sources of information useful in analyzing commercial potential,

2. An evaluation and written report on the estimated commercial potential of the technologies reviewed in the initial screening process, and

3. A written preliminary commercialization strategy for the selected subset of promising technologies analyzed in a second round of screening and analysis.

Appendix D contains a detailed outline of the individual activities that occur during the screening phase. In the sections below we provide a brief overview of those activities.

\subsubsection{Producing the First Output}

The first activity provides a mechanism for deciding which technologies offer the best opportunities for commercial success. Just as important, it provides a uniform approach to technology assessment which can assist in the laboratory-wide management and protection of intellectual 
property, and allow assessments made by individuals distributed throughout Los Alamos to be easily assimilated into the IPO database of available technologies.

There are several processes which collectively allow the first output to be produced. First, some mechanism must be found to seek out the candidate technologies. Since Los Alamos does not require a centralized approach to documenting intellectual property, this process will have to extend to the division level if all potential intellectual property is to be captured.

Next, a rating system must be developed which allows both qualitative and quantitative descriptions of the technology to be mapped into a form that allows comparisons or orderings of the technology's commercialization potential to be made.

Some of the factors which are included in the evaluations can best be answered by Los Alamos technologists. For example, the time and effort that will be required to bring the technology to a sufficiently mature state that transfers into the private sector is practical. Other issues which relate to market potential of the technology, analysis of customer needs, competitive forces, investment capital required, cost to manufacture/distribute/service, possible margins, etc. may require the involvement of business experts brought in as consultants to the process.

\subsubsection{Application of Methodology}

The methodology developed in the first activity of this phase must be applied to selected technologies to produce the information required to determine whether a promising commercialization strategy for the technology exists. There will be a significant variation in the level of detail of the evaluations produced under this activity. Some technologies may exist in a much more mature state of development and be closely related to large existing markets. A thorough evaluation of these technologies may be possible and/or desirable. Other niche technologies, or those which are too premature to evaluate, may be given only a cursory analysis and put on hold until more substantive results are available.

A written report which includes not only the results of the evaluation, but a rationale for the decisions that were made during the course of the evaluation provides an important record that can be revisited for a new evaluation when market conditions change, or as the state of the subject technology matures. Producing the written evaluations will probably be a joint activity that involves both Los Alamos personnel and external consultants. The reasons this may be necessary

are that extracting the information required to produce a viable commercialization strategy can be time consuming and will require skills that extend beyond the technical expertise that is abundant at Los Alamos. Once the reports are produced, they become input to the third activity contained in phase one.

\subsubsection{Producing Commercialization Strategies}

The third activity identifies a small set of technologies that appear very promising as commercialization candidates. Survivors to this stage of the screening process are expected to have a probability of commercialization potential that is high enough to justify further significant investment of government funds and effort.

History confirms that there are never enough resources available at Los Alamos to produce detailed commercialization strategies for all potentially commercializable technologies. Great care will have to be exercised in choosing which ones to pursue so that scarce resources can be applied wisely. Some small subset of promising technologies will be selected for further analysis based on the written evaluations that have been produced. A significantly more extensive market analysis and product definition will be conducted to close out the phase one technology screening process. 


\subsubsection{Technology Maturation}

Technology maturation includes two complementary facets. One of these focuses on the state of the technology and has as its goal evolving that state closer to product status in order to reduce risk to the receptor or licensee. The other facet focuses on business issues, i.e., continues to refine market and competitive data, establish relationships with potential customers, and determine staffing requirements. Each of these facets is discussed in detail in the following sections.

\subsubsection{Technology Evolution}

For some technologies, it may be necessary to produce engineering prototypes that have been developed to the alpha, or even beta, status. In addition to the technology testing that occurs internally to Los Alamos, it may be necessary also to involve selected external sites as a way of gathering potential customer input and to ensure that the technology can function well outside the Los Alamos environment where it was developed.

Several product-oriented issues also require analysis and testing during technology evolution. These include the ability to manufacture, distribute, service or maintain, and produce training and documentation plans. While all of these activities will eventually become the responsibility of the company that adopts the technology and converts it to products, the ability to attract financing and key management staff will be enhanced if these fundamentally important product-oriented issues have been addressed as part of the technology maturation process. It will be particularly important to include consideration of the resources available in northern New Mexico if the goal is to establish the new business in that location. This aspect of the commercialization strategy acquires even more significance in the following section.

\subsubsection{Business Development Strategy}

In parallel with the technology evolution activities it is essential to bring the definition of the target business and its products to a level that satisfies the metrics that will be imposed by the financial community during their evaluation of the opportunity. This requires a crisp and thorough definition of the first line of products and evolution strategies for follow-on products, convincing market and competitive analyses, sales and support plans, as well as promotion and advertising.

Once the business strategy is matured, the key management candidates must be identified and a dialogue established with them. Developing a financial strategy is the last activity that occurs as part of phase two. There are several paths that can be followed to obtain the startup capital required for the new venture. These should be carefully analyzed and prioritized in order to elevate the chance for success of the new venture, and maximize the amount of equity in the new venture that is retained by Los Alamos and by the founders of the business.

\subsubsection{Results of Phase Two}

There are two key outputs from this phase. The first of these focuses on the products that will be produced from the small set of technologies that have been selected for commercialization. The analysis of these technologies will include the identification of the target products, technical specifications for the target products, and alpha/beta test results for the products. The second output consists of individual detailed business plans for the technology-based businesses which are intended to bring the products to market.

\subsubsection{Business Creation and Spin-Off}

All of the activity that occurs during this phase of the commercialization process will be the responsibility of the business that has been established to market the technology-based products. No Los Alamos resources are used during this phase. 
Los Alamos has played a historic role in helping new, small businesses succeed when those businesses were developing and marketing dual-benefit products. Supercomputer technology provides an excellent example of how Los Alamos has supported high-risk spin-offs or new ventures. By providing an initial market for products and services for dual-benefit technologies, it is possible that Los Alamos can sustain (or at least nurture) the new business until it can develop the other components of the dual-benefit marketplace. Two specific examples in which Los Alamos supported the early growth of new small businesses are found in the support given to Cray Research, Inc. during its struggle to produce a reliable Cray-1 computer. Serial \#1 of that machine was essentially unusable when first delivered to Los Alamos as a result of hardware reliability problems and the virtual non-existence of usable software. As a more recent example, Los Alamos helped sustain the early development of Amtech by lending essential equipment to the founders of that company.

The following four subsections describe the actions required to complete the formation of the new venture. Several types of individuals are required to complete this transition and their roles are described below. Some of the individuals may be Los Alamos employees, but most of them will have to be drawn from a pool of experts who are external to Los Alamos.

\subsubsection{Form Key Venture Teams}

Some experts claim that the only real key team in the new venture is the management team, including the CEO as perhaps the most important figure. This team must now be recruited from the candidates who may have been identified and approached during earlier phases of the commercialization process. It may be necessary to arrange for access to key Los Alamos technical staff either as employees of the company or through one of the other Los Alamos agreements.

A board of directors that can advise on major strategic, financial, legal, and other issues is required. The relatively small pool of individuals who are located in northern New Mexico and who are qualified to perform this function may be quickly depleted if a flurry of spin-outs occur. It may or may not be time to bring a sales and support staff on board. This depends both on how mature the technology is and the schedule that has been established for delivering the first round of products.

\subsubsection{Complete and Refine the Business Plan}

Despite the fact that a comprehensive business plan was established and refined during earlier phases of the commercialization process, the new venture teams described above will all have important enhancements and possibly even major revisions to contribute. For example, the CEO or board members may be able to negotiate very favorable partnering opportunities or they may provide introductions and access to new key customers with sets of requirements that were not anticipated.

\subsubsection{Form the Company}

A variety of legal, banking, and accounting practices and relationships must be negotiated and put in place. This may include the completion of negotiations for licenses, supplier contracts, distribution outlets, etc. Facilities must be located and necessary conversions or modifications made. In addition, a facilities management team must be located and brought on board.

\subsubsection{Obtain Additional Investment}

In many cases, the seed capital or other early rounds of financing may be insufficient to maintain operation of the company during the early growth and ramp-up phases. One or more rounds of additional financing will be required. The new venture must have access to individuals who can arrange for and help negotiate the additional funding that will be needed. These individuals may be 
members of the management team, the CEO, members of the board, or may consist of consultants or consulting firms with a rich history of arranging and negotiating investment opportunities.

\subsubsection{Uncertainties in the Maturation Process}

There is a belief that " $a$ " technology maturation or " $a$ " technology commercialization process which adequately describes a "recipe" to be employed while creating a new technology-based business exists. Furthermore, there is the perception that most new technology-based businesses can be developed by applying these same frequently described, more or less orderly, processes which typically proceed with predictable timing along a pre-determined path toward successful commercialization and the creation of a new business.

In reality, the commercialization of technology through a start-up company is a process of "fits and starts," and is often experienced as a frustrating, semi-random walk rather than as an orderly process. While a model process may be described that enumerates the basic steps that a technologybased start-up must take on its way to creating a successful, growing business, the actual process of building a new company usually follows a convoluted path that is almost impossible to predict with any accuracy in advance. It is definitely not an even-paced, straight-through process, but is subjected to a great many unplanned, unsched uled events that may delay, or in some rare crses, actually speed up the development and growth of a new business. And finally, there is always the element of dumb luck, which has been a significant factor in many successful start-ups.

During the maturation phase of any commercialization effort, work usually continues both to better understand, characterize, refine, and gain control of the technology, while attention is also devoted to various business issues. In particular, attention is typically devoted to refining market and customer information. Efforts are directed to increasing the level of knowledge about customer needs and economics; competition, competitive product offerings, and competitive development plans; and the identification and quantification of the factors which are expected to influence the future development of the market. This information, in turn, is fed back to those involved in the maturation of the subject technology to help refine and better focus the ongoing development efforts. As information develops from the technical work-new discoveries, the creation of possible intellectual property, refined cost and performance data, the resolution of technical uncertainties (whether favorable or unfavorable), etc.- this information is tested against the growing level of market information, and revised market penetration and revenue estimates are developed. Attention must also be given to evaluating evolving opportunities for enhancement and improving the intellectual property position of the technology.

This ongoing bilateral flow of information is intended to result in a continuing refinement of the evolving business case, and an associated appraisal of the commercialization prospects. If, to take a rather obvious example, the cost of the conceptualized product escalates significantly as development work continues, and if it is determined that customer economics are unlikely to justify the increased cost of the expected solution to certain application requirements, then the question of whether to continue the program or to move it back in the priority stack must be considered. Often the biggest uncertainty is the current status and future potential competitive threat. Rapid change in the competitive environment is a frequent cause of the derailment of a commercialization effort midstream.

The actual process of maturing a specific technology will depend on a number of factors including the following:

- Type of technology involved. Various classes of technology will have their own intrinsic maturation requirements. At the broadest classification, does the technology consist of software or hardware, or both? Often software developments are the quickest to bring to a state of commercial maturity. Hardware 
technologies generally present far more complicated and lengthy maturation requirements.

- Current state of development of the base technology. Is this a new concept or some fundamental new scientific discovery (with an as-yet undetermined application target), or a technology that is years from the actual design and construction of a commercial product, or is it later in the cycle so that it might provide a commercial product in a relatively short and more-or-less predictable time schedule? In the case of software, a technology might consist of programs which have been used in the laboratory for a considerable time, and only need to be "hardened" for commercial use, and the necessary documentation, packaging, training materials, etc. developed to permit the market-testing of an early prototype. In the case of some fundamental new technology, generally the time required for maturation will be longer, and the associated uncertainties and risks much greater than in the case of a later-stage, more mature technology.

- Estimated cost to obtain a commercial product. The amount of time and money required to transit the maturation process is another indicator of risk, and is generally directly related to the current state of technology, the time required to achieve technical maturity, the complexity of the technology, and any remaining technical hurdles which remain to be solved.

- Size of the potential market. Market size is one of the key indicators of the potential reward for the successful development of a product. If the market is large enough, it may be worth the risk to develop a product in the case of a relatively immature technology where significant time and money will be required for this development. Conversely, if the targeted market is relatively small, and the time-to-market is long and filled with technical uncertainty, a decision not to proceed may be advisable.

- Amount of capital required to reach sustainable positive cash flow. Business opportunities which require significant up-front capital commitments to reach positive cash flow are less desirable. For such a business to succeed, a group of very substantial investors must be attracted or a corporate partnership arranged. Hence, plans to pursue the maturation of such a technology are generally more risky.

- Existence of committed champions. The existence of dedicated, enthusiastic proponents who have what has often been described as that "burning desire" to see their ideas successfully commercialized can overcome many other deficiencies which outsiders may see in a proposed opportunity. There are often points in the maturation of a new technology where the persistence of these champions is all that keeps the project going.

- Anticipated degree of market acceptance. Is the market ready for the resulting product, or is there expected to be a period of user education, and a requirement for changing usage patterns or customer habits?

- Competitive conditions. Is the existing competition fragmented and ineffective or is it concentrated and able to react to intruders? Does the business and technology appear to have clear and sustainable advantages over both existing and potential competition, or is the degree of competitive advantage doubtful? 
- Anticipated intellectual property protection. The relative degree of intellectual property protection that is anticipated and the contribution which that protection may provide towards maintaining a competitive advantage is another important consideration.

The path through maturation is generally neither direct nor predictable. The timing and sequence of events will vary tremendously from case to case depending on the combined effects of the abovementioned (among other) factors. Both the process and any new information being generated must be constantly evaluated to determine if the technology should continue to be pursued. As a result, the maturation process may be visualized as a spiral with each completed turn increasing the level of knowledge and narrowing the focus on resolving the major issues that bear most on the potential for commercial success. At the start, some of these issues may not even be known or may be misunderstood-serious problems affecting the potential for commercial success will only be revealed as early knowledge about the market and other commercialization requirements become known.

The initial attempts at Los Alamos will also be based on an experimental screening process. This initial effort may not be completely representative of how it may operate in a normal steady-state situation, which includes an ongoing routine identification of technology screening and commercialization.

The overall goal of the maturation process is to:

1. Identify, qualify, and verify the existence of substantial commercial needs that the technology in question can satisfy.

2. Do the necessary research, development, and engineering work to develop a proof-of-concept and to identify and resolve any remaining technical barriers or reduce technical uncertainties to eliminate or reduce the inherent technical risk. The obvious purpose is to insure that the technical content of the commercialization plan is under control and that remaining technical hurdles are clearly identified. It is also necessary to establish (to the greatest degree possible) that there are customers who have a significant need for the resulting product, and that they can justify and are willing to pay a price for the product that will allow a new business employing the technology in its products to earn a satisfactory profit.

The acid test of whether these goals have been achieved is the willingness of experienced professional investors to contribute capital to reach the next phase. The ability to attract interest and obtain commitments of seed capital during the latter stages of the maturation process is a key determinate of success. Similarly, the ability to attract and gain commitments from the key members of an experienced entrepreneurial management team is another key success factor. 
The Final Report of Los Alamos Contract No. 4790L0013-9Z, Volume 1 